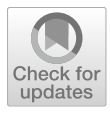

Cite as

Nano-Micro Lett.

(2022) 14:43

Received: 27 October 2021

Accepted: 3 December 2021

Published online: 3 January 2022

(C) The Author(s) 2022

\section{Shining Light on Anion-Mixed Nanocatalysts for Efficient Water Electrolysis: Fundamentals, Progress, and Perspectives}

\author{
Yaoda Liu ${ }^{1}$, Paranthaman Vijayakumar ${ }^{1}{ }^{凶}$, Qianyi Liu ${ }^{1}$, Thangavel Sakthivel ${ }^{1}$, \\ Fuyi Chen ${ }^{2}$, Zhengfei Dai ${ }^{1} \otimes$
}

\title{
HIGHLIGHTS
}

- This review introduces recent advances of various anion-mixed transition metal compounds (e.g., nitrides, halides, phosphides, chalcogenides, (oxy)hydroxides, and borides) for efficient water electrolysis applications in detail.

- The challenges and future perspectives are proposed and analyzed for the anion-mixed water dissociation catalysts, including polyanion-mixed and metal-free catalyst, progressive synthesis strategies, advanced in situ characterizations, and atomic level structureactivity relationship.

ABSTRACT Hydrogen with high energy density and zero carbon emission is widely acknowledged as the most promising candidate toward world's carbon neutrality and future sustainable eco-society. Water-splitting is a constructive technology for unpolluted and high-purity $\mathrm{H}_{2}$ production, and a series of non-precious electrocatalysts have been developed over the past decade. To further improve the catalytic activities, metal doping is always adopted to modulate the $3 d$-electronic configuration and electron-donating/accepting (e-DA) properties, while for anion doping, the electronegativity variations among different non-metal elements would also bring some potential in the modulations of e-DA and metal valence for tuning the performances. In this review, we summarize the recent developments of the many different anion-mixed transition metal compounds (e.g., nitrides, halides, phosphides, chalcogenides, oxyhydroxides, and borides/borates) for efficient water electrolysis applications. First, we have introduced the general information of

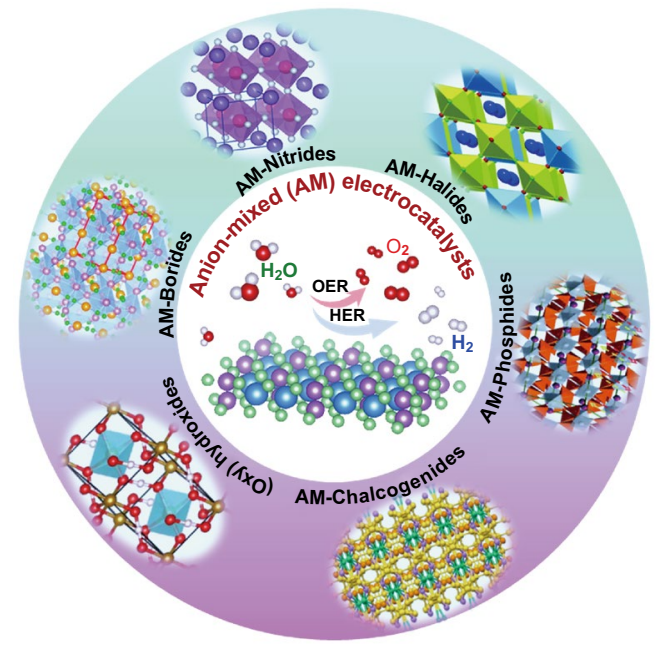
water-splitting and the description of anion-mixed electrocatalysts and highlighted their complementary functions of mixed anions. Furthermore, some latest advances of anion-mixed compounds are also categorized for hydrogen and oxygen evolution electrocatalysis. The rationales behind their enhanced electrochemical performances are discussed. Last but not least, the challenges and future perspectives are briefly proposed for the anion-mixed water dissociation catalysts.

KEYWORDS Multianions; Electrocatalysts; Water electrolysis; Hydrogen energy; Oxygen evolution

Paranthaman Vijayakumar, kumarphysics89@gmail.com; Zhengfei Dai, sensdai@mail.xjtu.edu.cn

State Key Laboratory for Mechanical Behavior of Materials, Xi' an Jiaotong University, Xi'an 710049, People's Republic of China

2 State Key Laboratory of Solidification Processing, Northwestern Polytechnical University, Xi'an 710072, People's Republic of China 


\section{Introduction}

In the past few decades, the rapidly expanding utilization of fossil fuels has caused serious environmental issues [1]. In this regard, searching and developing alternative green and renewable energy with low-cost and long-term durability is the most enchanting research area. Among the numerous alternative energy approaches, high-purity hydrogen $\left(\mathrm{H}_{2}\right.$, produced by photoelectrochemical and electrochemical water-splitting) serves as an economic, non-toxic, easily available, and abundant energy source due to zero emission of carbonaceous species [2-5]. As one of the most prospective techniques, photoelectrochemical water-splitting requires devices with a larger electrode area to deliver an equal volume of gas resulting in limitations while choosing feasible catalysts. By contrast, electrochemical watersplitting exhibits attractive, promising, and reliable future energy technology due to its high efficiency and convenience [6-11].

In general, the electrochemical water-splitting reaction (Eq. 1) consists of two critical parts [12], hydrogen evolution reaction (HER, Eq. 2) on the cathode and oxygen evolution reaction (OER, Eq. 3) on the anode (Fig. 1a). The corresponding water-splitting reactions (i.e., alkaline solution) are as follows [13]:

Overall reaction: $2 \mathrm{H}_{2} \mathrm{O}_{(\mathrm{l})} \rightarrow 2 \mathrm{H}_{2(\mathrm{~g})}+\mathrm{O}_{2(\mathrm{~g})}$

Cathode: $2 \mathrm{H}_{2} \mathrm{O}_{(\mathrm{l})}+2 \mathrm{e}^{-} \rightarrow \mathrm{H}_{2(\mathrm{~g})}+2 \mathrm{OH}_{(\mathrm{aq})}^{-}$

Anode: $4 \mathrm{OH}_{(\mathrm{aq})}^{-} \rightarrow 2 \mathrm{H}_{2} \mathrm{O}_{(\mathrm{l})}+\mathrm{O}_{2(\mathrm{~g})}+4 \mathrm{e}^{-}$

Regardless of the electrolyte media, the standard thermodynamic potential of $1.23 \mathrm{~V}$ (vs. reversible hydrogen electrode, RHE) is required to split water into $\mathrm{H}_{2}$ and $\mathrm{O}_{2}$. However, both the cathode and anode reactions involve multiple electron transfer steps, and additional energy is needed to overcome kinetic obstacles and accelerate electron transfer, resulting in the so-called overpotential $(\eta)$. Consequently, cost-effective water-splitting requires highly active and robust electrocatalysts that can significantly stimulate the kinetics of the essential two half-cell reactions. In brief, an excellent catalyst must meet two primary necessities: (i) the catalyst for per half-reaction must be highly efficient, with which small overpotential can generate high current density; (ii) the catalyst must display high durability. The fabrication (a)

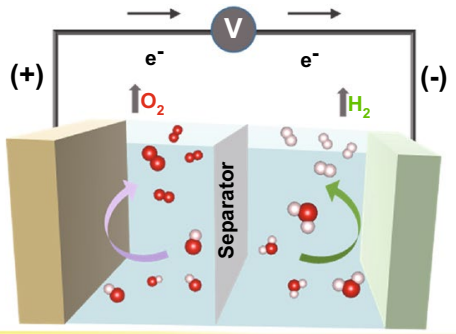

Oxygen Evolution Reaction Hydrogen Evolution Reaction

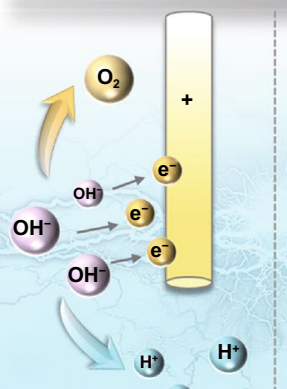

H.) $\mathrm{H}^{+}$

$\mathrm{H}_{2} \mathrm{O}$

Water Splitting in alkaline electrolyte (b)
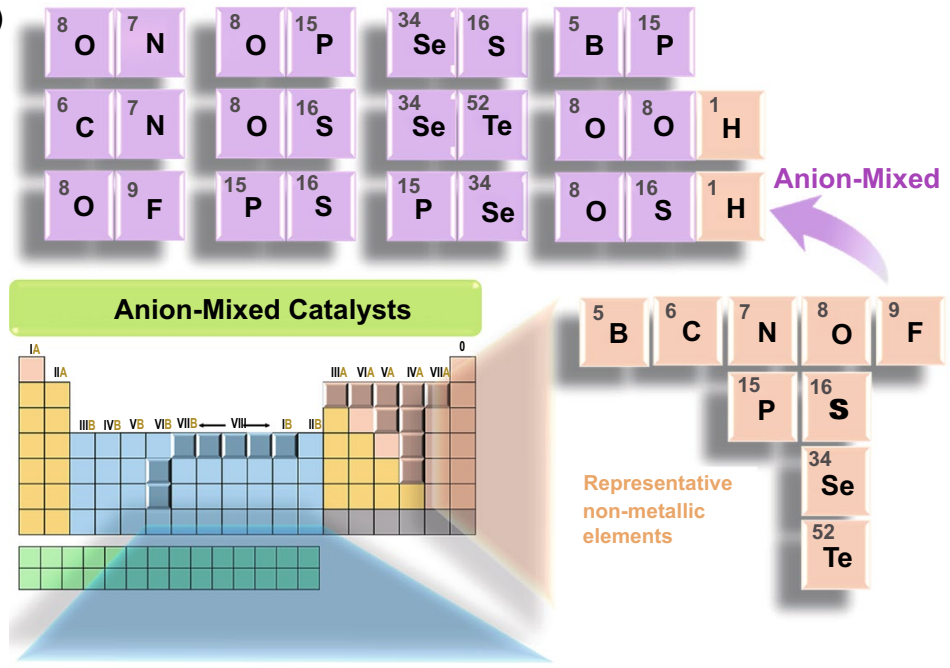

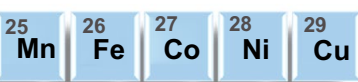

Non-metal elements

Main group metal elements

Transition group metal elements

Representative

transition metal

elements
Lanthanides and actinides

Unknown elements

Fig. 1 a Illustration of the device and mechanism of electrocatalytic water-splitting. b Overview of the representative elements constituting the water-splitting catalyst and the current anion-mixed pairs 
of the most efficient and durable HER/OER electrocatalysts is of commercial importance to lessen the cost. The following key parameters are to be fulfilled during the fabrication of an efficient and durable electrocatalyst [14-23]:

(i) Large number of surface-active sites.

(ii) High electronic conductivity.

(iii) High intrinsic activity.

(iv) Suitable specific adsorption/desorption energy of the intermediate species.

So far, noble metal iridium(IV) oxide $\left(\mathrm{IrO}_{2}\right)$, ruthenium(IV) oxide $\left(\mathrm{RuO}_{2}\right)$, and platinum-based electrocatalysts are commonly used in alkaline/acidic conditions due to their high electrocatalytic activity, unique electronic properties, and long-term durability [7, 12]. Nevertheless, the large-scale commercialization of noble metals for water electrolysis is severely hindered by their scarcities and instability in electrolytes at high potentials. Given this, transition metal (TM)-based oxides, carbides, nitrides, sulfides, phosphides, chalcogenides, hydroxides, halides, alkoxides, and borides/borates have been explored [24-38]. Unfortunately, most of these materials exhibit a low catalytic performance, impecunious electronic conductivity, passivation, and dissolution under strongly acidic conditions, hindering their practical application [21, 22, 39]. Thus, advanced modification strategies are urgently needed to stimulate the activity of the catalyst, including fabricating heterostructure, modulation of the morphology, defect-rich construction, manufacturing core-shell structures, anion doping, etc. [19, 21, 40-43]. Among them, anion strategies (substitution, modulation, etc.) have shown their great potential in HER and OER. In particular, anion-mixed strategy is identified to be an exceptionally promising route in catalysts development.

Here, we summarize the latest developments in nonprecious metal-based electrocatalysts for HER and OER with the anion-mixed strategy. The advantages of anionmixed strategies to achieve superior catalytic performance are also introduced. This review starts with introducing anion-mixed electrocatalysts and the role of mixed anions, followed by recent approaches on the HER, OER, and overall water-splitting electrocatalysts, including mixed nitrides, mixed halides, mixed phosphides, mixed chalcogenides, (oxy)hydroxides, and mixed borides/borates. Figure $1 \mathrm{~b}$ shows the representative elements constituting the water-splitting catalyst and the current anion-mixed pairs. Finally, the summary and future perspectives of the anion-mixed electrocatalysts for efficient water-splitting are also suggested.

\section{Anion-Mixed Electrocatalysts}

Combining or mixing multiple anions is a promising way, and this emerging strategy will promote the development of non-precious materials with chemical complexity and structural diversity that are beneficial for HER, OER, and overall water-splitting [50-52]. Notably, owning to the controllable anion components and relative ratios, the anion-mixed compounds would be endowed with adjustable electronic structure, controllable intermediate adsorption/desorption energy, and tunable reaction pathway. Therefore, they are more feasible to further improve the intrinsic catalytic activity, durability, and stability than single-anion materials [34, $53,54]$. Specifically, anion mixing usually regulates the physicochemical properties of materials through the following four aspects, so as to further activate their electrocatalytic properties.

\subsection{Electronegativity Regulation}

Electronegativity is one of the most significant fingerprint features for anions, which contains intrinsic physicochemical information (Fig. 2a) [55]. Mixing different anions can efficiently regulate the properties and strength of bonding and bring new flexibility to material design and functionalization, such as improving conductivity, balancing the electronic structures of active centers, enhancing structural stability, etc. [56, 57]. For example, due to the strong ionic nature of the metal hydroxy fluoride $(\mathrm{M}-(\mathrm{OH}) \mathrm{F})$ bond, $\mathrm{F}$ ion substitution is considered to be a powerful method to improve the catalytic activity, surface polarity, and kinetics of metal hydroxides [58]. In addition, the NiFeS system obtained by sulfurizing the $\mathrm{NiFe}$ layered double hydroxide precursor showed excellent OER performance because the polarized $\mathrm{S}$ and non-polarized $\mathrm{O}$ anions uniformly adjust the electronic structure of the active center [59].

Besides, the conductivity indirectly affects the activity of the catalyst, while the conductivity is directly related to the bonding polarity. For example, without using organic surfactants, the introduction of $\mathrm{F}$ can enhance charge mobility and improve weak conductivity [60]. 


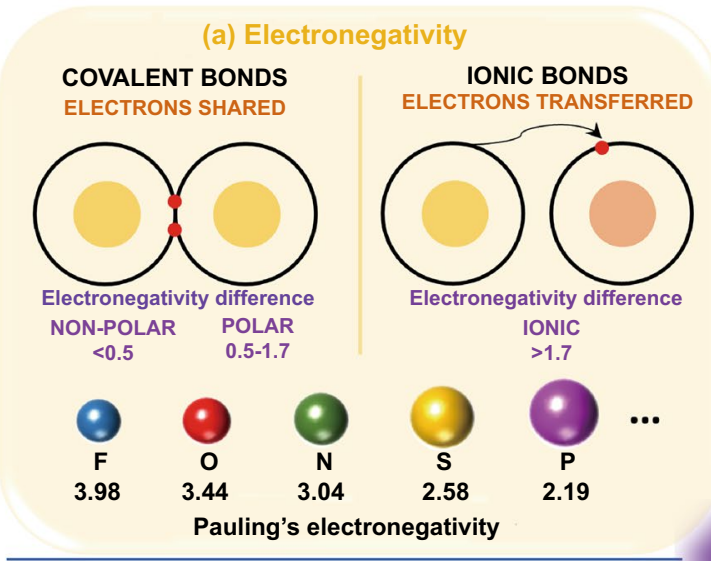

(c) Defects \& Reconstruction

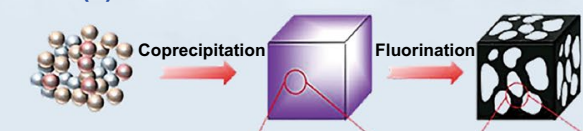

$9 \mathrm{CoCl}_{2} \cdot 6 \mathrm{H}_{2} \mathrm{O}$ $\mathrm{Na}_{3} \mathrm{C}_{6} \mathrm{H}_{5} \mathrm{O}_{7} \cdot \mathrm{H}_{2} \mathrm{O}$ $\mathrm{K}_{3} \mathrm{FeC}_{6} \mathrm{~N}_{6}$

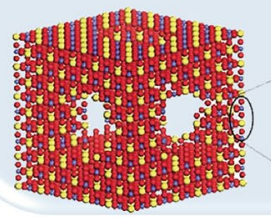

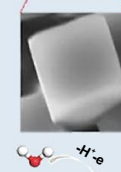
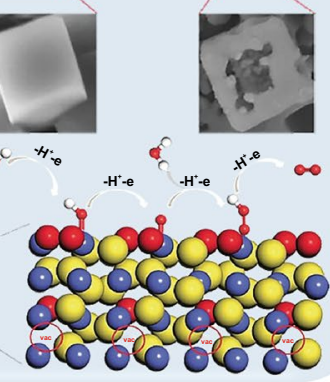

(b) Ideal Electronic Structure
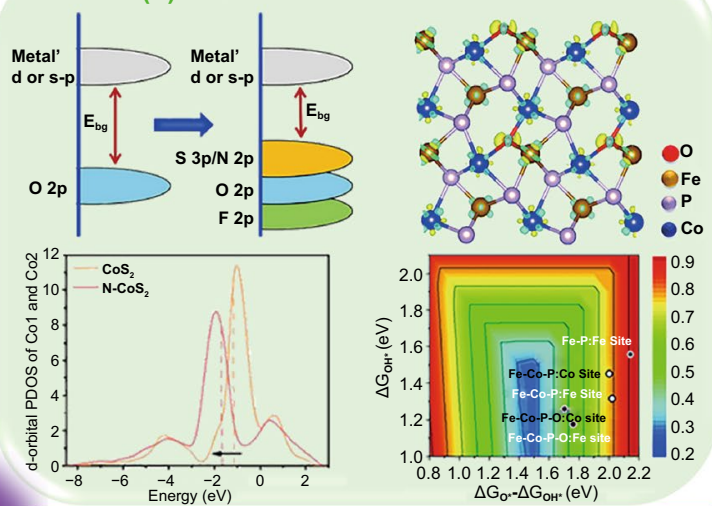

(d) Optimized Reaction Pathway

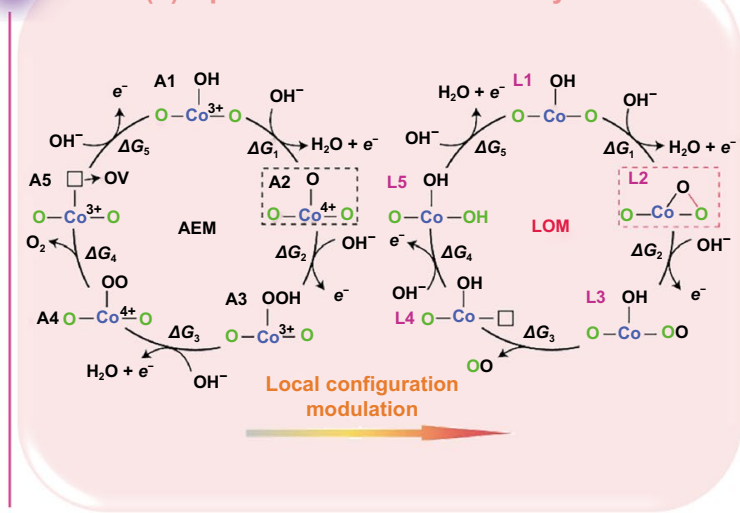

Fig. 2 Schematic illustration of the significant features of anion-mixed regulation involved in transition metal compounds for water-splitting. a Electronegativity. b Ideal electronic structure: Schematic illustration of the strategy for band gap narrowing through anion substitution (top left); The $d$-orbital partial density of states ( $d$-pdos) of $\mathrm{Co}$ in $\mathrm{CoS}_{2}$ and $\mathrm{N}-\mathrm{CoS}_{2}$ (bottom left); Calculated redistribution of charge density for Fe-Co$\mathrm{P}-\mathrm{O}$ (top right, the yellow isosurface indicates electron accumulation, while the blue one represents electron depletion); Calculated volcano plot of OER overpotential $\eta$ with $\Delta \mathrm{G}_{\mathrm{OH}^{*}}$ and $\Delta \mathrm{G}_{\mathrm{O}^{*}}-\Delta \mathrm{G}_{\mathrm{OH}^{*}}$ as the descriptors (bottom right). Reprinted with permission from Ref. [44]. Copyright Year 2019, Wiley-VCH Verlag GmbH \& Co. KGaA, Weinheim. Reprinted with permission from Ref. [45]. Copyright Year 2019, Wiley-VCH Verlag GmbH \& Co. KGaA, Weinheim. Reprinted with permission from Ref. [46]. Copyright Year 2019, Royal Society of Chemistry. c Defects and reconstruction: Schematic illustration of the synthesis process of $\mathrm{Fe}-\mathrm{Co}-\mathrm{F}$ samples (top); Schematic illustration of the oxygen-containing amorphous cobalt sulfide porous nanocubes with Co-S dangling bands (bottom). Reprinted with permission from Ref. [47]. Copyright Year 2019, Elsevier. Reprinted with permission from Ref. [48]. Copyright Year 2017, Wiley-VCH Verlag GmbH \& Co. KGaA, Weinheim. d Optimized reaction pathway: Proposed OER mechanisms of $\mathrm{ZnCo}-\mathrm{OOH}$, including AEM and LOM. A2 and L2 are the isomeric intermediates that differentiate between the OER pathways AEM and LOM. Reprinted with permission from Ref. [49]. Copyright Year 2019, Springer Nature

Furthermore, anion diffusion exists in some solids. The advantage of anion-mixed materials is to allow one anion with stronger ionic and less charge to diffuse (improve conductivity) while maintaining the stability of the other anion with stronger covalent and charge (maintaining structural stability) [56].

Interestingly, the regulation of electronegativity also plays a positive role in ameliorating stability. For example, compared with $\mathrm{NiCo}_{2} \mathrm{~S}_{4}$, the mixing of $\mathrm{OH}$ ligand with stronger electronegativity and $\mathrm{S}$ ligand in $\mathrm{NiCo}_{2}(\mathrm{SOH})_{x}$ makes $\mathrm{OH}$ an electron acceptor, which pushed electrons from the antibonding orbital of $\mathrm{M}-\mathrm{S}$ bonds to $\mathrm{M}-\mathrm{O}$ bonds, so that the $\mathrm{M}-\mathrm{S}$ bond in $\mathrm{NiCo}_{2}(\mathrm{SOH})_{x}$ becomes shorter and more stable than that in $\mathrm{NiCo}_{2} \mathrm{~S}_{4}$ [61]. This effect makes $\mathrm{NiCo}_{2}(\mathrm{SOH})_{x}$ catalyst owns good stability in longterm work.

\subsection{Ideal Electronic Structure}

According to Sabatier's principle, the $\mathrm{H}^{*}$ intermediate should have appropriate adsorption strength to facilitate the HER process [62]. Similarly, considering the adsorbate evolution 
mechanism (AEM), OER process is accompanied by the evolution of intermediates from $\mathrm{OH}^{*}$ to $\mathrm{O}^{*}, \mathrm{OOH}^{*}$, and $\mathrm{O}_{2}$ [63]. Given these, the key to improving catalyst performance is to optimize the adsorption/desorption behavior of intermediates on the catalyst surface, which is essentially achieved by adjusting the electronic structure of active sites (Fig. 2b).

The differences in radius, electronegativity, ionization potential, and electron affinity between various anions make it more possible to adjust the electronic structure [44, 64-66]. As a typical example, $\mathrm{O}$ incorporation in $\mathrm{MoS}_{2}$ could promote the hybridization between Mo $d$-orbitals and $\mathrm{S} p$-orbitals, resulting in a smaller band gap, better conductivity, and lower energy barrier than the original $2 \mathrm{H}-\mathrm{MoS}_{2}$ [67]. In addition, when $\mathrm{S}$ in $\mathrm{CoS}_{2}$ was replaced by $\mathrm{P}$, the antibonding orbital was depleted, and the metal-ligand bond was strengthened, thereby enhancing the stability. The hydrogen adsorption free energy $\left(\Delta \mathrm{G}_{\mathrm{H}^{*}}\right)$ could be more thermally neutral by changing the $\mathrm{S} / \mathrm{P}$ ratio, thus improving HER activity [68]. Furthermore, $\mathrm{Fe}-\mathrm{Co}-\mathrm{P}$ nanoboxes gradually transform into amorphous metal oxides during OER reaction in an alkaline medium [46]. The $\mathrm{O}$ and $\mathrm{P}$ bridges can reduce the $e_{\mathrm{g}}$ occupancy and the intermediates' free energy, thus leading to the promoted OER activity (Fig. 2b).

It is worth noting that the $d$-band center theory has been a hot research direction in the field of catalysis. The higher (lower) $d$-band center will have a stronger (weaker) affinity for the adsorbate [69]. For example, $\mathrm{N}$-doping effectively adjusted the $d$-band center of $\mathrm{CoS}_{2}$, thus optimizing $\Delta G_{\mathrm{H}^{*}}$ and water adsorption Gibbs free energy $\left(\Delta \mathrm{G}_{\mathrm{H} 2 \mathrm{O}^{*}}\right)$ and accelerating HER process in alkaline electrolytes [45].

\subsection{Defects and Reconstruction}

Besides enhancing the intrinsic catalytic performance of the original active site, anion-mixed will obtain more active sites by constructing defects, forming lattice distortion, and promoting surface reconstruction, which is another crucial way to improve catalytic performance (Fig. 2c). For example, fluorine and oxygen can more easily replace each other because they have similar ionic radii. Based on this, the constructed $\mathrm{NiFe}$ oxyfluoride $(\mathrm{NiFeOF})$ porous film exhibited a huge interconnected porous structure. The fluorine etching effect led to the exposure of active sites and increased the active surface area, significantly improving the electrochemical performance and further reducing the limit potential
[29]. Many oxyfluorides exhibit amorphous phases, and this disordered atomic mixing mode leads to a non-equilibrium bonding environment, resulting in more active sites [70]. Besides, anion-mixed strategy based on fluorination has also been used to construct other anion defects, such as highly exposing the S-edge active site of $\mathrm{MoS}_{2}$ [71].

It is worth pointing out that anion substitution with different radii will cause lattice distortion. In molybdenum sulfide selenide $\left(\mathrm{MoS}_{2 x} \mathrm{Se}_{2(1-x)}\right)$ alloy, $\mathrm{S}$ was replaced by $\mathrm{Se}$, and its incorporation increased the layer spacing (atom size of Se is larger than that of S), changed the edge electronic structure, and achieved high conductivity and narrow band gap, thus improving HER performance [72].

Furthermore, anion-mixed can promote surface reconstruction. As a typical example, iron-cobalt-fluoride (Fe-Co-F) nanocubes with abundant defects/voids were formed through fluoride etching [47]. The increased electrochemical specific surface area caused by surface roughness and the metal oxides easily formed on the catalyst surface make this new catalyst very active and stable for water oxidation. These advantages benefit from the surface reconstruction caused by the coexistence of metal-O and metal-F bonds. Similarly, amorphous $\mathrm{CoO}_{0.6} \mathrm{~S}_{4.6}$ porous nanocube was prepared by mixing $\mathrm{O}$ and $\mathrm{S}$ anions [48]. Due to the embedding of $\mathrm{O}$ atoms around the Co center, the local disordered structure was formed. There were $4.6 \mathrm{~S}$ atoms and $0.6 \mathrm{O}$ atoms around the $\mathrm{Co}$ atom, forming abundant $\mathrm{Co}-\mathrm{S}$ dangling bonds. Oxygen doping on $\mathrm{CoS}_{x}$ support and $\mathrm{Co}-\mathrm{S}$ hanging bond can greatly enhance the adsorption of $\mathrm{O}^{*}$.

\subsection{Optimized Reaction Pathway}

It is well known that both HER and OER are processes involving multiple electron steps. Therefore, advanced catalysts should not only be beneficial to the adsorption of a single intermediate but also coordinate and optimize the evolution process of each intermediate to minimize the energy of the rate-determining step (Fig. 2d). Anion-mixed strategy is a vital means to achieve this goal. For example, in alkaline conditions, under alkaline conditions, $\Delta G_{\mathrm{H}^{*}}$ is not the only descriptor for HER process, and the dissociation energy barrier of water plays a decisive role. Studies have shown that $\mathrm{P}$ doping reduced the electron density around $\mathrm{Ni}$ atoms and increased the charge of Se, thus reducing the energy barrier of hydrolysis [73]. 
As another typical example, the synergistic effect of $\mathrm{B}$ and $\mathrm{P}$ was studied in amorphous $\mathrm{Co}_{2.90} \mathrm{~B}_{0.73} \mathrm{P}_{0.27}$ ternary alloy [74]. Element $\mathrm{P}$ could accelerate the dissociation of $\mathrm{H}_{2} \mathrm{O}$ and promote the Volmer process. For Co-P system, H was strongly bound to $\mathrm{Co}^{\delta+}$, which was not conducive to $\mathrm{H}_{2}$ overflow. The addition of $\mathrm{B}$ in $\mathrm{Co}-\mathrm{B}-\mathrm{P}$ system made the binding energy of Co shift negatively, optimizing the H-Co interaction and promoting the Heyrovsky process. In addition, the "dual ligand coordinated modulation" strategy has realized the optimization of the OER reaction pathway. For example, the synergistic effect of $\mathrm{OH}$ and $\mathrm{S}$ ligands on the surface of $\mathrm{NiCo}_{2}(\mathrm{SOH})_{x}$ subtly adjusted the electronic structure and chemical environment of active metal centers, thus optimizing the binding energy of OER intermediates $\left(\mathrm{OH}^{*}, \mathrm{O}^{*}\right.$ and $\mathrm{OOH}^{*}$ ) synchronously, which is helpful to meet the energy requirements of OER evolution process [61].

Interestingly, (oxy)hydroxides are special anion-mixed OER catalysts. Before the start of OER, the transition metal center usually undergoes an electrochemical pre-oxidation process and deprotonation. Due to the structural flexibility and highly oxidized transition metal center, many (oxy) hydroxides are prone to form $\mathrm{O}-\mathrm{O}$ bonds directly, which will trigger the lattice oxygen oxidation mechanism (LOM) to obtain higher OER activity [75]. The introduction of $\mathrm{Zn}^{2+}$ in $\mathrm{CoOOH}$ has also been proved to effectively control the mechanism switching of catalysts in OER process [49].

Based on these advantages, in the following sections, the anion-mixed strategies applied in developing such electrocatalysts and their outstanding performances in water-splitting are described in detail.

\section{Electrocatalytic Performance of Anion-Mixed Electrocatalysts}

\subsection{Mixed Nitrides}

\subsubsection{Oxynitride}

The incorporation of nitrogen $(\mathrm{N})$ into oxides opens the facile route of tuning physical and chemical properties [76-78]. As $\mathrm{N}$ with weaker electronegative and is more polarizable than $\mathrm{O}$, the $\mathrm{M}-\mathrm{N}$ bond is more covalent than the $\mathrm{M}-\mathrm{O}$ bond in nature [79]. Besides, $\mathrm{N}$ has a higher ionic radius than $\mathrm{O}$, the substitution of $\mathrm{N}$ into the oxide makes an increase in bonding distance [80]. Thus, regulating the $\mathrm{N}$ ratio in TM-based compounds can modify their structure, improve the charge transfer process, and lead to enhanced electrocatalytic activities [81, 82]. Notably, combining transition metals (TMs) with oxynitrides is also an efficient and viable method to enhance its electrical conductivity and corrosion resistance [83].

Given these advantages, Miura et al. investigated the regulation of $\mathrm{N}$ ratio and electronic structure with a correlated electrocatalytic performance of manganese oxynitride [87]. Catalytic performance of N-rich manganese (Mn) oxynitrides can be enhanced by nearly single-electron occupancy of the antibonding $\mathrm{e}_{\mathrm{g}}$ states and highly covalent $\mathrm{Mn}-\mathrm{N}$ bonding. Similarly, Chang et al. designed a novel vanadium-nickel oxynitride (VNiON) layer covered on the corresponding oxide nanosheets, which have been proven to exhibit improved electrochemical performances [55]. The substitution of the -2 charged oxyanion by the -3 charged nitride anion results in transition-metal oxynitride (TMON) layers owning additional metal cation valence, which helps to absorb the lone pair of nitrogen electrons [88]. The similar atomic radii of $\mathrm{N}$ and $\mathrm{O}$ also enable them to reduce the effect of superimposed lattice distortion as much as possible in the process of mutual substitution and maintain good structural stability [89].

Recently, Lei's group developed porous cobalt oxynitride nanosheets (CoON PNS) for OER electrocatalysis (Fig. 3a) [84]. Specifically, this CoON PNS exhibited a low overpotential $\left(\eta_{10}\right)$ of $0.23 \mathrm{~V}$ at a current density $(j)$ of $10 \mathrm{~mA} \mathrm{~cm}^{-2}$ for the OER, which is much better than that of $\mathrm{Co}_{3} \mathrm{O}_{4}(0.34 \mathrm{~V})$ nanosheets (NSs). Density functional theory (DFT) calculation revealed that the free energy for $\mathrm{HO}^{*}\left(\Delta G_{\mathrm{HO}}\right)$ and $\mathrm{O} *\left(\Delta G_{\mathrm{O}^{*}}\right)$ formation on CoON PNS400 is 1.46 and $3.50 \mathrm{eV}$, respectively, noticeably smaller than that of $\mathrm{Co}_{3} \mathrm{O}_{4}$ nanosheets with $\Delta G_{\mathrm{HO}^{*}}=2.18 \mathrm{eV}$ and $\Delta G_{\mathrm{O}^{*}}=4.53 \mathrm{eV}$ (Fig. 3b). More crucially, the free energy significantly reduces from 6.93 to $4.98 \mathrm{eV}$, supremely can be considered as the rate-controlling step of water oxidation (HOO* formation). The above theoretical results prove the inclusion of foreign $\mathrm{N}$ atoms into $\mathrm{Co}_{3} \mathrm{O}_{4}$ effective regulation of the free energies toward an optimal value. Especially, $\mathrm{TiN}_{x} \mathrm{O}_{y}$ (TiNO) films were in situ synthesized in the oxygen partial pressure range of 5-25 mTorr by pulsed laser deposition (Fig. 3c, d) [85]. The electrochemical overpotential of TiNO film for water oxidation is as low as $290 \mathrm{mV}\left(10 \mathrm{~mA} \mathrm{~cm}^{-2}\right)$. The electrocatalytic performance improvement is due to the number increase of the active sites, which was realized by $\mathrm{O}$ replacing the anion 
(a)

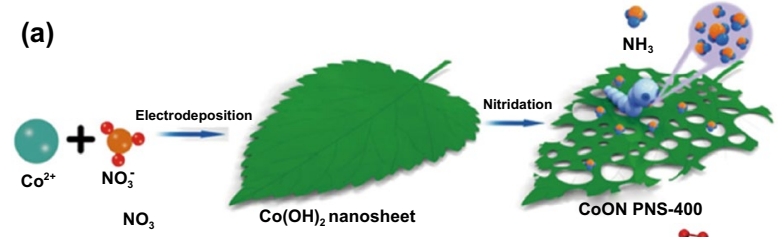

(b)

$\mathrm{NO}_{3}$
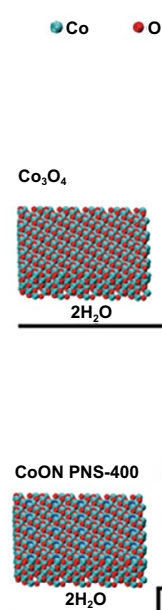

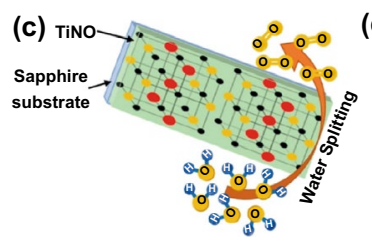

(e)

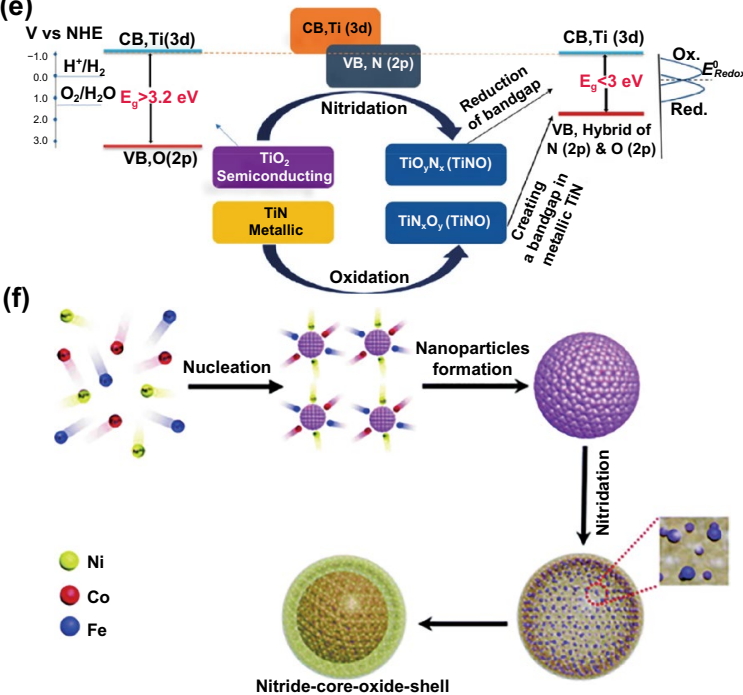

(d)

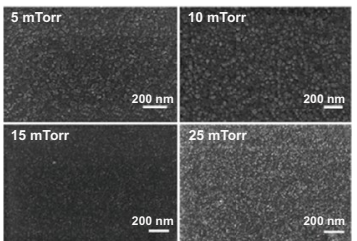

Nitride-core-oxide-shell

Fig. 3 a The schematic illustration of the formation of CoON PNS-400 nanosheets. b DFT calculated free energy diagram of the OER on $\mathrm{Co}_{3} \mathrm{O}_{4}$ and b CoON PNS-400, respectively. Reprinted with permission from Ref. [84]. Copyright Year 2018, Wiley-VCH Verlag GmbH \& Co. KGaA, Weinheim. c Schematic illustration of TiNO thin films for electrocatalytic water oxidation, $\mathbf{d}$ SEM images of TiNO films grown in oxygen pressures of $5,10,15$, and 25 mTorr, e Band diagram showing a downward movement of VB via nitridation of $\mathrm{TiO}_{2}$ and opening of a bandgap between overlapping valence and conduction band in a metallic TiN via oxidation of TiN. Reprinted with permission from Ref. [85]. Copyright Year 2020, American Chemical Society. f Illustration of the formation of nitride-core, oxide-shell FeCoNi oxynitride nanoparticles. Reprinted with permission from Ref. [86]. Copyright Year 2019, Royal Society of Chemistry

$\mathrm{N}$ site and the rearrangement of the valence band relative to the redox potential of the electrolyte medium (Fig. 3e).

Moreover, bimetallic/trimetallic catalysts have been given significant attention because of the multiple active species, enhanced charge transfer between different ions, and capability of the electronic structure tune at the electrode surface/interface. Taking advantage of bimetallic and anionmixed strategy, Song's group fabricated a 3D bifunctional nanohybrid electrode based on cobalt nitride-vanadium oxynitride on carbon cloth (CVN/CC) toward overall watersplitting [90]. CVN/CC achieved $\eta_{10}=0.263 \mathrm{~V}$ for OER and $\eta_{10}=0.118 \mathrm{~V}$ for HER in Ar-saturated 1.0 M KOH solution. In addition, it exhibited overall water-splitting with a cell voltage of $1.64 \mathrm{~V}$ at a $j$ of $10 \mathrm{~mA} \mathrm{~cm}^{-2}$ in alkaline media. A reported case by Dai and coworkers showed that the electrocatalytic performance of the iron-cobalt-nickel ( $\mathrm{FeCoNi}$ ) oxynitride sample $\left(\eta_{10}=0.291 \mathrm{~V}\right)$ outperformed that of stateof-the-art catalysts (Fig. 3f) [86]. A similar comparable result achieved by Xiong et al. showed that the combination of the excellent metal like OER activity of nitrides and the inherent oxidation resistance of oxides could obtain FeNi oxynitrides with excellent performance, which has a low overpotential of $295 \mathrm{mV}\left(10 \mathrm{~mA} \mathrm{~cm}{ }^{-2}, 1 \mathrm{M} \mathrm{KOH}\right)$ and considerable durability [91]. The synergistic interaction between $\mathrm{Fe}$ and Ni components creates a favorable local coordination environment for OER. These results suggest that the unique properties of oxynitrides bring excellent performance in water-splitting reactions.

\subsubsection{Carbonitride}

Among the high-performing several mixed nitrides, carbonitrides are considered effective and promising electrocatalysts due to their desirable electronic structures, and their density of states (DOS) around the Fermi levels is the same as that of the precious metals. The $p-d$ state equilibrium between TM 
and carbon or nitrogen atoms can be adjusted by additional elements, which can significantly affect its macro-mechanical properties, microstructure, and electronic stability.

For example, Kou et al. explored the WCN with a twinned structure that exhibited outstanding electrocatalytic activity $\left(\eta_{10}=140 \mathrm{mV}\right)$ for HER as compared to the $\mathrm{W}_{2}(\mathrm{C}, \mathrm{N})($ Fig. $4 \mathrm{a})$ [92]. Notably, the intergrown of $\mathrm{W}_{2} \mathrm{C}$ and $\mathrm{WN}$ in the $\mathrm{WCN}$ nanocrystals yields abundant $\mathrm{N}-\mathrm{W}-\mathrm{C}$ interfaces, driving a notable improvement in high electrocatalytic HER. Besides, 3D flower-like N-doped tungsten carbide (W2C/WC) with rationally regulated anions was prepared by annealing at a high temperature of $600-800{ }^{\circ} \mathrm{C}$ in Ar atmosphere (Fig. 4b) [93]. Interestingly, adjusting annealing temperature would change orthorhombic/hexagonal $\left(\mathrm{W}_{2} \mathrm{C} / \mathrm{WC}\right)$ structure and crystallographic phases. The $\mathrm{W}-\mathrm{C}$ and $\mathrm{W}-\mathrm{N}$ ratios can also be subsequently modulated. This $\mathrm{N}$-doped $\mathrm{W}_{2} \mathrm{C} / \mathrm{WC}-700{ }^{\circ} \mathrm{C}$ heterostructure array showed a low overpotential of $0.063 \mathrm{~V}$ at a current density of $10 \mathrm{~mA} \mathrm{~cm}^{-2}$ and a small Tafel slope of $73 \mathrm{mV} \mathrm{dec}^{-1}$.

The regulation of $\mathrm{N}$ doping also manages the improvement in electronic conductivity and electrochemical performance of Mo-based compounds. For example, Nakanishi et al. have developed MoCN nanoparticles by using in situ $\mathrm{CO}_{2}$ emission strategy and the highly abundant amino groupbased polydiaminopyridine (PDAP), polyaniline (PANI) precursors, which performed a high $\mathrm{H}_{2}$ production rate (at $-0.14 \mathrm{~V}$ vs. RHE, $10 \mathrm{~mA} \mathrm{~cm}^{-2}$ ) [95]. Besides, Wei et al. synthesized 3D nitrogen-doped flower-like carbon nanospheres (NFCNS) loaded with nitrogen-doped molybdenum carbide $\left(\mathrm{N}-\mathrm{Mo}_{2} \mathrm{C}\right)$ nanoparticles through cationic surfactants [96]. (a)

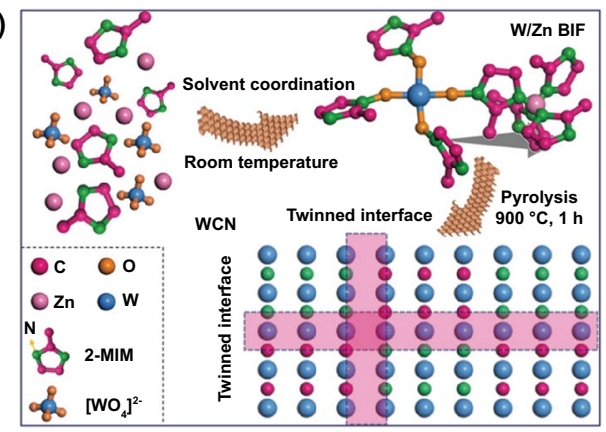

(c)

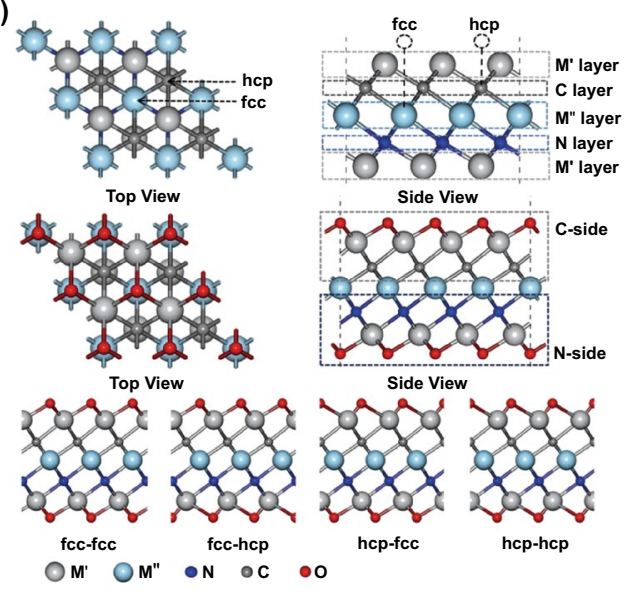

(b)
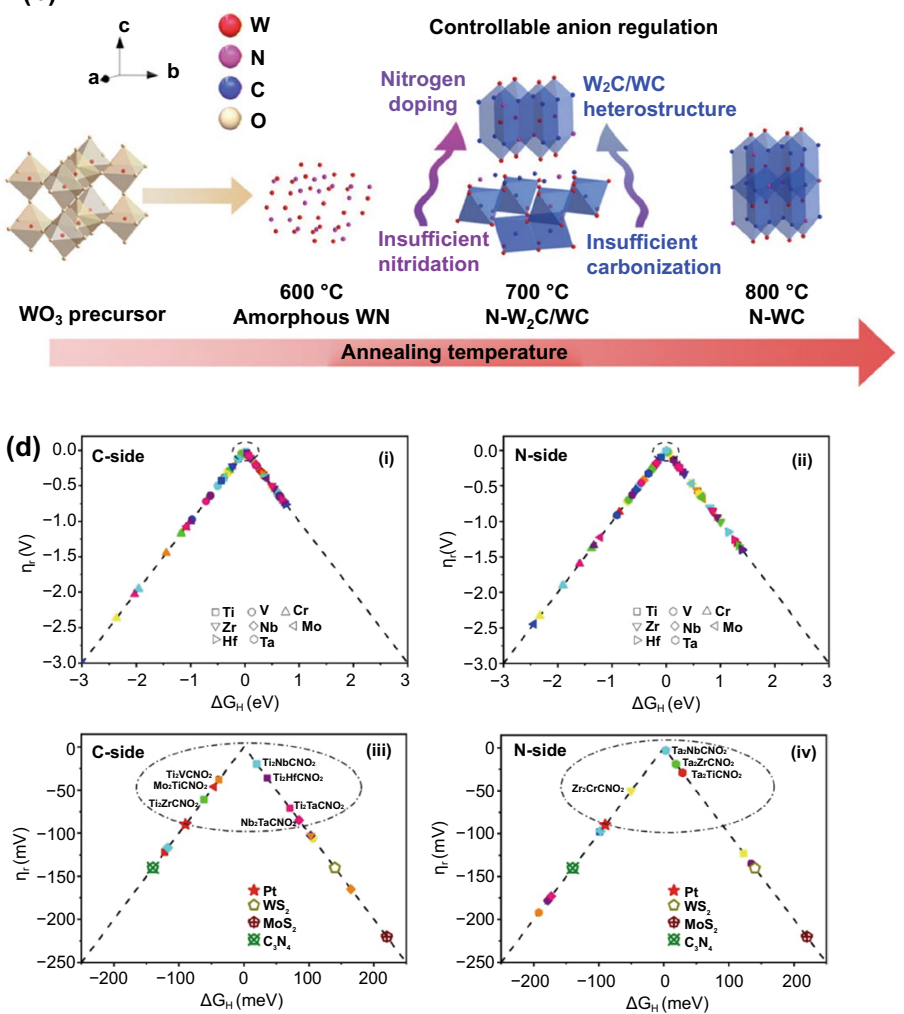

Fig. 4 a Schematic diagram of the construction method for twinned WCN. Reprinted with permission from Ref. [92]. Copyright Year 2019, Wiley-VCH Verlag GmbH \& Co. KGaA, Weinheim. b Schematic representation of the controllable anion regulation. Reprinted with permission from Ref. [93]. Copyright Year 2020, American Chemical Society. c The bare structure of ordered double transition metal carbonitrides, d The volcano plotted for all $64 \mathrm{M}_{2}^{\prime} \mathrm{M}^{\prime \prime} \mathrm{CNO}_{2}$-MXenes. (i) C-side of $\mathrm{M}_{2}^{\prime} \mathrm{M}^{\prime \prime} \mathrm{CNO}_{2}$-MXenes. (ii) $\mathrm{N}$-side of $\mathrm{M}_{2}^{\prime} \mathrm{M}^{\prime \prime} \mathrm{CNO}_{2}-\mathrm{MXenes}$ (iii) The corresponding enlarged view of the area near the volcano apex of C-side. (iv) The corresponding enlarged view of the area near the volcano apex of $\mathrm{N}$-side. The different shapes represent different $\mathrm{M}^{\prime}$, and different colors represent different $\mathrm{M}^{\prime \prime}$ (red, orange, yellow, green, cyan, blue, purple, and pink represent Ti, V, Cr, Zr, Nb, Mo, Hf, and Ta, respectively). Reprinted with permission from Ref. [94]. Copyright Year 2021, Springer Nature 
Nitrogen atoms are doped into the lattice and carbon skeleton of $\mathrm{Mo}_{2} \mathrm{C}$ at the same time, resulting in low desorption energy of the Mo-H bond and easy hydrogen evolution. In addition to experimental means, Li's group studied the HER activities of $64 \mathrm{O}$-terminated ordered double transition metal carbonitrides $\left(\mathrm{M}_{2}^{\prime} \mathrm{M}^{\prime \prime} \mathrm{CNO}_{2}, \mathrm{M}^{\prime}=\mathrm{Ti}, \mathrm{V}, \mathrm{Cr}, \mathrm{Zr}, \mathrm{Nb}, \mathrm{Mo}, \mathrm{Hf}\right.$, $\mathrm{Ta} ; \mathrm{M}^{\prime \prime}=\mathrm{Ti}, \mathrm{V}, \mathrm{Cr}, \mathrm{Zr}, \mathrm{Nb}, \mathrm{Mo}, \mathrm{Hf}$, Ta) utilizing DFT calculation (Fig. 4c) [94]. The results showed that $\mathrm{Ti}_{2} \mathrm{NbCNO}_{2}$ had a small hydrogen adsorption Gibbs free energy $\left(\Delta G_{\mathrm{H}^{*}}\right.$, $0.02 \mathrm{eV}$ ), abundant $\mathrm{C}$-side catalytic centers, and great stability; therefore, it is expected to be a Pt-like HER catalyst (Fig. 4d).

It is worth noting that boron carbonitride $(\mathrm{BCN})$ has recently been proved to be an effective electrocatalytic catalyst with excellent stability $[97,98]$. Taking representative research as an example, Lewis acid-base theory and DFT revealed that the enrichment of $\mathrm{B} / \mathrm{N}$ heteroatoms in boron carbon nitride (BCN) system could lead to stronger $\mathrm{OH}^{*} / \mathrm{H}_{2} \mathrm{O}$ adsorption strength, respectively [98]. The self-supporting $\mathrm{BCN}$ material electrode pair (B-BCN/N-BCN) with the best $\mathrm{B}$ and $\mathrm{N}$ content was able to complete overall water-splitting at a low voltage of $1.52 \mathrm{~V}\left(10 \mathrm{~mA} \mathrm{~cm}^{-2}\right)$. This novel work provides a valuable reference for developing advanced metal-free materials and multicomponent carbonitride materials for electrocatalytic water-splitting.

\subsection{Mixed Halides}

\subsubsection{Oxyfluoride}

TM oxyfluorides (OF) possess unique characteristics, including optical properties, catalytic activity, and electrical conductivity $[58,99,100]$. It is interesting to note that the intrinsically weak conductivity of metal-fluorides can be improved by introducing metal-oxygen $(\mathrm{M}-\mathrm{O})$ bonds, because the high ionicity of metal-fluorine (M-F) bonds can be well adjusted by high covalent $\mathrm{M}-\mathrm{O}$ bonds. Thus, $\mathrm{M}-\mathrm{OF}$ contains both extraordinary conductivity and electrochemical characteristics due to the coexistence of $\mathrm{M}-\mathrm{O}$ and $\mathrm{M}-\mathrm{F}$ bonds [101]. It is worth noting that the $\mathrm{F}$ atoms possess strong electronegativity among all of the elements in the periodic table; thus, they can easily capture electrons from neighboring metal atoms, resulting in numerous coordinatively unsaturated sites [101]. Meanwhile, during exploring highly active, low-cost, and long-term durable catalysts for water-splitting, oxyfluorides have attracted much attention due to their non-centrosymmetric macroscopic polarity, magnetic properties, and redox properties [102-105].

By employing a facile low-temperature synthetic methodology, Fan et al. developed the 3D iron fluoride-oxide nanoporous film (IFONF) with both abundant defect sites as a bifunctional electrocatalyst for water-splitting (Fig. 5a) [31]. For overall water-splitting, a $j$ of $10 \mathrm{~mA} \mathrm{~cm}^{-2}$ can be achieved at a voltage of $1.58 \mathrm{~V}$, which is lower than the benchmark of $\mathrm{Ir} / \mathrm{C}-\mathrm{Pt} / \mathrm{C}$ couple $(1.62 \mathrm{~V})$. Besides, due to the highest electronegativity of the $\mathrm{F}^{-}$anion $(\sim 3.98)$ and the comparable ionic radii of $\mathrm{F}^{-}(1.31 \AA)$ to $\mathrm{O}^{2-}(1.38 \AA)$ ions, the $\mathrm{F}^{-}$anion at the oxygen sites showed the aniondoping extremum and acts as a suitable $n$-type dopant for cobalt-oxide ( $\mathrm{Co}-\mathrm{O})$-based electrocatalysts. Taking this as an advantage, Huang et al. indicated that 2D cobalt-oxyfluoride with the incorporation of cobalt-fluoride ( $\mathrm{Co}-\mathrm{F}$ ) and $\mathrm{Co}-\mathrm{O}$ bonds for effectively modulated electronic structure, exhibiting an efficient electrochemical activity $\left(\eta_{10}=230 \mathrm{mV}\right)$ with high durability $(45 \mathrm{~h})$ toward OER [106].

Multielement transition metal oxyfluorides are also the current research hotspot object [101]. For instance, Svengren et al. prepared $\mathrm{Co}_{3} \mathrm{Sb}_{4} \mathrm{O}_{6} \mathrm{~F}_{6}$ with an electrocatalytic watersplitting activity of $\eta_{10}=0.43 \mathrm{~V}$ for OER [107]. Yang et al. developed a NiFe oxyfluoride (NiFeOF) holey film (HF) as an overall water-splitting electrocatalyst [29]. The as-prepared NiFeOF HF showed excellent overall water-splitting performance $\left(\eta_{10}=0.6 \mathrm{~V}\right.$ in $\left.1 \mathrm{M} \mathrm{NaOH}\right)$ due to the combination of mixed phases (crystalline $\mathrm{NiFe}$ alloy/amorphous $\mathrm{NiFeOF}$ ) and porous structure. In addition, $\mathrm{F}$ and $\mathrm{O}$ can be interchanged with each other more quickly due to the similar ionic radii of $\mathrm{O}^{2-}$ and $\mathrm{F}^{-}$, providing higher electrical conductivity to enhance the electrochemical catalytic performance.

The structural advantage and the synergistic effect of the bimetal components also contribute to improving the catalytic activity. For example, Lei et al. produced amorphous CoMo bimetallic oxyfluoride (CoMoOF/GF) on graphite felt, and proper anodizing made it more abundant in defects and larger pore structure (Fig. 5b-h) [108]. CoMoOF/ GF showed a quite low overpotential and Tafel slope at $j=10 \mathrm{~mA} \mathrm{~cm}{ }^{-2}\left(79 \mathrm{mV}, 43.3 \mathrm{mV} \mathrm{dec}^{-1}\right.$ in the alkaline electrolyte; $94 \mathrm{mV}, 60.2 \mathrm{mV} \mathrm{dec}^{-1}$ in the acid electrolyte). Additionally, perovskite fluoride oxide is also a typical configuration. Hua et al. reported a $\mathrm{La}_{0.5} \mathrm{Ba}_{0.25} \mathrm{Sr}_{0.25} \mathrm{CoO}_{2.9-\delta} \mathrm{F}_{0.1}$ (LBSCOF) catalyst for alkaline water-splitting (Fig. 5i, j) [104]. For HER, the overpotential value of LBSCOF at 
(a)
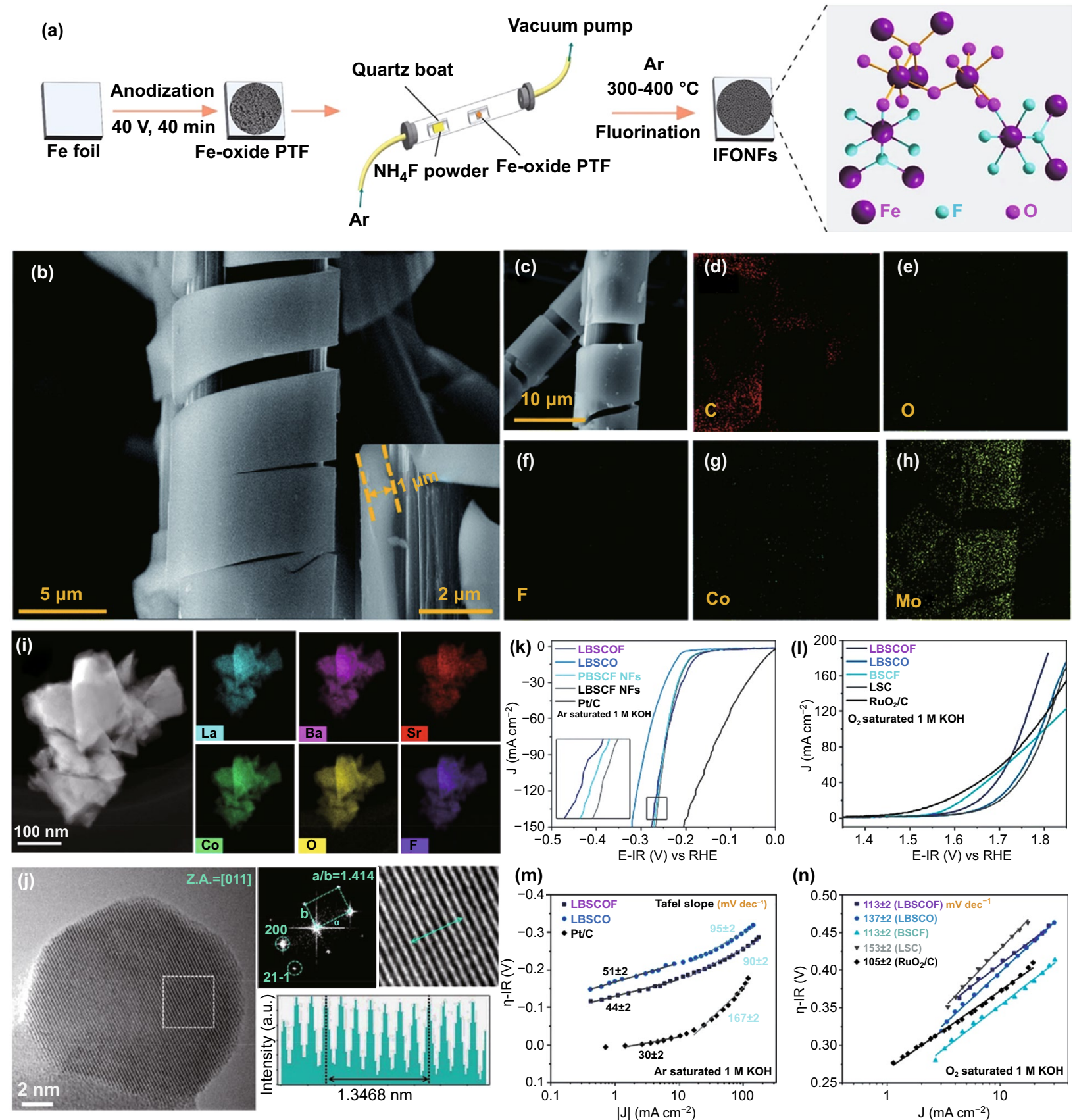

Fig. 5 a Schematic of the fabrication process for IFONFs, starting with a Fe foil. Reprinted with permission from Ref. [31]. Copyright Year 2018, Springer Nature. b SEM images for CoMoOF/GF. Inset: cross-sectional SEM image at a higher magnification, c-h SEM image for $\mathrm{CoMoOF/GF}$ and the corresponding EDS elemental mapping. Reprinted with permission from Ref. [108]. Copyright Year 2021, Royal Society of Chemistry. i Scanning transmission electron microscope (STEM)-energy dispersive X-ray spectroscopy (EDX) analysis of LBSCOF shows the uniform element distributions, $\mathbf{j}$ A typical high resolution transmission electron microscope (HRTEM) image of LBSCOF and the corresponding simulation results, $\mathbf{k}$ LSV curves and $\mathbf{l}$ Tafel plots and slopes for HER in Ar-saturated $1 \mathrm{M} \mathrm{KOH,} \mathbf{m}$ LSV curves and $\mathbf{n}$ Tafel plots and slopes for OER in $\mathrm{O}_{2}$-saturated $1 \mathrm{M} \mathrm{KOH}$. Reprinted with permission from Ref. [104]. Copyright Year 2018, Elsevier

$100 \mathrm{~mA} \mathrm{~cm}^{-2}$ is $256 \mathrm{mV}$ (Fig. 5k). It should be noted that the Tafel slope $\left(90 \mathrm{mV} \mathrm{dec}^{-1}\right)$ of LBSCOF in the high current density region $\left(>10 \mathrm{~mA} \mathrm{~cm}^{-2}\right)$ is only about half of $\mathrm{Pt} / \mathrm{C}$ $\left(167 \mathrm{mV} \mathrm{dec}^{-1}\right)$ (Fig. 51). For OER, LBSCOF can reach a current density of $100 \mathrm{~mA} \mathrm{~cm}^{-2}$ at an operating voltage of $1.748 \mathrm{~V}$, and the Tafel slope is $113 \mathrm{mV} \mathrm{dec}^{-1}$ (Fig. 5m, n). 
$\mathrm{F}$ anion helps to enhance the center of the $\mathrm{O} p$ band and activate the redox ability of lattice $\mathrm{O}$.

\subsubsection{Hydroxy Fluoride}

Recently, F anion substituting was found as an assuring to increase the catalytic activity, surface polarity, and kinetics of the metal hydroxyl oxide because of the high ionicity of metal hydroxyl fluoride (M- $(\mathrm{OH}) \mathrm{F})$ bond. Interestingly, the inclusion of $\mathrm{F}$ anions into the host hydroxyl oxide lattice improved the polarity of the chemical bonds, which enhanced the adsorption capacity of hydroxide $(\mathrm{OH})$ anions and oxygenic intermediates [58].

The F-guided synthesis approach offered the possibility to improve poor conductivity without resorting to organic surfactants. For instance, Wan et al. developed the synthesis of 3D cobalt hydroxy fluoride $(\mathrm{Co}(\mathrm{OH}) \mathrm{F})$ microspheres using $\mathrm{F}$ as an oxidatively robust ligand (Fig. 6a) [60]. In particular, the substitution of the fluorine anion ensured that the development of a unique $3 \mathrm{D}$ structure is pure orthorhombic $\mathrm{Co}(\mathrm{OH}) \mathrm{F}$ phases, with modified electronic structure contributed better charge mobility (Fig. 6b, c). Owing to these, the $\mathrm{Co}(\mathrm{OH}) \mathrm{F}$ electrode showed superior catalytic activity $\left(10 \mathrm{~mA} \mathrm{~cm} \mathrm{~cm}^{-2}\right.$ at $0.313 \mathrm{~V}$ ) and excellent OER stability (more than $10 \mathrm{~h}$ with a $j$ of $8 \mathrm{~mA} \mathrm{~cm}{ }^{-2}$ ). Analogously, to improve charge transferability, Hu's group reported $\mathrm{NiFe}$ hydroxide nanosheets incorporating fluoride $(\mathrm{NiFe}-(\mathrm{OH}) \mathrm{F})$ on $\mathrm{Ni}$ foam demonstrating the enhanced HER activity and lower ohmic resistance than NiFe hydroxide ( $\mathrm{NiFe}-\mathrm{OH})$ catalyst [109].

In addition to adjusting the electronic state, $\mathrm{F}$ ions also have unique properties to promote catalyst reconstruction in the OER process. NiFe-hydroxide NS arrays on 3D $\mathrm{NF}(\mathrm{NiFe}-\mathrm{OH}-\mathrm{F})$ were further developed by incorporating fluoride through the one-step hydrothermal method [110]. $\mathrm{NiFe}-\mathrm{OH}-\mathrm{F}$ was converted to a highly mesoporous and amorphous metal oxide hierarchical structure through surface self-reconstruction by fluoride leaching under OER conditions. Excitingly, the resulting surface reconstructed (SR) NiFe-OH-F achieved a $j$ of $10 \mathrm{~mA} \mathrm{~cm} \mathrm{~cm}^{-2}$ at a small overpotential $(0.176 \mathrm{~V})$ in the alkaline medium for OER. Besides, $\mathrm{Xu}$ et al. demonstrated a new electrochemically driven F-induced surface-reconstruction strategy for converting ultra-thin $\mathrm{NiFeO}_{x} \mathrm{~F}_{y}$ nanosheets into $\mathrm{Fe}$-enriched $\mathrm{Ni}(\mathrm{Fe})$ $\mathrm{O}_{x} \mathrm{H}_{y}$ phase [111]. Moreover, through a fluorination strategy, Ma et al. obtained a hierarchical NiFe Prussian blue analogue
(NiFe-PBA)-F catalyst, which showed an ultra-low OER overpotential of $190 \mathrm{mV}\left(10 \mathrm{~mA} \mathrm{~cm}{ }^{-2}\right)$ with excellent stability [112]. The dynamic migration of fluoride ions promotes the interesting reconstruction of NiFe-PBAs-F, presenting more F-doped $\mathrm{NiFeOOH}$ active sites for intermediates' adsorption.

Typically, the high entropy effect, amorphous state, and structure effect are new ideas to enhance OER performance. Zhu et al. applied chronopotentiometry to in situ activate multicomponent non-noble metal oxyfluoride as an advanced OER catalyst [113]. The increase of current density was conducive to reconstructing the catalyst's structure into a nanoporous core-shell structure and introducing metal hydroxyl oxide on the surface, which increased effective ion/mass transport channels and active catalytic sites (Fig. 6d-f). The activated five-membered oxyfluorides showed the best catalytic activity, with an overpotential of $348 \pm 2 \mathrm{mV}$ at a current density of $10 \mathrm{~mA} \mathrm{~cm}^{-2}$ (Fig. $6 \mathrm{~g}, \mathrm{~h}$ ), a double layer capacitance $\left(\mathrm{C}_{\mathrm{dl}}\right)$ value of $11.28 \pm 0.04 \mathrm{mF}$ (Fig. 6i), and stability of up to $50 \mathrm{~h}$ (Fig. 6j).

\subsection{Mixed Phosphides}

\subsubsection{Oxyphosphide}

Oxygen (O) anion incorporation in metal phosphides (M-P) can further boost the intrinsic activity of electrocatalysts. Indeed, due to the firmness of $\mathrm{M}-\mathrm{P}-\mathrm{O}$ metal bonds in oxyphosphide, it has been proved to have excellent stability [114]. In addition, the metal-P (M-P) and metal-O (M-O) bonds in oxyphosphide will help to adjust the electronic structure and optimize the adsorption/desorption free energy of intermediates. And the interaction of phosphorus and oxygen produces plentiful surface vacancy/defects and large active surface area [46, 115-117]. Given these, oxyphosphides are considered highly potential water-splitting catalysts. Besides, various appearance configuration is another feature for the oxyphosphides' family.

Lou and his colleagues have carried out lots of typical research work on oxyphosphides with novel configurations and excellent performance. For example, they creatively designed highly complex multishell MnCo oxide particles with seven layers of shells [118]. After phosphorization treatment, the multishell were transformed into $\mathrm{MnCo}$ oxyphosphide particles (Fig. 7a-d), exhibiting better OER performance than previous MnCo oxide particles. The 
(a)

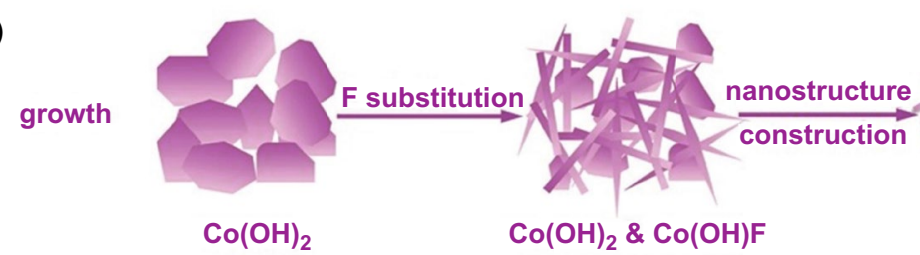

substructures

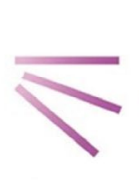

1D nanorod
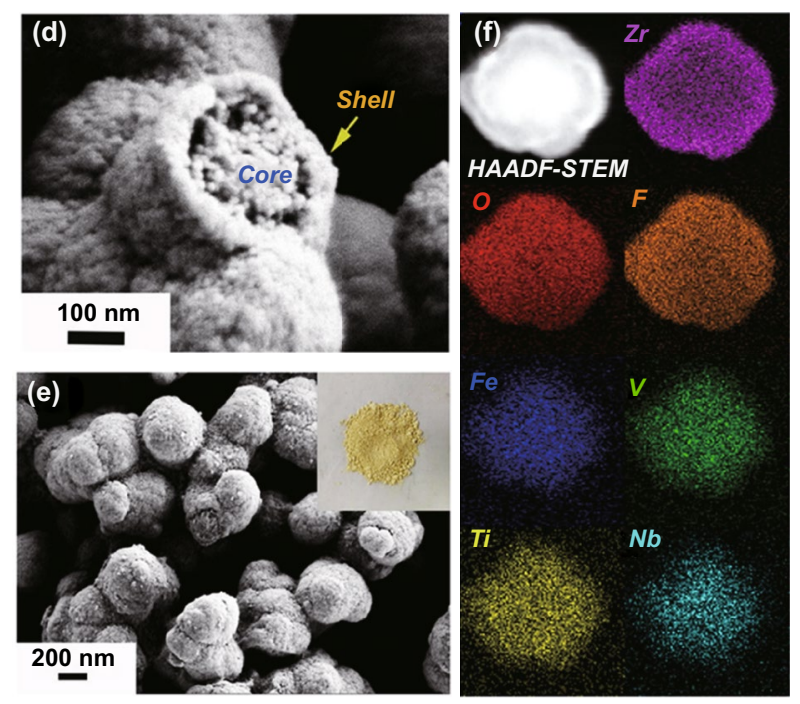
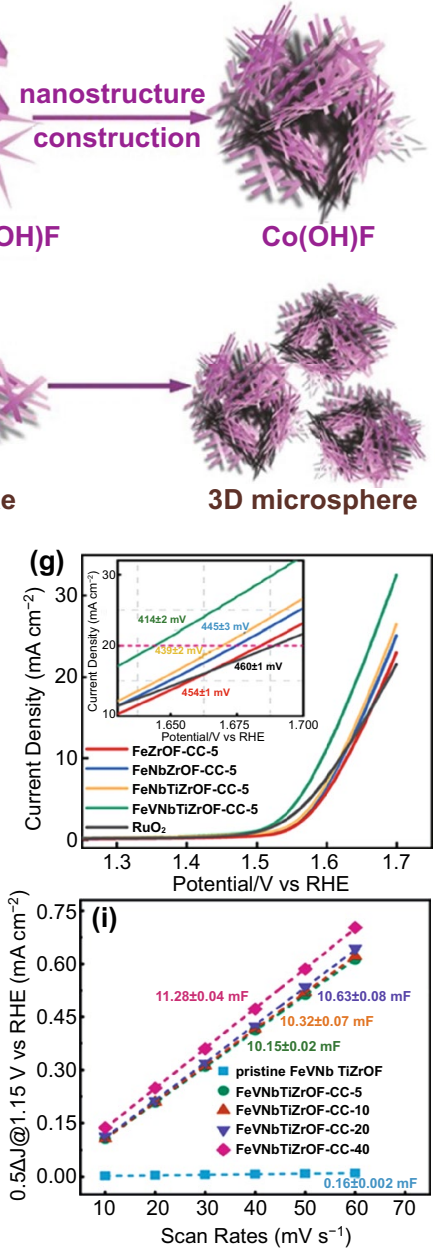
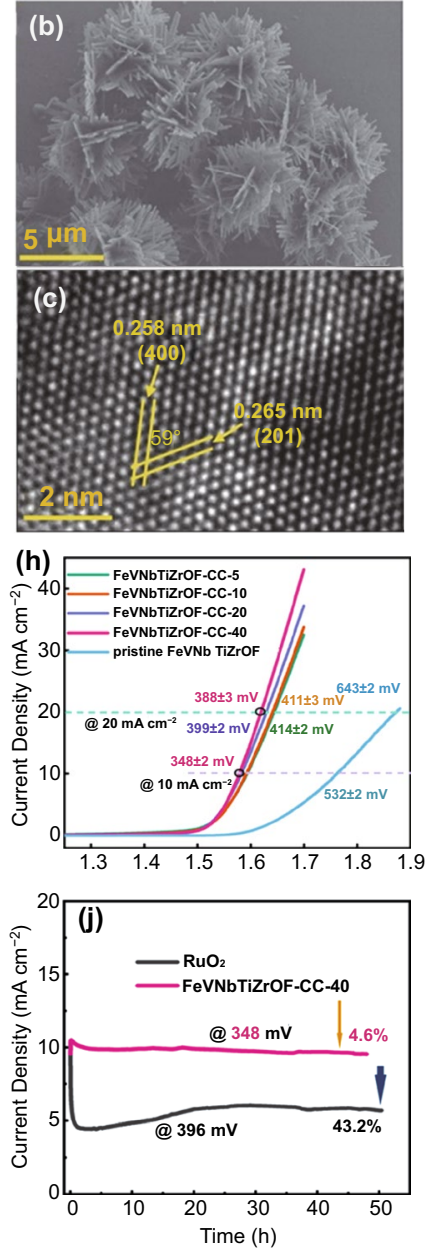

Fig. 6 a Schematic of the growth and substructures of the hierarchical $3 \mathrm{D} \mathrm{Co}(\mathrm{OH}) \mathrm{F}$ microspheres. The $3 \mathrm{D}$ structure is constructed by $2 \mathrm{D}$ networked nanoflakes, and the 2D nanoflakes are further woven by the $1 \mathrm{D}$ nanorods, $\mathbf{b}$ SEM and $\mathbf{c} \mathrm{HRTEM}$ images of the hierarchical $3 \mathrm{D}$ Co(OH)F microspheres. Reprinted with permission from Ref. [60]. Copyright Year 2017, Wiley-VCH Verlag GmbH \& Co. KGaA, Weinheim. d-e SEM images and $\mathbf{f}$ EDS mappings of the pristine FeVNbTiZrOF, the insert map is the optical photo of the pristine FeVNbTiZrOF, $\mathbf{g}$ LSV curves of FeZrOF-CC-5, FeNbZrOF-CC-5, FeNbTiZrOF-CC-5, FeVNbTiZrOF-CC-5 and $\mathrm{RuO}_{2}$ in $1 \mathrm{M} \mathrm{KOH}$ solution with a scan rate of 5 mV/s; h LSV curves of the pristine and activated FeVNbTiZrOF at different current densities; $\mathbf{i}$ corresponding linear plots of capacitive current densities versus scan rates; j Chronoamperometric response of FeVNbTiZrOF-CC-40 and $\mathrm{RuO}_{2}$ at the overpotential of $348 \mathrm{mV}$ and $396 \mathrm{mV}$, respectively. Reprinted with permission from Ref. [113]. Copyright Year 2021, Elsevier

substitution of $\mathrm{Mn}^{2+}$ cations and $\mathrm{O}^{2-}$ anions into the $\mathrm{CoP}$ was beneficial for conductivity enhancement and the generation of new active sites. Likewise, they fabricated hierarchical $\mathrm{CoFe}$ oxyphosphide microtubes with hollow structures via a facile self-templated synthetic approach, including phosphorization treatment (Fig. 7e) [119]. Typically, field emission scanning electron microscopy (FESEM) and transmission electron microscope (TEM) analysis of the sample confirms the formation of the tubular structure (Fig. $7 \mathrm{f}-\mathrm{h}$ ). The obtained electrocatalyst exhibits overpotentials of 280 and $180 \mathrm{mV}$ for OER and HER $\left(10 \mathrm{~mA} \mathrm{~cm}{ }^{-2}\right.$, alkaline media), respectively.
Similarly, some mixed hybrid oxyphosphides with other configurations are also reported. Wang and coworkers constructed a mixed-metal-organic framework (MMOF) self-template supported CoFe hybrid oxyphosphides [8]. Significantly, due to the oxygen incorporation, $\mathrm{Co}_{3} \mathrm{FeP}_{x}$ considerably strengthened the $\mathrm{O}^{*}$ adsorption, which augmented the OER activity. As a result, the mixed-metal oxyphosphides were found to have a lower overpotential $0.291 \mathrm{~V}$ at a $j$ of $10 \mathrm{~mA} \mathrm{~cm}^{-2}$. Hong's group constructed a novel template-engaged technique to make bimetal oxyphosphide of different $\mathrm{Fe}$ ions as modulators in hollow $\mathrm{NiFe}$ spheres $(\mathrm{H}-\mathrm{NiFe})$ [121]. The resulting material duly showed 
(a)

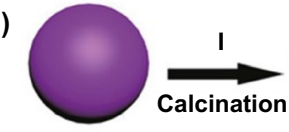

Mixed-metal coordination polymer

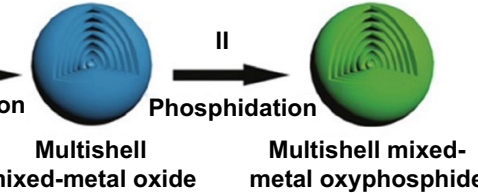
metal oxyphosphide
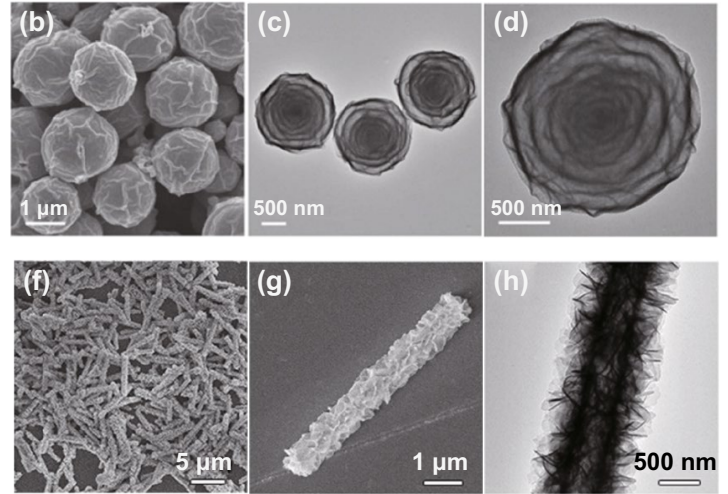

Co-Fe oxyphosphide MT

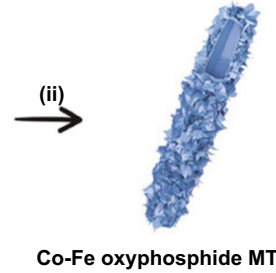

Co-Fe LDH MT
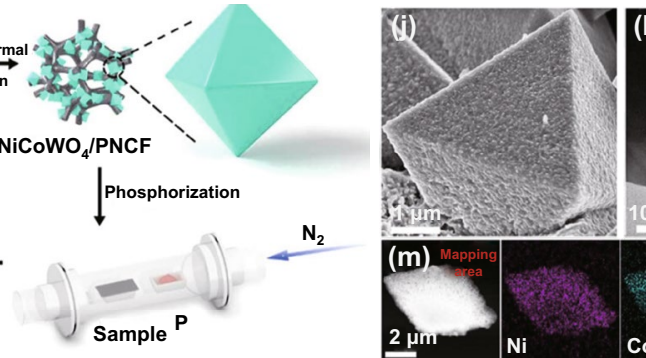

(k)

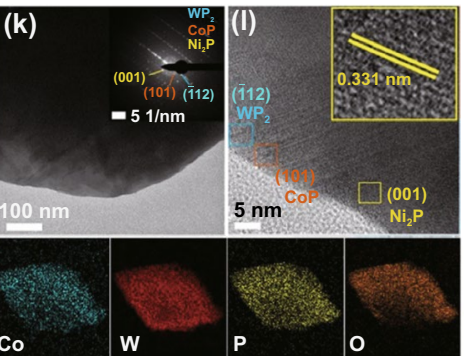

Fig. 7 a Formation of multishell mixed-metal oxyphosphide particle, b FESEM and c, d TEM images of the multishell Mn-Co oxyphosphide particles. Reprinted with permission from Ref. [118]. Copyright Year 2017, Wiley-VCH Verlag GmbH \& Co. KGaA, Weinheim. e Schematic illustration of the formation process of hierarchical Co-Fe oxyphosphide MTs, f, $\mathbf{g}$ FESEM and $\mathbf{h}$ TEM images of hierarchical Co-Fe LDH MTs. Reprinted with permission from Ref. [119]. Copyright Year 2019, Wiley-VCH Verlag GmbH \& Co. KGaA, Weinheim. i Fabrication of a multiphase, trimetallic Ni-Co-W phosphoxide electrocatalyst: Regular octahedral multiphase $\mathrm{M}_{x} \mathrm{O} @ \mathrm{M}_{x} \mathrm{P}$ crystals are formed in situ on plasmadefect-engineered $\mathrm{Ni}$-Co support, $\mathbf{j}$ high-resolution SEM image, $\mathbf{k}, \mathbf{l}$ low-and high-resolution TEM images, the inset in $\mathbf{k}$ is the SAED pattern of the $\mathrm{M}_{x} \mathrm{O} @ \mathrm{M}_{x} \mathrm{P} / \mathrm{PNCF}$ particle, and $\mathbf{m}$ HAADF-STEM image and EDX elemental mapping of a single $\mathrm{M}_{x} \mathrm{O} @ \mathrm{M}_{x} \mathrm{P} / \mathrm{PNCF}$. Reprinted with permission from Ref. [120]. Copyright Year 2021, American Chemical Society

excellent OER performance with long-term stability $(20 \mathrm{~h}$ at a static overpotential of $0.27 \mathrm{~V}$ ) due to the optimized chemical composition and the subtly constructed hollow structure of $\mathrm{H}-\mathrm{NiFe}$ spheres. Furthermore, researchers from Du's group successfully developed the ultra-fine nickel-zinc oxyphosphide (NiZnPO) nanosheets (NSs) [122]. Interestingly, the NiZnPO NSs doped with oxyphosphide anions enhance modulated the local electronic structure, promoted active areas, as well as improved electron conductivity. The NiZnPO NSs demonstrated high activity, with an overpotential of $0.29 \mathrm{~V}$ required to achieve a $j$ of $10 \mathrm{~mA} \mathrm{~cm}^{-2}$ for the OER, and showed excellent long-term stability for over 3000 cyclic voltammetric cycles. In another study, Xu et al. developed a 3D-1D CoZn oxyphosphide NSs anchored on CNTs with uniform surface coverage, displaying an excellent electrocatalytic performance toward OER at an overpotential of $0.28 \mathrm{~V}\left(j=10 \mathrm{~mA} \mathrm{~cm}^{-2}\right)$ [123]. The overpotential would be decreased significantly by the presence of 3D-1D architecture, modified electronic structure, increased surface active sites and the promotion effect of $\mathrm{P}$ atoms.

For practical applications, the catalyst that meets the industrial needs should have the characteristics of low overpotential $(\leq 300 \mathrm{mV})$ under high current density $\left(\geq 500 \mathrm{~mA} \mathrm{~cm}^{-2}\right)$, high performance, and excellent durability. Given this, regular octahedral nickel-cobalt-tungsten-phosphorus oxide particles (MxO@MxP/PNCF $(\mathrm{M}=\mathrm{Ni}, \mathrm{Co}, \mathrm{W}))$ were successfully formed in situ on plasma-defect-engineered $\mathrm{Ni}-\mathrm{Co}$ support and served as HER catalyst (Fig. 7i) [120]. Notably, low overpotentials of only 53 and $343 \mathrm{mV}$ for current densities of 10 and $1000 \mathrm{~mA} \mathrm{~cm}^{-2}$ were required for $\mathrm{H}_{2}$ production. Notably, the strong metal oxide octahedral support is conducive to improving the electrocatalytic stability of MxO@MxP (Fig. 7j-m), which demonstrates excellent longterm stability and durability with no significant activity loss. 


\subsubsection{Hydroxy Phosphate}

Hydroxy phosphate (HP) is another representative oxyphosphide. As an excellent electrocatalyst, $\mathrm{Fe}_{2.95}\left(\mathrm{PO}_{4}\right)_{2}(\mathrm{OH})_{2}$ thin-film electrode exhibited an overpotential of $281 \mathrm{mV}$ for OER ( $1 \mathrm{M} \mathrm{KOH}, 10 \mathrm{~mA} \mathrm{~cm}{ }^{-2}$ ) and $165.7 \mathrm{mV}$ for $\operatorname{HER}\left(1 \mathrm{M} \mathrm{H}_{3} \mathrm{PO}_{4}, 10 \mathrm{~mA} \mathrm{~cm}{ }^{-2}\right.$ ), respectively [124]. As per previous reports, the TM-HP are commonly much more durable than the corresponding TM-phosphates in alkaline electrolytes [125]. For instance, Mani et al. reported orthorhombic iron hydroxy phosphate $\left(\mathrm{Fe}_{5}\left(\mathrm{PO}_{4}\right)_{4}(\mathrm{OH})_{3} \cdot 2 \mathrm{H}_{2} \mathrm{O}(\mathrm{FeHP})\right)$ synthesized by hydrothermal method from metal chloride precursors and disodium hydrogen phosphate as a source of phosphate ligand precursor (Fig. 8a) [126]. To enhance the OER behavior, the authors introduced Sn into FeHP to form $\mathrm{Sn}-\mathrm{FeHP}$ to weaken $\mathrm{M}^{3+}-\mathrm{OH}$ bonding. After Sn incorporation, the nanocrystal morphology of the FeHP was changed, showing a star-like nanostructure (Fig. 8b-g). Notably, Sn-FeHP has achieved catalytic activity with a small onset overpotential of $0.35 \mathrm{~V}$ at $10 \mathrm{~mA} \mathrm{~cm}{ }^{-2}$ with a Tafel slope of $81 \mathrm{mV} \mathrm{dec}^{-1}(1 \mathrm{M} \mathrm{KOH})$. Moreover, the $\mathrm{SN}-\mathrm{FeHP}$ possessed remarkable stability in alkaline media for $800 \mathrm{~min}$ at $1.65 \mathrm{~V}$ vs. RHE. Additionally, the electrocatalytic activity of the FeHP electrode can be further developed with a combined effect of $\mathrm{Ni}$ or $\mathrm{Co}$. As such, $\mathrm{Fe}(\mathrm{Ni} / \mathrm{Co})$ hydroxyphosphate/NF was reported as demonstrating a bifunctional electrocatalyst [127]. Summing up, a cell voltage of just $1.65 / 1.67 \mathrm{~V}$ at a current density of $10 \mathrm{~mA} \mathrm{~cm}{ }^{-2}$ was required to achieve overall water-splitting by using $\mathrm{Fe}(\mathrm{Ni} / \mathrm{Co}) \mathrm{HP} / \mathrm{NF}$ as both the anode and cathode in alkaline solution. In addition to the quaternary compound, the construction of trimetallic $(\mathrm{Co} / \mathrm{Ni} / \mathrm{Cu}) \mathrm{HP} N S s$ on $\mathrm{Ni}$ foam has also been published. Zhang et al. examined the design of CuHP loaded CoNi hybrid nanostructures by an ion exchanging method [125]. The excellent OER catalytic activity (a low overpotential of $370 \mathrm{mV}$ at $50 \mathrm{~mA} \mathrm{~cm}$ ) was mainly attributed to the high-valent cobalt species produced in situ during the electrooxidation process. At the same time, the introduction of cobalt and nickel increased the electrochemically active area and provided more effective active sites for OER. The synergy

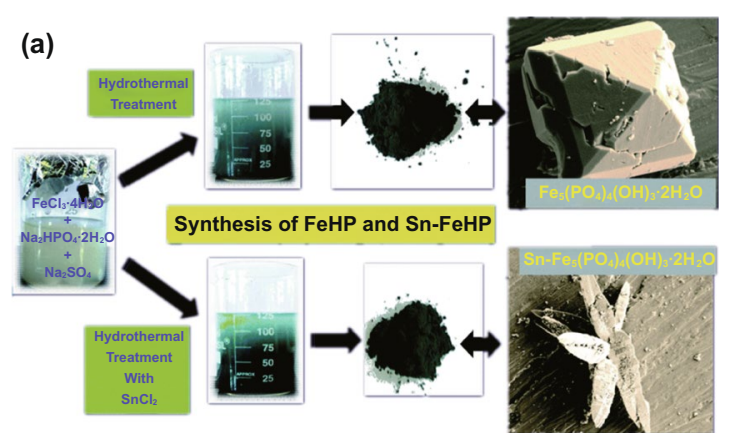

(h)

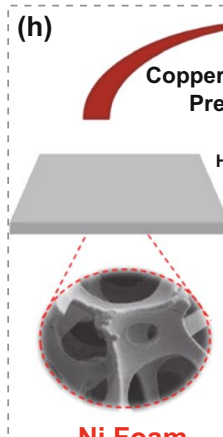

Ni Foam
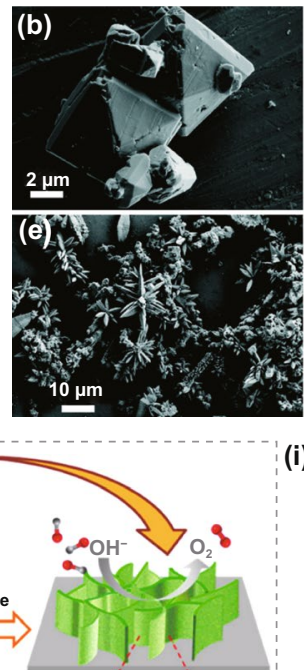

क*
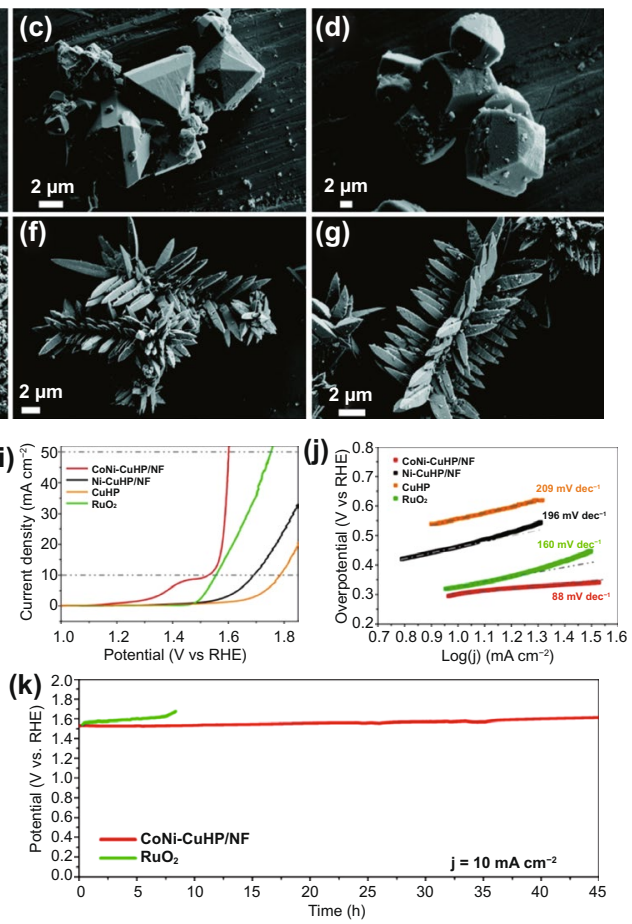

Fig. 8 a The synthesis of FeHP and Sn-FeHP from iron(III) chloride, tin(II) chloride, and disodium hydrogen phosphate. b-d FE-SEM images of FeHP octahedral crystals, e-g FE-SEM images of Sn-FeHP self-assembled needle-like microcrystals. Reprinted with permission from Ref. [126]. Copyright Year 2017, Royal Society of Chemistry. h Schematic illustration of the synthesis of CoNi-CuHP/NF, i LSV curves, and j the related Tafel curves of $\mathrm{CoNi}-\mathrm{CuHP} / \mathrm{NF}$ and different catalysts, $\mathbf{k}$ long-term cycling tests of the $\mathrm{CoNi}-\mathrm{CuHP} / \mathrm{NF}$ catalyst and commercial $\mathrm{RuO}$. Reprinted with permission from Ref. [125]. Copyright Year 2017, Royal Society of Chemistry 
of the three metals and the combination with the nickel foam matrix improved the conductivity of the electrode.

\subsection{Mixed Chalcogenides}

\subsubsection{Oxysulfide}

Numerous efforts have been made to develop oxysulfides (OS) to achieve high performance in electrocatalysis [52, $128,129]$. Oxygen anions are typically hard (non-polarized), and sulfur anions are soft (polarized in sulfides). The $\mathrm{O}$ and $\mathrm{S}$ derived from the same VIA group of the periodic table are easily mixed to modify the compounds. To date, a wide range of TM compounds with oxysulfides, e.g., (CoNi) $\mathrm{O}_{x} \mathrm{~S}_{y}, \mathrm{Si}-\mathrm{MWs} @ \mathrm{MoO}_{x} \mathrm{~S}_{y}, \mathrm{CoO}_{0.87} \mathrm{~S}_{0.13} / \mathrm{GN}$, $\mathrm{Ni}_{y} \mathrm{Co}_{1-y} \mathrm{O}_{x} \mathrm{~S}_{z}$, and $\mathrm{Mn}(\mathrm{Zn}, \mathrm{Ge})$ oxysulfide $[8,130,131]$, have been explored as a catalyst for electrochemical applications such as supercapacitors [132], PEC [130], Zn-air batteries [133], PEMWE [134] and ORR [135].

Subsequently, Suntivich's group investigated a partial S anionic substitution in CoO NPs to increase the $\mathrm{H}_{2}$ evolution [50]. The excellent electrocatalytic activity of $\mathrm{CoO}_{x} \mathrm{~S}_{y}$ was attributed to the exchange of anion $\mathrm{S}^{2-}$ and $\mathrm{O}^{2-}$ in Co-oxysulfide NPs, which decreased the intermediate energy during HER. However, exchanging more $\mathrm{S}$ atoms would increase the $\mathrm{H}^{*}$ intermediate energy and decrease HER kinetics, resulting in a lower performance. In another example, based on TM-oxysulfide from anion exchange strategy, Cai et al. prepared amorphous $\mathrm{CoO}_{0.6} \mathrm{~S}_{4.6}$ porous nanocubes (PNCs) from corresponding $\mathrm{CoFe}$ Prussian blue analogue (PBA) as a precursor [48]. The local disordered structure was generated due to the insertion of $\mathrm{O}$ atoms around the Co center, which was evidenced by significantly decreased intensity beyond the first shell peaks. Besides, the Co atom is surrounded by 4.6 $\mathrm{S}$ atoms and $0.6 \mathrm{O}$ atoms with abundant $\mathrm{Co}-\mathrm{S}$ dangling bonds. These $\mathrm{Co}-\mathrm{S}$ dangling bonds and oxygen incorporation into the $\mathrm{CoS}_{x}$ host can greatly enhance $\mathrm{O} *$ adsorption, thereby significantly improving the activity on a single site. More impressively, the obtained $\mathrm{CoO}_{0.6} \mathrm{~S}_{4.6}$ PNCs showed excellent performance for water oxidation with a low onset potential of $1.52 \mathrm{~V}(1 \mathrm{M} \mathrm{KOH}), 1.50 \mathrm{~V}(0.1 \mathrm{M} \mathrm{PBS})$ to achieve a $j$ of $10 \mathrm{~mA} \mathrm{~cm}^{-2}$.

Self-supporting structures own the advantages of high current density and simple preparation. Li et al. prepared $\mathrm{Ni}$ foam supported 3D NiCo sulfoxide $\left(\mathrm{NiCoS}_{x} \mathrm{O}_{y}\right)$ nanosheets through electrodeposition on $\mathrm{NF}$ with $\mathrm{Ni}, \mathrm{Co}, \mathrm{S}$ precursors (Fig. 9a) [136]. As a result, a cell voltage of $1.64 \mathrm{~V}$ was required to attain a $20 \mathrm{~mA} \mathrm{~cm}{ }^{-2}$ current density (Fig. 9b). The electronegativity of the $\mathrm{S}$ ligand was comparable to $\mathrm{OH}$ species in alkaline electrolyte, which made the $\mathrm{OH}$ species attract electrons intensively, inhibiting the transformation electron from the $\mathrm{M}-\mathrm{S}$ to $\mathrm{M}-\mathrm{O}$ bond, which resulted in a shorter and more stable $\mathrm{M}-\mathrm{S}$ bond in $\mathrm{NiCoS}_{0.14} \mathrm{O}_{3.25}$ than the other TM sulfides. On the other hand, the nanosheet arrays constructed from $\mathrm{O}^{2-}$ and large $\mathrm{S}^{2-}$ anions with $\mathrm{Ni}$ and $\mathrm{Co}$ cations at different valence states could help diverse active sites achieve lower activation potential.

$\mathrm{NiFe}$ oxysulfide is also very active as a bifunctional catalyst. For example, Liu et al. reported the in situ grown fullerene-like nickel oxysulfide hollow nanospheres on 3D $\mathrm{Ni}$ foam by a solvothermal method [138]. The as-prepared catalyst showed a low overpotential of $0.29 \mathrm{~V}$ and $0.14 \mathrm{~V}$ at $10 \mathrm{~mA} \mathrm{~cm}^{-2}$ for OER and HER, respectively. Similarly, Li et al. fabricated NiFe oxysulfide (NiFeS-2) by the vulcanization treatment of NiFe layered double hydroxide (LDH) precursor using thioacetamide [59]. The catalyst exhibited superior OER performance $\left(\eta_{10}=0.286 \mathrm{~V}\right)$ because the polarized $\mathrm{S}$ and non-polarized $\mathrm{O}$ anions equally adjusted the electronic configuration of the active sites in the catalyst. For overall water-splitting, a $j$ of $10 \mathrm{~mA} \mathrm{~cm}^{-2}$ was achieved at $1.64 \mathrm{~V}$ in $\mathrm{N}_{2}$ saturated $1 \mathrm{M} \mathrm{KOH}$ solution with NiFeS-2/ $\mathrm{NF}$ electrode served as anode and cathode. Furthermore, Tran et al. designed a novel catalyst derived from a porous interconnected network of nickel cobalt oxysulfide interfacial assembled $\mathrm{Cu} @ \mathrm{Cu}_{2} \mathrm{~S}$ nanowires (NWs) via a three-step process (Fig. 9c-e) [137]. In 1.0 M KOH medium, the catalyst only required an overpotential of $203 \mathrm{mV}$ to achieve a current response of $295 \mathrm{mV}$ to reach $50 \mathrm{~mA} \mathrm{~cm}^{-2}$ for the OER and $20 \mathrm{~mA} \mathrm{~cm}^{-2}$ for the HER. Besides, a developed electrolyzer enabled a small cell voltage of $1.61 \mathrm{~V}$ at $20 \mathrm{~mA} \mathrm{~cm}^{-2}$ without performance decay upon long-term operation (Fig. 9f-g).

\subsubsection{Phosphosulfides}

Nowadays, TM phosphosulfides (TMPS) exhibit exceptional catalytic performance. The electrocatalytic activity of $\mathrm{S}$ completely depends on the electron-donation of chalcogen ligands $\left(\mathrm{X}_{2}^{2-}\right)$. While the $\mathrm{P}$ atoms enhance the electron-donating ability of $\mathrm{X}_{2}^{2-}$, which encourages the redox 

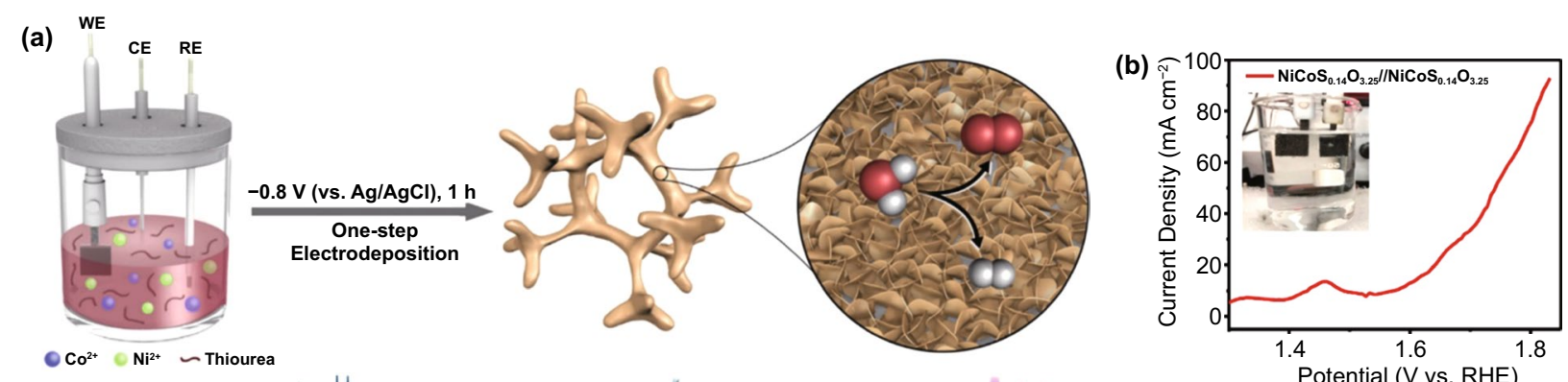

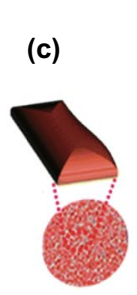

3D foam

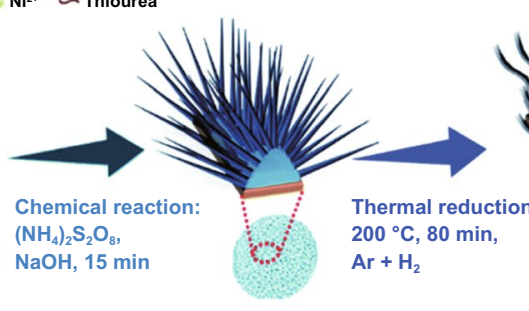

$\mathrm{Cu}(\mathrm{OH})_{2}$ nanoneedles on 3DF
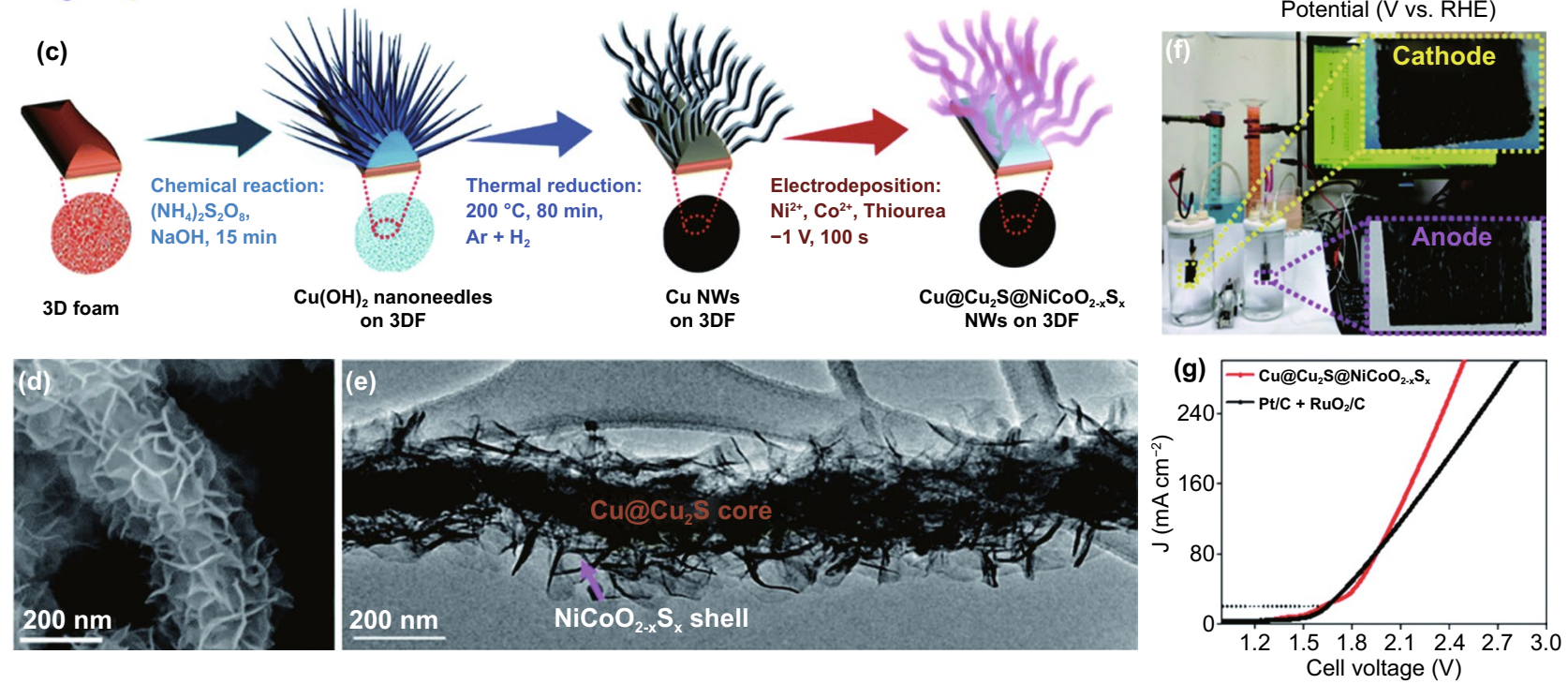

Fig. 9 a Schematic illustration of the synthesis of 3D NiCoSxOy nanosheet arrays on Ni foam, and the application as OER and HER catalysts for overall water-splitting, $\mathbf{b}$ two electrode OER polarization curves (without iR compensation) of $\mathrm{NiCoS}_{0.14} \mathrm{O}_{3.25} \mathrm{NSs} / \mathrm{NF} / / \mathrm{NiCoS}{ }_{0.14} \mathrm{O}_{3.25} \mathrm{NSs} /$ $\mathrm{NF}$ at a scan rate of $1 \mathrm{mV} \mathrm{s}^{-1}$. Inset: A photograph of the all Ni-Co nanosheets arrays-based electrolyzer. Reprinted with permission from Ref. [136]. Copyright Year 2018. Elsevier. c Schematic illustration of the $\mathrm{Cu} @ \mathrm{Cu}_{2} \mathrm{~S} @ \mathrm{NiCoO}_{2-x} \mathrm{~S}_{x} \mathrm{NW}$ fabrication, d FE-SEM and e TEM image images of $\mathrm{Cu} @ \mathrm{Cu}_{2} \mathrm{~S} @ \mathrm{NiCoO}_{2-x} \mathrm{~S}_{x} \mathrm{NWs}$ on 3DF, $\mathbf{f}$ the fabrication of an electrolyzer based on cathodic and anodic $\mathrm{Cu} @ \mathrm{Cu}_{2} \mathrm{~S} @ \mathrm{NiCoO} \mathrm{N}_{2-x} \mathrm{~S}_{x} \mathrm{NW}$ electrodes, $\mathbf{g}$ LSV measurement for the overall water-splitting performance of the electrolyzer devices based on $\mathrm{Cu}_{0} @ \mathrm{Cu}_{2} \mathrm{~S} @ \mathrm{NiCoO}_{2-x} \mathrm{~S}_{x} \mathrm{NW}$ electrodes and $\left(\mathrm{Pt} / \mathrm{C}+\mathrm{RuO}_{2} / \mathrm{C}\right)$ electrodes. Reprinted with permission from Ref. [137]. Copyright Year 2020. Royal Society of Chemistry

reactions of metal atoms [68]. Recently, numerous reports are available in the literature for TM-based phosphosulfides such as MoPS, PdPS, CoPS, FePS 3 , NiPS 3 , and so on [26, 66, 139-147].

In this regard, Kibsgaard et al. developed a wet chemical route to prepare MoPS with sulfidation treatment [148]. The anion-mixed MoPS catalyst demonstrated a low overpotential of $0.064 \mathrm{~V}$ at $10 \mathrm{~mA} \mathrm{~cm}^{-2}$ in acidic media for HER (sample supported on Ti foil), which is much better than that of MoP/Ti-based catalyst. Palladium (Pd) with phosphosulfide also possesses excellent electrochemical properties. From the report by Sampath's group, PdPS/rGO composites exhibited excellent HER activity with a low overpotential of approximately $0.09 \mathrm{~V}$ versus RHE and a small Tafel slope of $46 \mathrm{mV} \mathrm{dec}^{-1}$ [149]. It is worth mentioning that the overall structure was found to be "layered-type" made up of pentagons joints to result in wrinkled two-dimensional sheets, in which four layers are needed to generate one unit cell. The $\mathrm{P}$ and $\mathrm{S}$ atoms are estimated to form polyanions of type $[\mathrm{S}-\mathrm{P}-\mathrm{P}-\mathrm{S}]^{4-}$. The same group also used few-layered $2 \mathrm{D} \mathrm{FePS}{ }_{3}$ nanosheets as the composite material for preparing $\mathrm{rGo}-\mathrm{FePS}_{3}$ composite electrocatalysts [150]. It was proposed that a direct bond between $\mathrm{P}$ and $\mathrm{S}$ in the $\mathrm{FePS}_{3}$ could enhance its HER activity. The reason for the enhanced HER activity was further supported by DFT calculations, which confirmed that the presence of $\left[\mathrm{P}_{2} \mathrm{~S}_{6}\right]^{4-}(\mathrm{P}$ and $\mathrm{S}$ sites) unit could participate in the adsorption and desorption of the $\mathrm{H}$ atom.

In a few reports, flexible carbon fiber (CF) conductive substrates have been used for 2D growth. He's group 
successfully prepared $\mathrm{WP}_{2 x} \mathrm{~S}_{2(1-x)}$ nanoribbons (NRs) on CF substrate through phosphatization and sulfidation reaction of $\mathrm{WO}_{3}$ NWs [152]. Surprisingly, electronic perturbation also occurred in $\mathrm{WS}_{2}$ after doping of $\mathrm{P}$ atoms in the $\mathrm{WP}_{2 x} \mathrm{~S}_{2(1-x)}$ which played a prominent role in improving HER activity, stability, and durability.

Pyrite-type transition metal dichalcogenides (TMDs) with non-metal anion incorporation are well-known to be an efficient and high catalytic activity than other TM compounds. As Jin's group reported, ternary pyrite-type cobalt phosphosulfide (CoPS) (NWs, NPs) electrodes show higher HER performance than $\mathrm{CoS}_{2}$ NWs and CoSe NPs [68]. Notably, the CoPS electrode exhibited a lower overpotential of $48 \mathrm{mV}$ at the $j$ of $10 \mathrm{~mA} \mathrm{~cm}^{-2}$, a Tafel slope of $56 \mathrm{mV} \mathrm{dec}^{-1}$, and long-term operational stability $(36 \mathrm{~h})$ in acidic solution. As a typical example, our group developed a partial sulfurization/ phosphorization strategy to synthesize pyrrhotite-type cobalt mono-phosphosulfide $\left(\mathrm{Co}_{0.9} \mathrm{P}_{0.42} \mathrm{~S}_{0.58}\right)$ yolk-shell spheres with hexagonal close-packed phase (Fig. 10a-f) [64]. It is worth pointing out that the synergy of non-stoichiometric nature and the adjustable $\mathrm{P} / \mathrm{S}$ ratio results in the reinforced $\mathrm{Co}^{3+} / \mathrm{Co}^{2+}$ couples and tunable electronic structure. $\mathrm{Co}^{3+}$ ions effectively enhance the OER activity due to their higher valence $3 \mathrm{~d}$ electron orbits and more electron-accepting features than $\mathrm{Co}^{2+}$ ions. For HER, it showed a low operating overpotential around $140 \mathrm{mV}$ with small Tafel slopes around $70 \mathrm{mV} \mathrm{dec}^{-1}$ in both alkaline and acidic media (Fig. 10g-j). Coupled with the high HER activity of $\mathrm{Co}_{0.9} \mathrm{~S}_{0.58} \mathrm{P}_{0.42}$, the overall water-splitting was demonstrated with a low $\eta_{10}$ at $1.59 \mathrm{~V}$.

Similarly, layered nickel phosphosulfide is another kind of novel electrocatalyst. For example, Ren's group prepared pure layered $\mathrm{NiPS}_{3}$ and $\mathrm{NiPS}_{3} \mathrm{NSs} /$ Graphene (G) composites as electrocatalysts toward OER [153]. They believed that non-metallic elements such as $\mathrm{P}$ and $\mathrm{S}$ generally do not directly contribute to OER performance. However, due to their strong electronegativity, they can affect the local electronic structure of $\mathrm{Ni}$, thereby promoting the oxidation of $\mathrm{Ni}^{2+}$ to $\mathrm{Ni}^{3+}$. Besides, $\mathrm{NiP}_{0.62} \mathrm{~S}_{0.38} / \mathrm{NiOOH}$ heterostructure displayed increased OER performance [65]. For HER, the $\mathrm{NiP}_{0.62} \mathrm{~S}_{0.38}$ nanosheets owned a small overpotential of $52 \mathrm{mV}$ at $10 \mathrm{~mA} \mathrm{~cm}^{-2}$, whereas an overpotential of $240 \mathrm{mV}$ was observed at $10 \mathrm{~mA} \mathrm{~cm}$-2 for the OER. It is noteworthy that the electronegative phosphosulfide species moved $\Delta \mathrm{G}_{\mathrm{H}^{*}}$ to the thermally neutral position and achieved the balance of hydrogen adsorption/desorption at the nickel position.
Apart from ternary PS compounds, the HER, OER activities of multicomponent mixed PS-based materials have also been investigated [154]. For example, using $\mathrm{P}_{2} \mathrm{~S}_{5}$ as a source, 3D hierarchical flower-like P-doped Ni-Fe disulfide microspheres were prepared by successive hydrothermal and one-step phosphosulfidation (Fig. 10k-o) [151]. These microspheres deliver outstanding OER performance with an overpotential of $264 \mathrm{mV}$ to achieve a $j$ of $10 \mathrm{~mA} \mathrm{~cm}^{-2}$ and excellent long-term durability over $50 \mathrm{~h}$ with negligible degradation in alkaline media.

\subsubsection{Sulfoselenide}

Transition metal chalcogenides (TMCs) are an extremely attractive material with unique electronic structures and physicochemical properties [31, 103, 155-159]. In particular, the electrocatalytic activity of TMDs has received considerable attention $[156,160,161]$. Controlling the S, selenium (Se) substitution, and varying composition ratios can improve the HER/OER performance [160, 162, 163].

Liu et al. fabricated a ternary cobalt sulfoselenide $\left(\mathrm{CoS}_{2 x} \mathrm{Se}_{2(1-x)}\right) \mathrm{NW}$ arrays via a two-step process supported on CFs [164]. The unique electronic structure, large surface area, and lower charge transfer resistance of $\mathrm{CoS}_{2 x} \mathrm{Se}_{2(1-x)}$ NWs could augment its HER performance. More impressively, Xu's group replaced S atoms with Se in molybdenum sulfoselenide $\left(\mathrm{MoS}_{2 x} \mathrm{Se}_{2(1-x)}\right)$ alloys and thus achieved high electrical conductivity with a narrowing bandgap [72]. Also, Se incorporation expanded the interlayer distance (Se atoms have a larger size than $\mathrm{S}$ atoms) and modified edge electronic structure, and hence improved the HER performance. The HER activity of ternary $\operatorname{MoS}_{2 x} \operatorname{Se}_{2(1-x)}\left(\eta_{10}=0.219 \mathrm{~V}\right)$ was better than that of the binary $\mathrm{MoS}_{2}$. Similarly, ternary tungsten sulfoselenide $\left(\mathrm{WS}_{2(1-x)} \mathrm{Se}_{2 x}\right.$ ) particles were grown on 3D porous $\mathrm{NiSe}_{2}$ foam as an efficient HER electrocatalyst [165]. This catalyst demonstrated high conductivity, large specific surface area, and high density of active edge centers, with a $\eta_{10}=88 \mathrm{mV}$. Except for 3D $\mathrm{NiSe}_{2}$ foam, FTO is another ideal conductive substrate for growing TMDs. Hussain et al. deposited $\mathrm{MoS}_{2(1-x)} \mathrm{Se}_{2 x}$ and $\mathrm{WS}_{2(1-x)} \mathrm{Se}_{2 x}$ alloys on FTO by RF magnetron sputtering of Mo, $\mathrm{W}$ target (Ar atmosphere) followed by sulfurization and selenization processes [166]. Finally, the resulting $\mathrm{MoS}_{2(1-x)} \mathrm{Se}_{2 x}$ and $\mathrm{WS}_{2(1-x)} \mathrm{Se}_{2 x}$ films performed an overpotential of 0.141 and $0.167 \mathrm{~V}$ at a $j$ of $10 \mathrm{~mA} \mathrm{~cm}^{-2}$ for HER. 

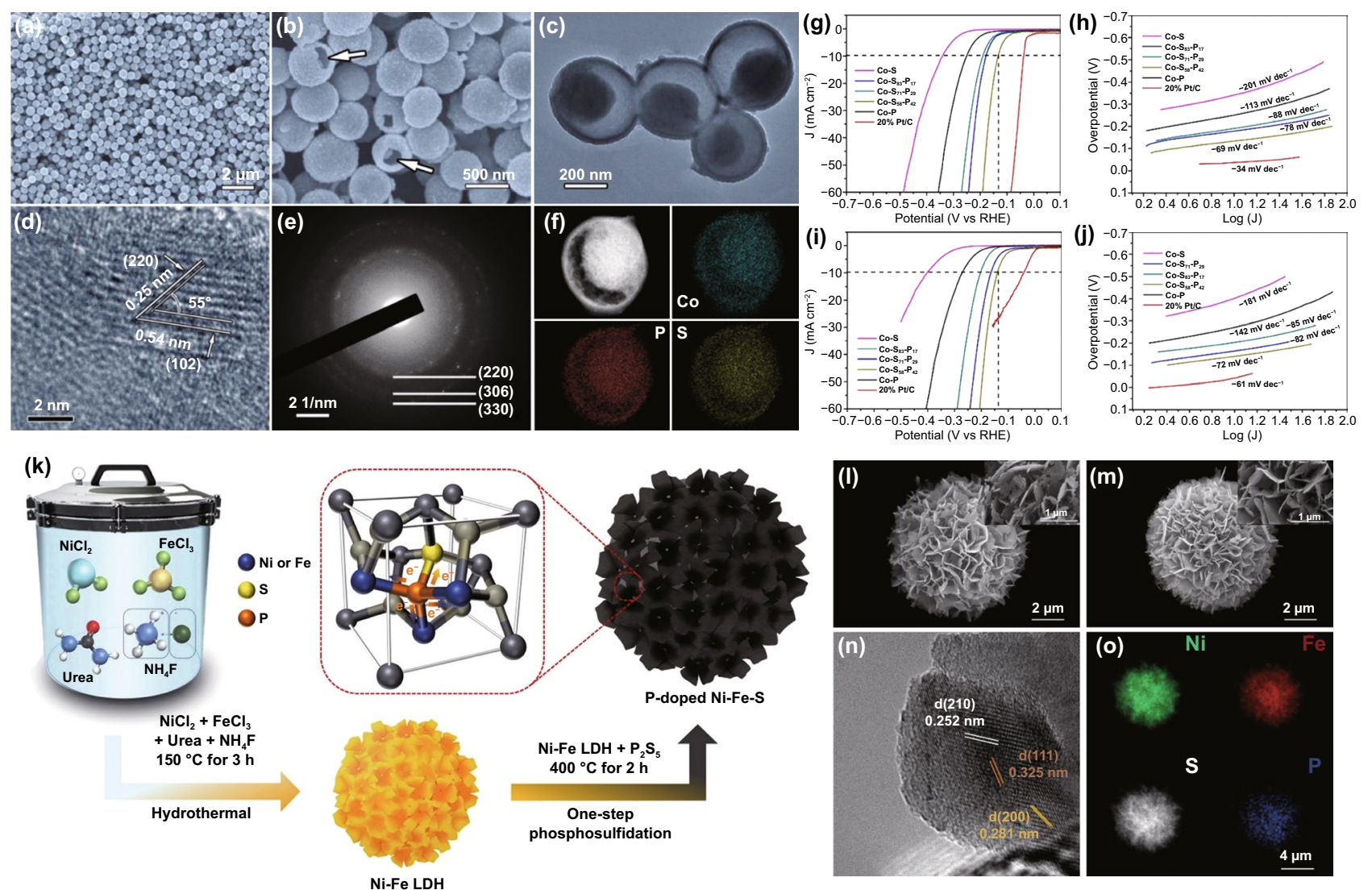

Fig. 10 a SEM, b expanded SEM view. c TEM image. d High-resolution TEM image. e SAED pattern. f STEM image and elemental mapping of the $\mathrm{Co}_{0.9} \mathrm{~S}_{0.58} \mathrm{P}_{0.42}$ yolk-shell spheres. $\mathbf{g}$-j Electrocatalytic performance of different catalysts for HER in alkaline and acidic electrolytes. g Polarization curves and $\mathbf{h}$ Tafel plots in $0.5 \mathrm{M} \mathrm{H}_{2} \mathrm{SO}_{4}$. $\mathbf{i}$ Polarization curves and $\mathbf{j}$ Tafel plots in $1 \mathrm{M} \mathrm{KOH}$. Reprinted with permission from Ref. [64]. Copyright Year 2017. American Chemical Society. k Schematic illustration of the preparation of the P-doped Ni-Fe-S microspheres. High-magnification SEM images of $\mathbf{l} \mathrm{Ni}-\mathrm{Fe}-\mathrm{S}$, and $\mathbf{m}$ P-doped Ni-Fe-S, $\mathbf{n}$ HRTEM image of the P-doped Ni-Fe-S, $\mathbf{o}$ EDS elemental mapping of the P-doped Ni-Fe-S. Reprinted with permission from Ref. [151] Copyright Year 2021. Elsevier

Except for binary anion mixing, recently, Yi et al. reported the molybdenum sulfoselenophosphide $\left(\mathrm{MoS}_{x} \mathrm{Se}_{y} \mathrm{P}_{z}\right)$ catalyst synthesized through a scalable hydrothermal method followed by the phosphorization process (Fig. 11a, b) [158]. When phosphorus was doped, Se-MoS exposed uniformly distributed microspheres covered by stretched nanoflakes (Fig. 11c-f). These nanoflakes with prominent edges on the circumference of the sphere can be attributed to the numerous edge sites, which is in favor of HER activity enhancement on $\mathrm{P} / \mathrm{Se}-\mathrm{MoS}_{2}$ (Fig. 11g). As a result, this catalyst exhibited high HER catalytic activity $\left(\eta_{10}=93 \mathrm{mV}\right)$ and exceptional stability in an acidic medium. The substitution of Se by P significantly changes the morphology of the catalyst, and these $\mathrm{p}$ atoms are not only the basis for proton capture but also provide superior activity for $\mathrm{H}_{2}$ dissociation. To further explore different compositions of both cations and anions on the performance of HER, the high-temperature solution method has been used to develop a series of ternary and quaternary $\mathrm{Mo}_{x} \mathrm{~W}_{1-x}\left(\mathrm{~S}_{y} \mathrm{Se}_{1-y}\right)_{2}$ alloys [167]. The variation of S-to-Se ratio had a certain impact on bond strength between TMD and $\mathrm{H}$ atom intermediates, and the enhanced performance of MoSSe relative to $\mathrm{MoSe}_{2}$ or $\mathrm{MoS}_{2}$ was owing to its optimal $\Delta \mathrm{G}_{\mathrm{H}^{*}}$. As another interesting sulfoselenide example, Smialkowski et al. developed seleno-substituted pentlandites $\left(\mathrm{Fe}_{4.5} \mathrm{Ni}_{4.5} \mathrm{~S}_{8-\gamma} \mathrm{Se}_{\gamma}\right)(\gamma=1-8$, Se1-Se8) via a high-temperature solid-state method [168]. The catalytic activity of pentlandite was attributed to the distance between different $\mathrm{M}$ sites. Only Se1 displayed a reduced overpotential of $172 \mathrm{mV}$ at $10 \mathrm{~mA} \mathrm{~cm}{ }^{-2}$, defeated the benchmark material pentlandite $(190 \mathrm{mV})$, and confirmed the possibility to further tune up $\mathrm{Fe} / \mathrm{Ni}$-chalcogenide catalysts via $\mathrm{S} / \mathrm{Se}$ exchange. 
(a)

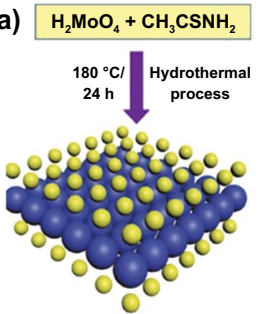

Molybdenum disulphide

Ono $O$ s

Mo
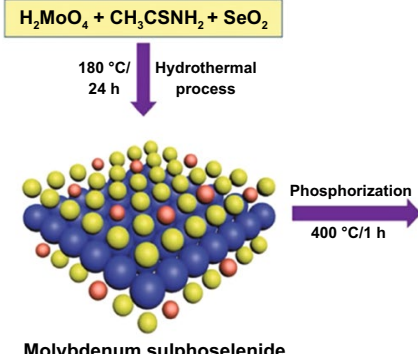

Molybdenum sulphoselenide Se $O P$ (b)

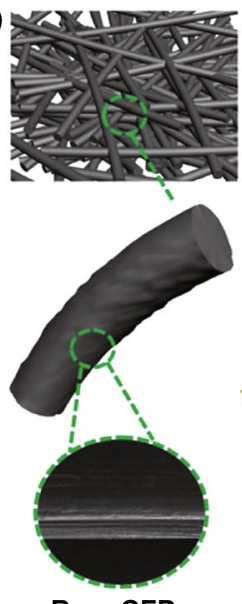

Bare CFP
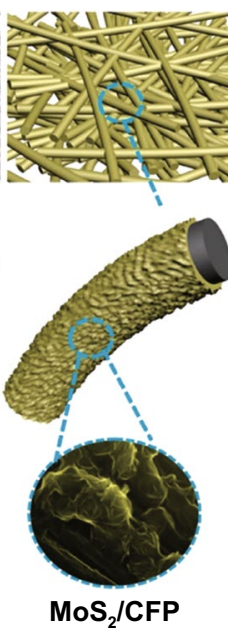
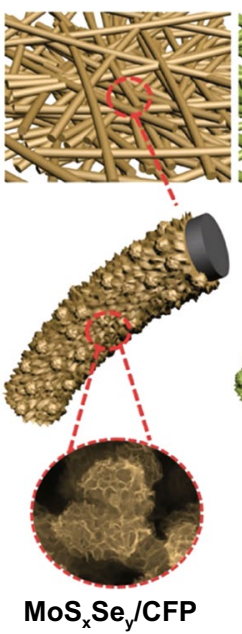

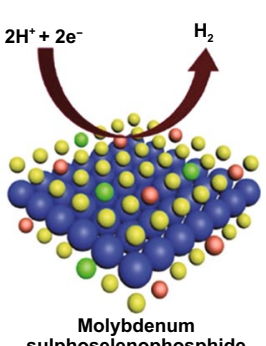

sulphoselenophosphide
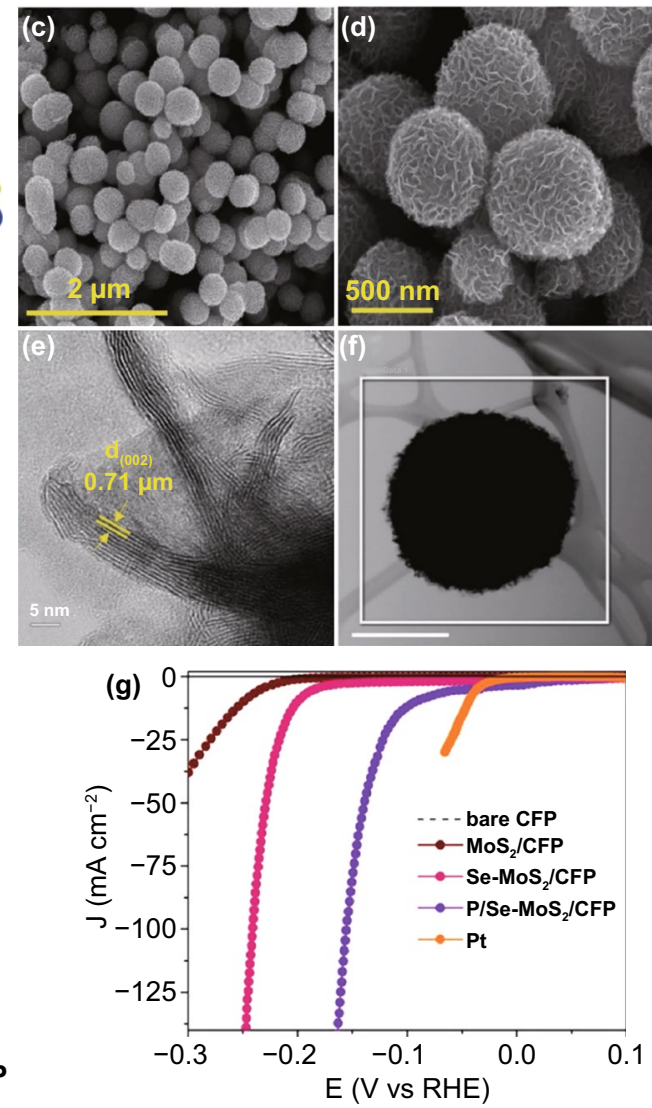

Fig. 11 a Schematic illustration of the fabrication of the $\mathrm{MoS}_{2}, \mathrm{MoS}_{x} \mathrm{Se}_{y}$, and $\mathrm{MoS}_{x} \mathrm{Se}_{y} \mathrm{P}_{z}$ on CFP by facile hydrothermal and phosphorization process. b Schematic diagram to illustrate the structural change of CFP, $\mathrm{MoS}_{2}, \mathrm{MoS}_{x} \mathrm{Se}_{y}$, and $\mathrm{MoS}_{x} \mathrm{Se}_{y} \mathrm{P}_{z}$ based on anion incorporation. c-f FESEM (P/Se- $\mathrm{MoS}_{2}$ spheroids distributed on CFP), HRTEM and STEM images of P/Se- $\mathrm{MoS}_{2}$ g Polarization curves of as-prepared various catalysts in comparison with commercial Pt and bare CFP. Reprinted with permission from Ref. [158]. Copyright Year 2018, Wiley-VCH Verlag GmbH \& Co. KGaA, Weinheim

\subsubsection{Selenotellurides}

For the improvement of catalytic activity, the form of solid solutions in different TMCs plays a significant role [169]. Kosmala et al. has reported a comparative analysis of HER performance for ultrathin films of $\mathrm{MoTe}_{2}, \mathrm{MoSe}_{2}$, and their solid solutions on highly oriented pyrolytic graphite [170]. DFT study has confirmed that the chemical function of the reactive $2 \mathrm{H}$ phases could be enhanced by including metallic twin boundaries. The catalytic performance of $\mathrm{MoSe}_{0.12} \mathrm{Te}_{1.79}$ was $-0.41 \mathrm{~V}$ after the sputtering and $\mathrm{MoSe}_{0.17} \mathrm{Te}_{1.83}$ with the different stoichiometry exhibited an overpotential of $-0.45 \mathrm{~V}$. It is worth pointing out that after sputtering, a little increase in the activity indicated the creation of anion vacancies caused by oxide removal and metal terminating edges exposure were advantageous to the electrochemical activity up to an extent. And the basal plane of these materials provided high intrinsic activity. The $\mathrm{MoTe}_{2}$ was more active than pure $\mathrm{MoSe}_{2}$, and the higher fraction of tellurium (Te) (or lower Se) in the selenotellurides constituted better performance.

\subsubsection{Hydroxy (Sulfates, Sulfides)}

Like other ternary/quaternary TMCs materials, TMHydroxy (sulfate, sulfides) are extensively employed in heterogeneous catalysis due to their high activity and robust stability [171]. As an interesting example, the $\mathrm{S}$ ligand was incorporated into the stable structure of layered hydroxides to form $\mathrm{NiCo}_{2}\left(\mathrm{~S}_{x} \mathrm{OH}_{2-x}\right)$ with a single-phase and homogeneous composition, which inherited the superior stability 
from the conventional transition metal hydroxides and excellent activity from the conventional transition metal sulfides and even exceeds the predecessors (Fig. 12a) [61]. As an OER catalyst, this optimized $\mathrm{NiCo}_{2}(\mathrm{SOH})_{x}$ exhibited a lower overpotential of $0.29 \mathrm{~V}$ to reach a $j$ of $10 \mathrm{~mA} \mathrm{~cm}^{-2}$ and a Tafel slope of $47 \mathrm{mV} \mathrm{dec}^{-1}$ in $1.0 \mathrm{M} \mathrm{NaOH}$ electrolyte. Impressively, the catalyst also showed excellent durability with no decay for OER at large $j$ of $100 \mathrm{~mA} \mathrm{~cm}{ }^{-2}$ with $30 \mathrm{~h}$ continuous operation (Fig. 12b, c). Furthermore, the DFT calculations revealed that the synergetic effect of $\mathrm{OH}$ and $\mathrm{S}$ ligands on the surface of $\mathrm{NiCo}_{2}(\mathrm{SOH})_{x}$ were able to tune the electronic structure and their chemical environment around the metal active centers. This resulted in optimal binding energies of the OER intermediates $(* \mathrm{OH}, * \mathrm{O}$, and $* \mathrm{OOH})$ and enhanced the binding energy between $\mathrm{M}$ and $\mathrm{S}$ anion, rendering for intrinsically improved activity and durability respectively (Fig. 12d, e).

Very recently, Zhao et al. made a systematic investigation on $\mathrm{NiFe}$ hydroxysulfide- $x$ (LDH- $x$. $\mathrm{x}$ represents the cyclic number) with oxygen-sulfur hetero-anionic structure served as outstanding OER catalysts [172]. An electrochemical reaction assisted by an anionic regulation strategy was proposed for the precise construction of advanced electrocatalysts (Fig. 12f). Specifically, by precisely regulating the anion, the LDH-10 showed greatly enhanced performance with a low overpotential of $0.286 \mathrm{~V}$ at $10 \mathrm{~mA} \mathrm{~cm}{ }^{-2}$ (Fig. 12g). Besides, the LDH-10 electrocatalyst also exhibited remarkable stability, maintaining $89.2 \%$ of the initial OER current density after a $6.0 \mathrm{~h}$ potentiostatic test (Fig. 12h).

\subsubsection{Phosphoselenide}

The substitution of Se into phosphides (PSe) would be the next significant step toward outstanding electrochemical properties. The Se doping enhances the electron transfer from interior phosphides and provides more active sites $[173,174]$. Although enormous research have been carried out in the field of mixed chalcogenides, there is still room for improvement in the electrochemical properties and the construction of TM binary/ternary hybrid phosphoselenide at a maximum level.

For example, Yu et al. prepared the P-NiSe ${ }_{2} @ \mathrm{~N}-\mathrm{CNTs} /$ NC hybrid catalyst via a two-step method (Fig. 13a), which delivered low overpotentials of 95 and $306 \mathrm{mV}$ at
$10 \mathrm{~mA} \mathrm{~cm}{ }^{-2}$ for HER and OER in alkaline media, respectively [73]. DFT calculations revealed that the electron density surrounding $\mathrm{Ni}$ atoms was reduced while the charges accumulated around Se due to $\mathrm{P}$ doping, respectively, which in turn reduced the energy barriers for both water dissociation and intermediates adsorption for both HER and OER (Fig. 13b-e). A cell assembled by P-NiSe ${ }_{2} @ \mathrm{~N}-\mathrm{CNTs} / \mathrm{NC}$ hybrid catalyst-based anode and cathode performed a low applied voltage of $1.609 \mathrm{~V}$ to reach $10 \mathrm{~mA} \mathrm{~cm}{ }^{-2}$ with outstanding long-term stability. Besides, He et al. demonstrated that cobalt phosphoselenide $\left(\mathrm{CoP}_{2 x} \mathrm{Se}_{2(1-x)}\right)$ was an efficient electrocatalyst with overpotentials of $70 \mathrm{mV}$ and $98 \mathrm{mV}$ for HER in acidic and alkaline media, respectively, and $0.29 \mathrm{~V}$ for OER in alkaline media to achieve $10 \mathrm{~mA} \mathrm{~cm}^{-2}$ [175]. The excellent HER activity of $\mathrm{CoP}_{2 x} \mathrm{Se}_{2(1-x)}$ can be attributed to the substitution of $\mathrm{P}$ atoms into $\mathrm{CoSe}_{2}$ to form a unique electronic structure.

Besides, Hou et al. successfully prepared porous cobalt phosphoselenide nanosheets $\left(\mathrm{H}-\mathrm{Co}_{0.85} \mathrm{SeP}\right)$ by the combined hydrogenation and phosphation method (Fig. 13f) [176]. Figure 13g, h shows the HRTEM and FESEM images of ternary $\mathrm{H}-\mathrm{Co}_{0.85} \mathrm{SeP}$ nanosheets. The $\mathrm{H}-\mathrm{Co}_{0.85} \mathrm{SeP} \mathrm{NSs}$ became higher porous, which can be attributed to the structural disorder of NSs through the phosphorization reaction. It should be mentioned that the presence of selenium vacancies and the subsequent phosphorus displacement of selenium atoms around the vacancies favorably changed the electronic structure of cobalt selenide, ensuring rapid charge transfer and the best energy barrier for hydrogen desorption, thereby promoting proton dynamics. The $\mathrm{H}-\mathrm{Co}_{0.85} \mathrm{SeP}$ catalyst exhibited superior HER activity with current densities of 10 and $20 \mathrm{~mA} \mathrm{~cm}^{-2}$ at an overpotential of 0.15 and $0.18 \mathrm{~V}$. Finally, using ternary electrode as both anode and cathode, the overall-water-splitting with $10 \mathrm{~mA} \mathrm{~cm}^{-2}$ at a low voltage of $1.64 \mathrm{~V}$ was achieved, which is better than that of the Ir/C-Pt/C couple.

\section{5 (Oxy)hydroxides}

Considerable efforts have been constructed in the field of TM-(oxy)hydroxides (OOH) to produce highly efficient and stable electrocatalysts [177-184]. TM-OOH are constructed by layered-stacking $\mathrm{TMO}_{6}$ octahedrons with protons sandwiching between layers, and the different 

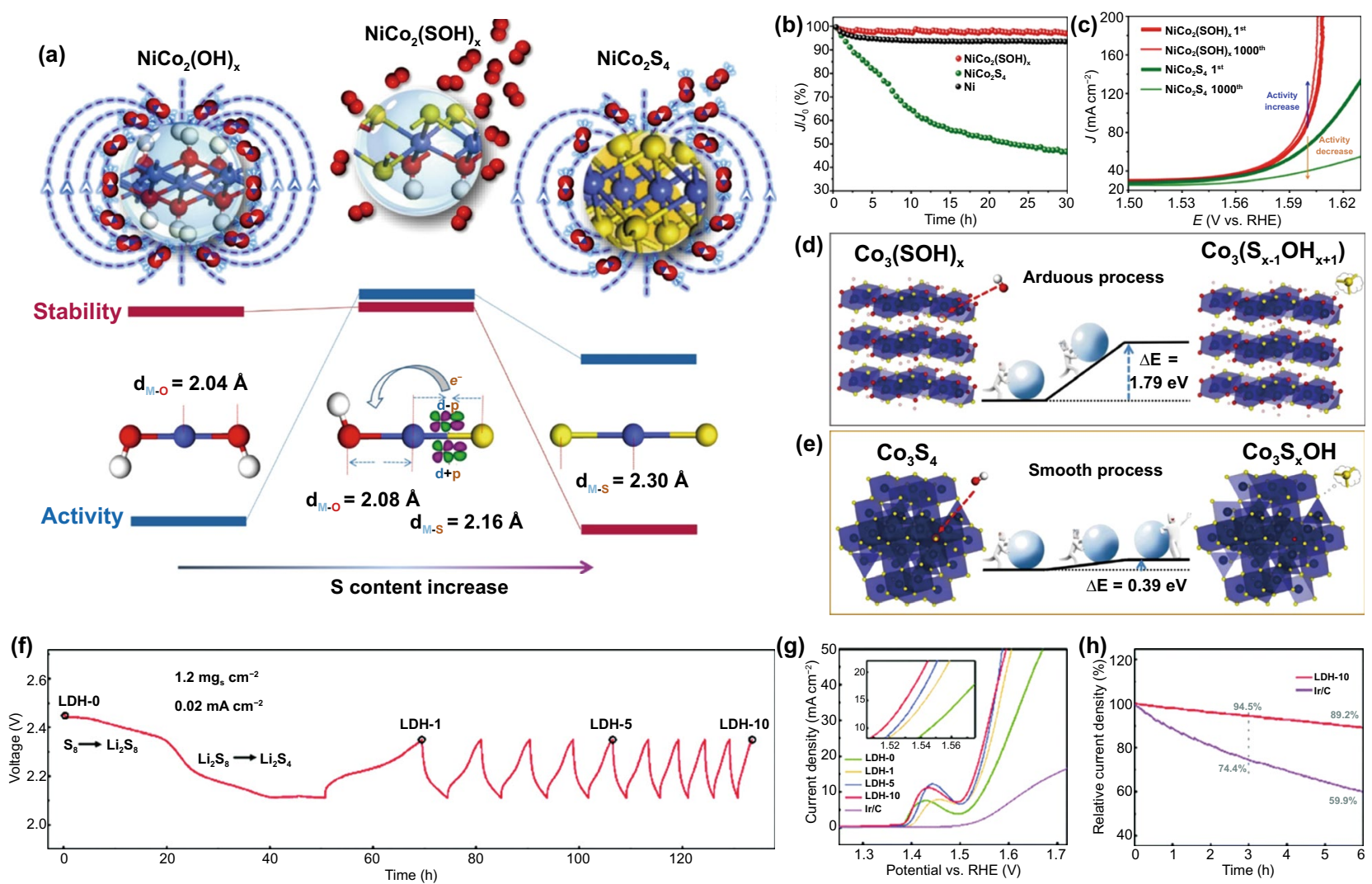

Fig. 12 a Ultimate unity of OER performance of $\mathrm{NiCo}_{2}\left(\mathrm{~S}_{x} \mathrm{OH}_{2-x}\right)_{y}$. Here, $\mathrm{Co}, \mathrm{S}, \mathrm{O}$, and $\mathrm{H}$ atoms are shown in blue, yellow, red and white, respectively, b Chronoamperometric curves of $\mathrm{Ni}, \mathrm{NiCo}_{2}(\mathrm{SOH})_{x}$ and $\mathrm{NiCo}_{2} \mathrm{~S}_{4}$ at a current density of $100 \mathrm{~mA} \mathrm{~cm}{ }^{-2}$, c first and 1000 th polarization curves of $\mathrm{NiCo}_{2}(\mathrm{SOH})_{x}$ and $\mathrm{NiCo}_{2} \mathrm{~S}_{4}$. d, e Total energy change during the desulfuration process of $\mathrm{S}^{2-}$ in $\mathrm{Co}_{3} \mathrm{~S}_{4}(\mathrm{upper})$ and $\mathrm{Co}_{3}\left(\mathrm{SOH}_{x}\right.$ (bottom) replaced by $\mathrm{OH}^{-}$. The non-spontaneous process of $\mathrm{Co}_{3}(\mathrm{SOH})_{x}$ with a more positive energy change discloses a more thermodynamic stable structure of $\mathrm{Co}_{3}(\mathrm{SOH})_{x}$ compared to $\mathrm{Co}_{3} \mathrm{~S}_{4}$. Reprinted with permission from Ref. [61]. Copyright Year 2017, American Chemical Society. f Electrochemical anionic regulation process. Galvanostatic discharge/charge curves of the Li-S cell reactor, $\mathbf{g} 95 \%$ iR-compensated LSV curves of the LDH-x and $\mathrm{Ir} / \mathrm{C}$ electrocatalysts at a scan rate of $10.0 \mathrm{mV} \mathrm{s}^{-1}$ and the rotation rate of $1600 \mathrm{rpm}$ in $\mathrm{O}_{2}$-saturated $0.10 \mathrm{M} \mathrm{KOH}$ electrolyte, h Chronoamperometric response of the LDH-10 and Ir/C electrocatalysts for stability evaluation. Reprinted with permission from Ref. [172]. Copyright Year 2020, Royal Society of Chemistry

intercalating species can alter the layer spacing. Especially, $\mathrm{Ni}, \mathrm{Fe}, \mathrm{Co}$, and Mn-based (oxy)hydroxides have been extensively studied as highly efficient catalysts for water-splitting owing to their diversity, numerous active sites in alkaline medium, potential stability, and low cost [131, 185-193].

Shen et al. synthesized stainless steel (SS) nanocone array coated with layer $\mathrm{NiFe}$ oxides/(oxy)hydroxides with more active edges, which eventually contributed to the promotion of OER activity $\left(\eta_{10}=0.232 \mathrm{~V}\right.$ and $340 \mathrm{~h}$ stability $\left.\left(20 \mathrm{~mA} \mathrm{~cm}^{-2}\right)\right)$ [194]. Similarly, Sun's group recently fabricated hierarchical layered structured $\mathrm{FeNiO}_{x} \mathrm{H}_{y}$ as an efficient OER electrocatalyst [195]. The electrocatalyst was synthesized on Ni foam via simple electrodeposition through surface modification with pretreatment by phosphoric acid. In alkaline solution $(1 \mathrm{M} \mathrm{KOH})$, to reach a $j$ of 10 and $50 \mathrm{~mA} \mathrm{~cm}{ }^{-2}, \mathrm{FeNiO}_{x} \mathrm{H}_{y} / \mathrm{NF}$ (Phosphoric acid treatment) only required overpotential of 0.206 and $0.234 \mathrm{~V}$, whereas the values are 0.253 and $0.279 \mathrm{~V}$ for conventionally electrodeposited $\mathrm{FeNiO}_{x} \mathrm{H}_{y} / \mathrm{NF}$. They claimed that the enhanced intrinsic activity was caused by the anion exchange of phosphate to (oxy)hydroxide.

To gain deeper insights into the role of metal dopants in enhancing (oxy)hydroxides' OER activity, Ir-doped $\mathrm{Ni}(\mathrm{OH})_{2}$ nanosheets were fabricated through a combination of hydrothermal assembly and liquid exfoliation, with the nanosheets transforming to Ir-doped $\mathrm{NiOOH}$ during OER and offering superior activity relative to pristine $\mathrm{Ni}(\mathrm{OH})_{2}$ nanosheets or a 
(a)

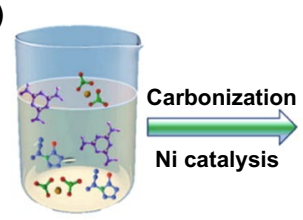

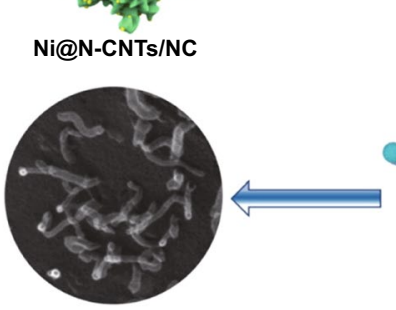

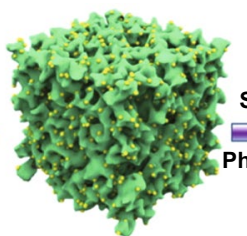

Pelenization Phosphorization

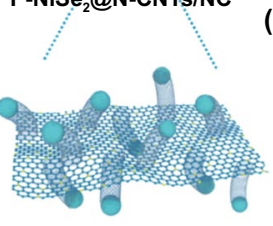

(d)

(b)

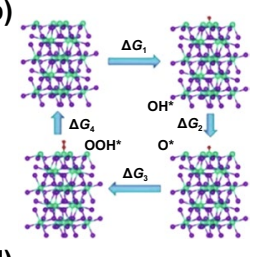

(c)

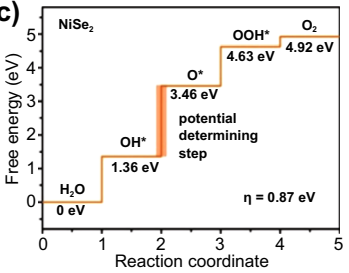

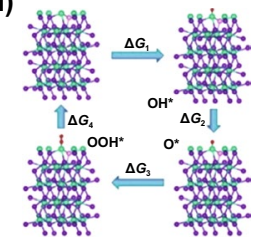

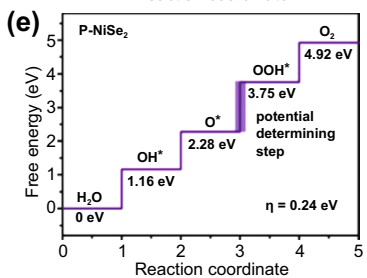

(f)
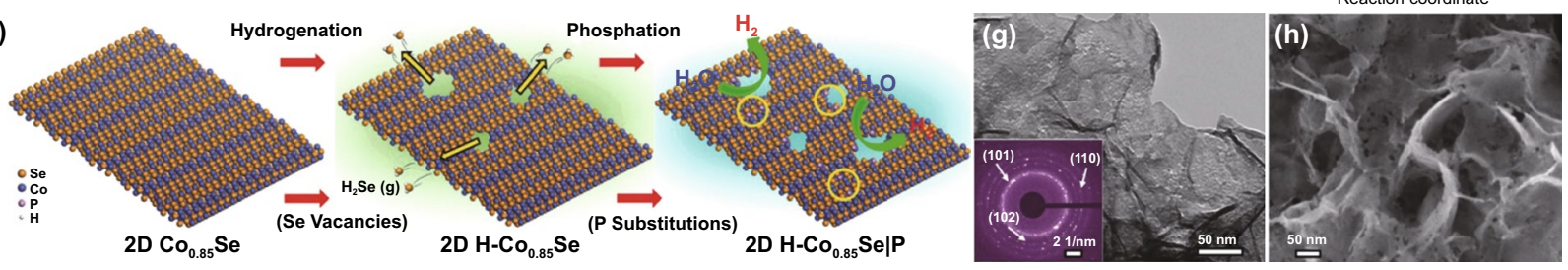

Fig. 13 a Schematic illustration for the preparation procedure of $\mathrm{P}-\mathrm{NiSe}_{2} @ \mathrm{~N}-\mathrm{CNTs} / \mathrm{NC}, \mathbf{b}$ Schematic illustration for the four elementary steps during oxygen generation process on $\mathrm{NiSe}_{2}$, $\mathbf{c}$ Calculated free-energy diagram for the OER paths on $\mathrm{NiSe}_{2}$ at zero potential, $\mathbf{d}$ Schematic illustration for the four elementary steps during oxygen generation process on $\mathrm{P}-\mathrm{NiSe}_{2}$ in $1 \mathrm{M} \mathrm{KOH}$, e Calculated free-energy diagram for the OER paths on and $\mathrm{P}-\mathrm{NiSe}_{2}$ at zero potential. $\mathrm{Ni}, \mathrm{Se}, \mathrm{P}, \mathrm{O}$, and $\mathrm{H}$ atoms are represented by green, purple, pink, red and white spheres, respectively. Reprinted with permission from Ref. [73]. Copyright Year 2021, Elsevier. f Schematic illustration for the synthesis process of $\mathrm{H}-\mathrm{Co}_{0.85} \mathrm{SelP} \mathbf{g}$ TEM image of $\mathrm{H}-\mathrm{Co}_{0.85} \mathrm{SelP}$, h FESEM image of $\mathrm{H}-\mathrm{Co}_{0.85} \mathrm{SelP}$. Reprinted with permission from Ref. [176] Copyright Year 2017, Wiley-VCH Verlag GmbH \& Co. KGaA, Weinheim

commercial $\mathrm{IrO}_{2}$ catalyst [196]. The DFT calculations with Hubbard $U$ correction indicated that Ir doping increased the conductivity of $\beta-\mathrm{NiOOH}(001)$ and activated the oxygen site containing $3 \mathrm{Ni}$ atoms $\left(\mathrm{Ni}_{3}\right.$ site). Boettcher et al. investigated emphasized the significant influence of iron ion OER catalyst activity [186]. Under OER conditions, thermodynamics seems more inclined to hydrated phases, such as (oxy) hydroxides or hydrous oxides, rather than crystalline oxides. Iron impurities are ubiquitous in neutral and alkaline electrolytes, which can significantly improve the activity of $\mathrm{Ni}$ and Co-based OER catalysts. The active center may be Fe, and the host provides a conductive framework with a high specific surface area, which is chemically stable and further activates the $\mathrm{Fe}$ center.

Alternatively, TM-OOH porous nanostructure arrays on carbon fiber cloth (CFC) are outstanding OER catalysts. For example, Fe-substituted $\mathrm{CoOOH}\left(\mathrm{Fe}_{x} \mathrm{Co}_{1-x} \mathrm{OOH}\right.$, $0 \leq x \geq 0.33$ ) with uniformly dispersed porous nanosheet arrays on CFC was also reported [197]. Undoubtedly, $\mathrm{Fe}_{0.33} \mathrm{Co}_{0.67} \mathrm{OOH} / \mathrm{CFC}$ exhibited exceptional OER catalytic performance with a low overpotential of $0.26 \mathrm{~V}$ at $10 \mathrm{~mA} \mathrm{~cm}^{-2}$. Besides, Fe-incorporated CoNi (oxy)hydroxide
( $\mathrm{Fe}-\mathrm{CoNi}-\mathrm{OH})$ nanosheet-assembled nanorod arrays were fabricated [198]. Fe-incorporated effection exposed more active sites, facilitated the mass transfer, modified $\mathrm{CoNi}$ (oxy)hydroxide (CoNi-OH)'s electron structure, and enhanced its electronic conductivity, thus promoting the intrinsic OER activity. Consequently, the $\mathrm{Fe}-\mathrm{CoNi}-\mathrm{OH}$ possessed excellent OER activity with low overpotentials of $210,248,304$, and $349 \mathrm{mV}$ to achieve current densities of $10,100,500$, and $1000 \mathrm{~mA} \mathrm{~cm}^{-2}$, respectively.

Recently, operando technique has become a powerful method to study the real-time catalytic state of OER reaction. For example, Zhao and coworkers revealed that the crystalline multiphase $\mathrm{NiFe}$ and $\mathrm{CoFe}$ oxides/hydroxides could be efficiently transformed into homogeneous amorphous nanodots through the introduction of Cr [199]. Through operando electrochemical Raman spectroscopy, the impact of $\mathrm{Cr}$ on the $\mathrm{NiFe}$ and $\mathrm{CoFe}$ catalysts for OER kinetics was systematically studied (Fig. 14a). For the CoFe and $\mathrm{CoFeCr}$ systems, the introduction of $\mathrm{Cr}$ only disturbed the lattice crystallization. For the $\mathrm{NiFeCr}$ compound, $\mathrm{Cr}$ could promote the generation of a more active $\beta-\mathrm{NiOOH}$ phase than that of the NiFe composite during water oxidation. 
Besides, through a suite of correlative operando scanning probe and X-ray microscopy techniques, a link between the oxygen evolution activity and the local operational chemical, physical, and electronic nanoscale structure of singlecrystalline $\beta-\mathrm{Co}(\mathrm{OH})_{2}$ platelet particles was established [200]. The interlayer water and protons de-intercalate to form contracted $\beta-\mathrm{CoOOH}$ particles that contain $\mathrm{Co}^{3+}$ species upon increasing the voltage to drive oxygen evolution. The observed Tafel behavior is correlated with the local concentration of $\mathrm{Co}^{3+}$ at these reactive edge sites, demonstrating the link between bulk ion insertion and surface catalytic activity (Fig. 14b-f).

Furthermore, a design combining ultrathin, amorphous, and alloyed oxyhydroxide has also been paid great attention. For example, Yang's group prepared ultrathin amorphous cobalt-vanadium bimetal oxyhydroxide (CoV-UAH) as a promising electrocatalyst for OER [202]. The CoV-UAH performed more structural flexibility than bulky highly crystalline CoV-C and exhibited an outstanding OER catalytic activity with a smaller Tafel slope $\left(44 \mathrm{mV} \mathrm{dec}^{-1}\right)$ and abundant defects.
Due to customizable electrochemical performance and excellent reactivity, high-entropy materials have become a new generation of electrocatalysts for water-splitting. A novel high-entropy $\mathrm{Co}-\mathrm{Cu}-\mathrm{Fe}-\mathrm{Mo}$ (oxy)hydroxide electrocatalysts were fabricated by a new low-temperature electrochemical reconstruction method (Fig. 14g-k) [201]. These as-prepared quaternary metallic (oxy)hydroxides demonstrated a low overpotential of $199 \mathrm{mV}$ at $j=10 \mathrm{~mA} \mathrm{~cm}^{-2}$, a Tafel slope of $48.8 \mathrm{mV} \mathrm{dec}^{-1}$, and excellent stability without decay over $72 \mathrm{~h}$ in $1 \mathrm{M} \mathrm{KOH}$. The performance enhancement mechanism is due to the usefulness of high-entropy design and the tremendous synergistic effect by incorporating four elements.

Moreover, many discussions on lattice oxygen boost OER activity in oxyhydroxide have been reported [49, 203]. The OER catalyst operated with LOM can break the linear scale relationship in the traditional adsorbate evolution mechanism (AEM) [203]. The catalytic species in various OER catalysts are essentially transition metal oxyhydroxides, and their low dimensional layered structure is conducive to the direct formation of $\mathrm{O}-\mathrm{O}$ bonds. Huang et al. reported $\mathrm{CoOOH}$ OER
(1)
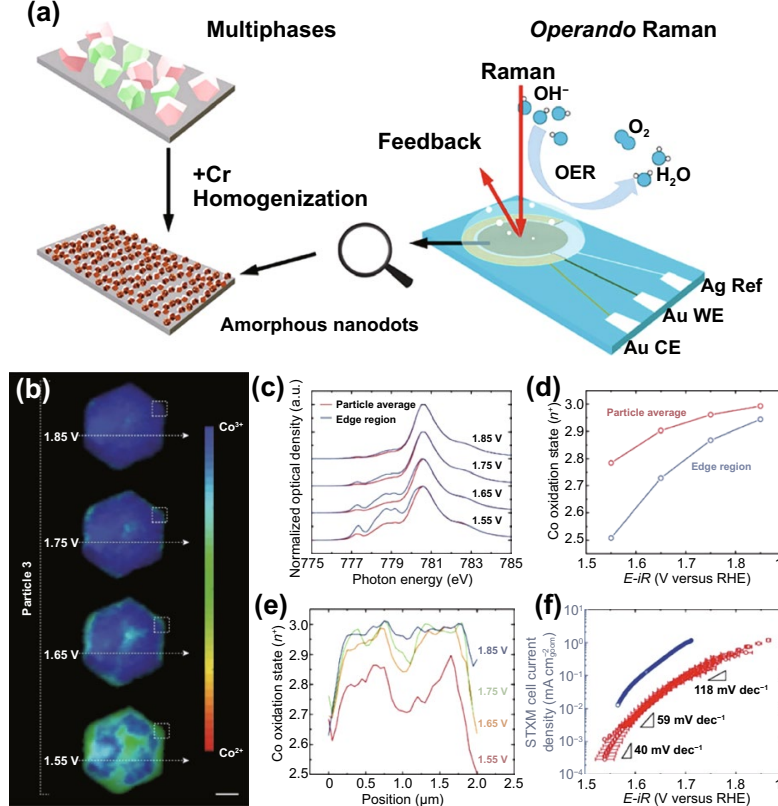

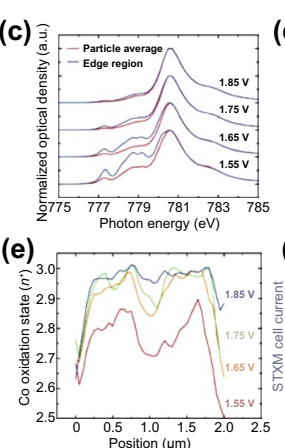

(d)

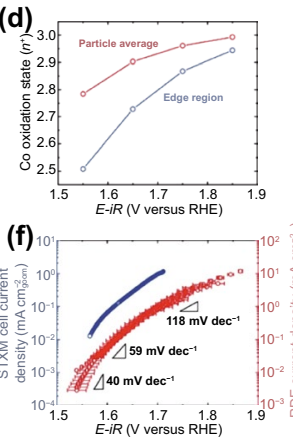

(g)
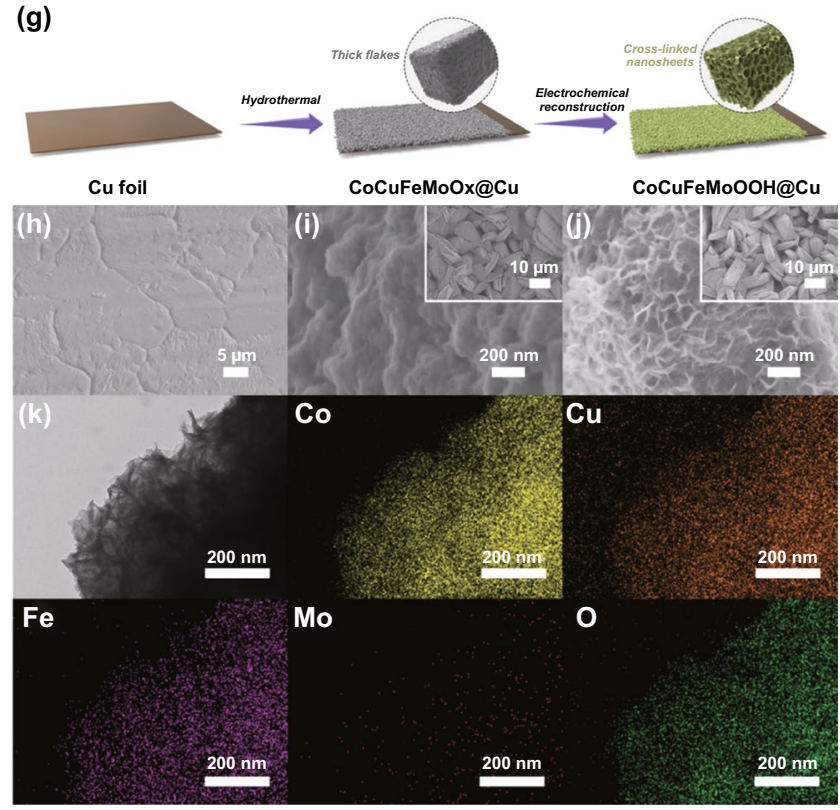

Fig. 14 a Scheme of the amorphization by introducing $\mathrm{Cr}$ and operando Raman testing during OER. Reprinted with permission from Ref. [199]. Copyright Year 2020. American Chemical Society. b Phase maps of a $\beta-\mathrm{Co}(\mathrm{OH})_{2}$ particle at applied voltages in different OER Tafel regions. Scale bar, $500 \mathrm{~nm}$, c Co LIII-edge STXM-XAS spectra of the particle average and the boxed edge region in a, showing a reduced Co oxidation state at the edge of the particles, $\mathbf{d}$ Corresponding Co oxidation state for the full particle average and edge region from the Co LIIIedge XAS spectra in $\mathbf{c}$, e Co oxidation state line scans for the lines shown in $\mathbf{b}, \mathbf{f}$ OER Tafel data taken in the STXM cell and in a macroscopic RDE cell at a scan rate of $10 \mathrm{mV} \mathrm{s}^{-1}$. Reprinted with permission from Ref. [200]. Copyright Year 2021. Springer Nature. g Schematic illustration of the synthesis of $\mathrm{CoCuFeMoOOH@Cu,} \mathrm{h} \mathrm{SEM} \mathrm{image} \mathrm{of} \mathrm{bare} \mathrm{Cu} \mathrm{foil} \mathrm{as} \mathrm{the} \mathrm{substrate,} \mathrm{i} \mathrm{SEM} \mathrm{images} \mathrm{of} \mathrm{CoCuFeMoOx} \mathrm{and} \mathbf{j} \mathrm{CoCuFeMo-}$ $\mathrm{OOH}$, k EDS elemental mapping images of $\mathrm{Co}, \mathrm{Cu}, \mathrm{Fe}, \mathrm{Mo}$, and $\mathrm{O}$ for $\mathrm{CoCuFeMoOOH}$. Reprinted with permission from Ref. [201]. Copyright Year 2021. Wiley-VCH Verlag GmbH \& Co. KGaA, Weinheim 
catalysts doped by low-valence and catalytically inactive $\mathrm{Zn}^{2+}$ [49]. They proposed that the OER mechanism depended on the amount of $\mathrm{Zn}^{2+}$ in the catalyst. Specifically, only when two adjacent oxidized oxygens could hybridize their oxygen holes without significantly sacrificing metal-oxygen hybridization could OER be carried out on metal oxyhydroxides through the LOM pathway. The prepared $\mathrm{Zn}_{0.2} \mathrm{Co}_{0.8} \mathrm{OOH}$ displayed the best catalytic activity, showing a low OER overpotential of $235 \mathrm{mV}\left(10 \mathrm{~mA} \mathrm{~cm}_{\text {disk }}^{-2}\right)$ in $1 \mathrm{M} \mathrm{KOH}$. Their new insights into LOM provide a reference for the development of efficient oxyhydroxides catalysts.

\subsection{Mixed Borides/Borates}

Among kinds of cost-effective electrocatalytic water-splitting catalysts, transition metal borides/borates (TMB) have caused a great sensation in the past decade. Particularly, the research on the influence of metal-B bonds in TMB on electron transfer is more intense. For example, B plays a sacrificial effect by providing electrons in many amorphous Co and Ni-based borides. The reverse electron transfer from $\mathrm{B}$ to the metal causes the enrichment of electrons at the metal site, preventing the metal site's oxidation and improving its stability while promoting electrochemical reactions [204]. In addition, Ai et al. demonstrated that the strong hybridization of Ru $d_{x z, y z}$ orbital and B $s p$ orbital would cause the downward shift of $d$-band center in $\mathrm{RuB}$, and the adequate adjustment of the electronic structure made RuB a promising and efficient HER catalyst [205]. The study by Ma et al. exhibited that highly electronegative $\mathrm{B}$ atoms could reduce the density of states of Ni-3d orbitals near the Fermi level, thereby optimizing the binding energy of $\mathrm{OOH}^{*}$ [206].

Recently, the incorporation of phosphorous $(\mathrm{P})$ has become an efficient strategy to improve the catalytic performance of TMB. In these mixed borides, $\mathrm{P}$ plays a vital role in changing the electronic structure and enhancing their activity. Ma et al. displayed a nickel-borate-phosphate nanoarray (Ni-Bi-pi/CC) prepared by topological transformation, which owned a high catalytic activity of only $440 \mathrm{mV}$ overpotential $\left(10 \mathrm{~mA} \mathrm{~cm}^{-2}\right)$ in $0.1 \mathrm{M}$ potassium borate $(\mathrm{KBi})$ solution [208]. This electrode also showed $100 \%$ Faraday oxygen evolution efficiency and long-term electrochemical durability. Similarly, an in situ derived iron phosphate-iron borate nanosheet array ( $\mathrm{Fe}-\mathrm{Pi}-\mathrm{Bi} / \mathrm{CC})$ has also been reported, which only required an overpotential of $434 \mathrm{mV}$ to drive a geometric catalytic current density of $10 \mathrm{~mA} \mathrm{~cm}^{-2}$ and maintained its activity for at least $20 \mathrm{~h}$ within 0.1 M KBi [209].

In a typical study, through a scalable one-step chemical deposition method, the $\mathrm{Co}-\mathrm{B}-\mathrm{P}$ micro/nanostructure was directly synthesized on a foamed nickel substrate, showing a porous and interconnected thin nanosheet configuration (Fig. 15a-d) [74]. As shown in Fig. 15e-f, the B and P elements are uniformly distributed. As a result, $\mathrm{Co}_{2.90} \mathrm{~B}_{0.73} \mathrm{P}_{0.27}$ nanosheets exhibited excellent HER catalytic performance with an initial overpotential of $12 \mathrm{mV}$ and a Tafel slope of $42.1 \mathrm{mV} \mathrm{dec}^{-1}$ in alkaline media. Besides, this self-supporting monolithic electrode could maintain a high current density of $1000 \mathrm{~mA} \mathrm{~cm}^{-2}$ and extend polarization for more than $20 \mathrm{~h}$. The reasonable reaction mechanism of $\mathrm{B}$ and $\mathrm{P}$ synergistically enhancing the catalytic performance was discussed in detail, as shown in Fig. 15g. In step 1, the interaction between $\mathrm{Co}^{\delta+}$ and $\mathrm{O}^{2-}, \mathrm{P}^{\delta-}$, and $\mathrm{H}^{+}$could enhance the adsorption of $\mathrm{H}_{2} \mathrm{O}$, weaken the $\mathrm{HO}-\mathrm{H}$ bonds, and promote the effective dissociation of $\mathrm{H}_{2} \mathrm{O}$. In step $2, \mathrm{OH}^{-}$produced by $\mathrm{H}_{2} \mathrm{O}$ dissociation combined with $\mathrm{Co}^{\delta+}$ around $\mathrm{P}$, and $\mathrm{H}$ was transferred to nearby $\mathrm{Co}^{\delta+}$. For $\mathrm{Co}-\mathrm{P}, \mathrm{H}$ combined strongly with $\mathrm{Co}^{\delta+}$, which was unfavorable for $\mathrm{H}_{2}$ evolution. By contrast, in the ternary $\mathrm{Co}-\mathrm{B}-\mathrm{P}$, the electron transfer from $\mathrm{B}$ to Co could inhibit the oxidation of the Co-active site, and the chemical bond was optimized, thereby increasing HER activity. In another study, the Co-P-B catalyst was directly electrodeposited on carbon paper (CP) [207]. The $\mathrm{Co}_{59} \mathrm{P}_{20} \mathrm{~B}_{21} / \mathrm{CP}$ particle showed a size in the range of 100-200 nm (Fig. 15h, i) and displayed higher intrinsic activity than other $\mathrm{CoP}_{x}$ HER catalysts reported in previous literature (Fig. 15j). Interestingly, the intrinsic activity of $\mathrm{HER}$ and the $\mathrm{B} / \mathrm{P}$ ratio in the $\mathrm{Co}-\mathrm{P}-\mathrm{B}$ catalysts presented a volcanic function relationship (Fig. 15k). The electron transfer between the three elements was an essential factor to improve the inherent activity of HER. The highest activity was obtained when the $\mathrm{B} / \mathrm{P}$ ratio was around 1 , and the electron transfer was maximized between the three elements. In addition to the Ni/Co-based system, Ma et al. recently designed a $\mathrm{B}, \mathrm{P}$ co-doped ternary $\mathrm{NiVFe}$ layered double hydroxide nanosheet (NiVFe-B-P LDHs@NF) [210]. The results show that $\mathrm{B}, \mathrm{P}$ co-doping promoted the formation of defects and amorphous regions, increasing the active sites and active surface area. 

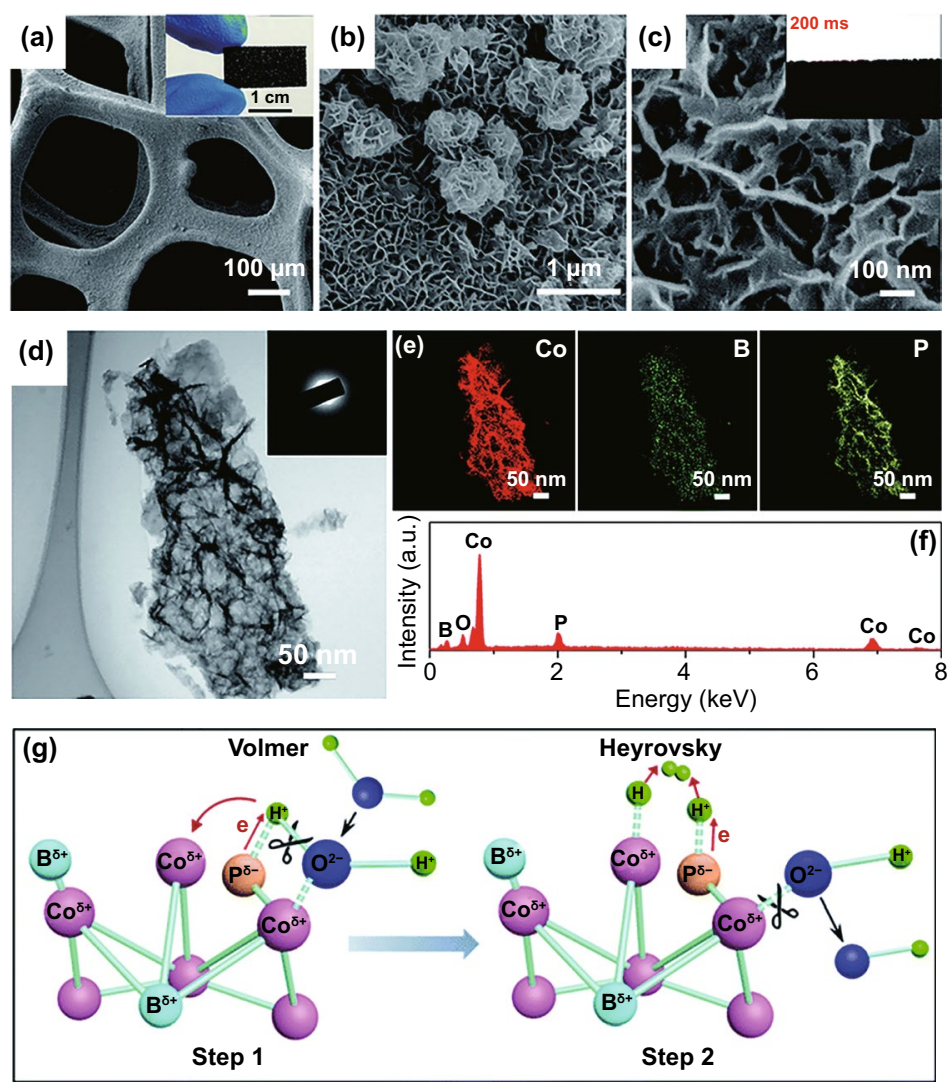
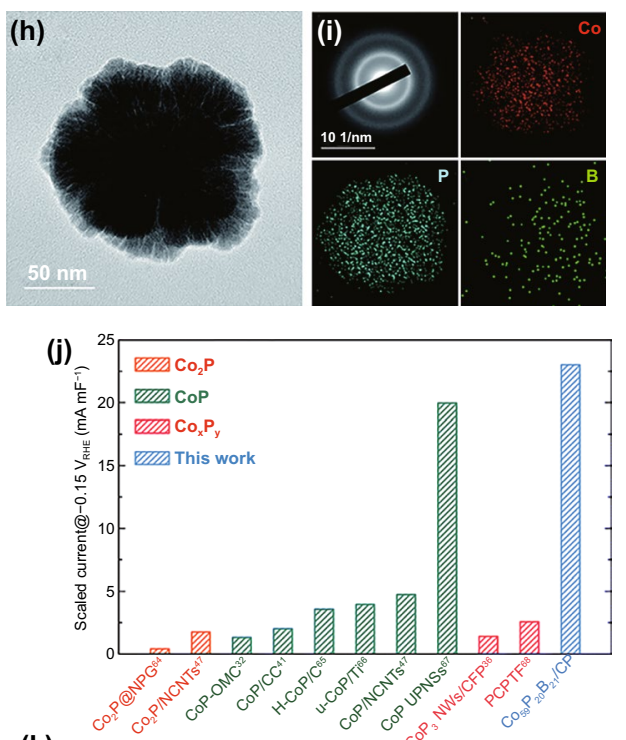

(k)

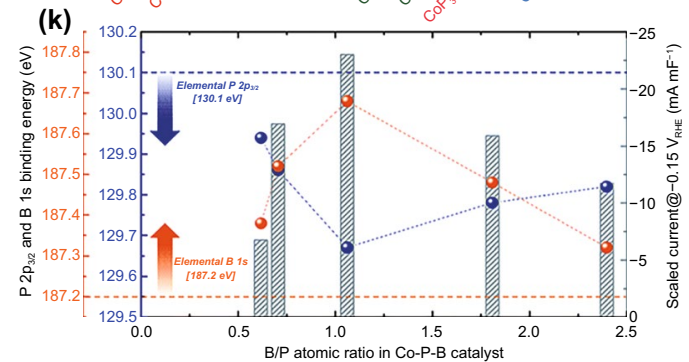

Fig. 15 a Low-magnification and b, $\mathbf{c}$ high-magnification SEM images of synthesized Co-B-P/NF, $\mathbf{d}$ TEM image and SAED pattern (inset), $\mathbf{e}$ elemental mapping and $\mathbf{f}$ the corresponding EDS spectrum of Co-B-P sheets scraped off from the Ni foam substrate, $\mathbf{g}$ Schematic HER electrocatalysis on Co-B-P with a synergistic effect of Co, B and P. Reprinted with permission from Ref. [74]. Copyright Year 2018. Royal Society of Chemistry. $\mathbf{h}$ TEM image, $\mathbf{i}$ SAED patterns and elemental mapping images of $\mathrm{Co}_{59} \mathrm{P}_{20} \mathrm{~B}_{21} / \mathrm{CP}$ catalyst, $\mathbf{j}$ Comparison of HER performance in $0.5 \mathrm{M} \mathrm{H}_{2} \mathrm{SO}_{4}$ with other $\mathrm{CoP}_{x}$ electrocatalysts reported in literature, $\mathbf{k}$ Scaled current of $\mathrm{Co}-\mathrm{P}-\mathrm{B}$ catalyst corresponding to binding energy of $\mathrm{P}$ $2 p_{3 / 2}$ (navy) and B $1 s$ (orange) with atomic ratio of catalyst. Reprinted with permission from Ref. [207]. Copyright Year 2018. Royal Society of Chemistry

\section{Summary and Future Perspective}

In this review, we have summarized the recent research advances of non-precious metal electrocatalysts for oxygen evolution reaction, hydrogen evolution reaction, and bifunctional (HER/OER) activity with particular attention on anion mixed strategy. Tables 1, 2 and 3 summarize the various types of mixed anions, substrate, electrolyte, and electrochemical performance of anion-mixed electrocatalysts based on water-splitting activity. The incorporation/replacement of anions like $\mathrm{O}, \mathrm{S}, \mathrm{N}, \mathrm{P}, \mathrm{F}, \mathrm{Se}, \mathrm{Te}, \mathrm{B}$, and $\mathrm{OH}$ to form $\mathrm{OS}, \mathrm{ON}$, OS, OSe, PO, OOH, SSe, SeTe, OHS, PS, and BP into TMs have been demonstrated as a promising strategy in regulating/adjusting the electronic structure of materials, creating defects and vacancies that served as active sites. Finally, it is concluded that anion-mixed electrocatalyst is one of the fascinating and reliable methods to achieve cost-efficient and high-performance electrocatalysts for water hydrolyzers.

Although numerous reports have been investigated in using anion-mixed electrocatalysts for water hydrolyzer, it still has much more possibility for further improvement. Many studies only focus on improving performance and neglect the exploration of the mechanism, which has no reference significance for other researchers. Besides, the synthesis method is too single, and the research model is gradually becoming routine and single, without considering the requirements of actual production and application. Furthermore, innovative and challenging works are rare. Given these, future research directions (Fig. 16) can be presented as follows: 
Table 1 Comparison of the OER and HER performance of typical mixed nitrides, halides, and phosphides-based electrocatalysts

\begin{tabular}{|c|c|c|c|c|c|c|c|c|}
\hline Catalyst & $\begin{array}{l}\text { Mixed } \\
\text { anions }\end{array}$ & Electrolyte & Substrate & $\begin{array}{l}\text { Overpotential } \\
(\mathrm{mV}) \\
\text { HER } \\
\left(10 \mathrm{~mA} \mathrm{~cm}^{-2}\right)\end{array}$ & $\begin{array}{l}\text { Overpotential } \\
(\mathrm{mV}) \\
\text { OER } \\
\left(10 \mathrm{~mA} \mathrm{~cm}^{-2}\right)\end{array}$ & $\begin{array}{l}\text { Tafel slope } \\
\left(\mathrm{mVdec}^{-1}\right)\end{array}$ & Stability & Refs. \\
\hline WON@NC NAs/CC & $\mathrm{ON}$ & $\begin{array}{l}0.5 \mathrm{M} \\
\mathrm{H}_{2} \mathrm{SO}_{4} \\
1.0 \mathrm{M} \mathrm{PBS} \\
1.0 \mathrm{M} \mathrm{KOH}\end{array}$ & Carbon cloth & $\begin{array}{l}106 \\
152 \\
130\end{array}$ & $\begin{array}{l}- \\
- \\
-\end{array}$ & 65 & $30 \mathrm{~h}$ & [211] \\
\hline $\mathrm{CoMnON}$ & $\mathrm{ON}$ & $0.1 \mathrm{M} \mathrm{KOH}$ & $\begin{array}{l}\text { Glassy } \\
\text { carbon }\end{array}$ & - & 470 & 79 & $\begin{array}{l}10,000 \\
\text { cycles }\end{array}$ & [212] \\
\hline CoON PNS-400 & $\mathrm{ON}$ & $\begin{array}{l}1 \\
\mathrm{M} \mathrm{KOH}\end{array}$ & $\begin{array}{l}\text { Graphite } \\
\text { disk }\end{array}$ & - & 230 & 48 & $20 \mathrm{~h}$ & [84] \\
\hline TiNO films-25 mTorr & $\mathrm{ON}$ & $1 \mathrm{M} \mathrm{KOH}$ & $\begin{array}{l}\text { TiNO thin } \\
\text { films }\end{array}$ & - & 290 & 57 & $12 \mathrm{~h}$ & {$[85]$} \\
\hline $\mathrm{CVN} / \mathrm{CC}$ & $\mathrm{ON}$ & $1 \mathrm{M} \mathrm{KOH}$ & Carbon cloth & 118 & 263 & $64 \& 73$ & $100 \mathrm{~h}$ & {$[90]$} \\
\hline $\mathrm{FeCoNi}$ & $\mathrm{ON}$ & $1 \mathrm{M} \mathrm{KOH}$ & $\begin{array}{l}\text { Glassy } \\
\text { carbon }\end{array}$ & - & 291 & 64 & 1000 cycles & [86] \\
\hline $\mathrm{FeNi}$ & ON & $1 \mathrm{M} \mathrm{KOH}$ & $\begin{array}{l}\text { Glassy } \\
\text { carbon }\end{array}$ & - & 295 & 66 & 1000 cycles & [91] \\
\hline $\mathrm{Fe}-\mathrm{WCN}\left(800^{\circ} \mathrm{C}\right)$ & $\mathrm{CN}$ & $\begin{array}{l}0.1 \mathrm{M} \\
\mathrm{H}_{2} \mathrm{SO}_{4} \\
0.5 \mathrm{M} \\
\mathrm{Na}_{2} \mathrm{SO}_{4}\end{array}$ & $\begin{array}{l}\text { Glassy } \\
\text { carbon }\end{array}$ & $\begin{array}{l}100 \\
120\end{array}$ & - & 47 & $\begin{array}{l}3000 \\
1000 \\
\text { cycles }\end{array}$ & [213] \\
\hline HP-CoNC-L & $\mathrm{CN}$ & $1 \mathrm{M} \mathrm{KOH}$ & $\begin{array}{l}\text { Glassy } \\
\text { carbon }\end{array}$ & - & 300 & 85 & $12 \mathrm{~h}$ & [214] \\
\hline WCN & $\mathrm{CN}$ & $\begin{array}{l}0.5 \mathrm{M} \\
\mathrm{H}_{2} \mathrm{SO}_{4} \\
1 \mathrm{M} \mathrm{KOH}\end{array}$ & $\begin{array}{l}\text { Glassy } \\
\text { carbon }\end{array}$ & $\begin{array}{l}128 \\
138\end{array}$ & - & 65 & $50 \mathrm{~h}$ & {$[92]$} \\
\hline $\mathrm{N}-\mathrm{W}_{2} \mathrm{C} / \mathrm{WC}$ & $\mathrm{CN}$ & $1 \mathrm{M} \mathrm{KOH}$ & Ni foam & 63 & - & 73 & $60 \mathrm{~h}$ & [93] \\
\hline $\mathrm{N}-\mathrm{Mo}_{2} \mathrm{C}$ & $\mathrm{CN}$ & $\begin{array}{l}0.5 \mathrm{M} \\
\mathrm{H}_{2} \mathrm{SO}_{4} \\
1 \mathrm{M} \mathrm{KOH}\end{array}$ & $\begin{array}{l}\text { Glassy } \\
\text { carbon }\end{array}$ & $\begin{array}{l}60 \\
48\end{array}$ & - & $\begin{array}{l}31 \\
34\end{array}$ & $\begin{array}{l}40 \mathrm{~h} \\
40 \mathrm{~h}\end{array}$ & {$[96]$} \\
\hline $\begin{array}{l}\text { Boron carbonitride } \\
\text { (BCN) }\end{array}$ & $\mathrm{CN}$ & $1 \mathrm{M} \mathrm{KOH}$ & $\begin{array}{r}\text { Carbon } \\
\text { Paper }\end{array}$ & 50 & 170 (onset) & $61.3 \& 65.2$ & $48 \mathrm{~h}$ & [98] \\
\hline $\mathrm{NiFeOF}$ & $\mathrm{OF}$ & $1 \mathrm{M} \mathrm{NaOH}$ & $\begin{array}{l}\text { Stainless } \\
\text { steel }\end{array}$ & 253 & 295 & $96 \& 38$ & $10 \mathrm{ks}$ & [29] \\
\hline IFONF & $\mathrm{OF}$ & $1 \mathrm{M} \mathrm{KOH}$ & $\mathrm{Fe}$ foil & 20 (onset) & 260 & $31 \& 45$ & $\begin{array}{r}30,000 \mathrm{~s} \& \\
100,000 \mathrm{~s}\end{array}$ & {$[31]$} \\
\hline $\mathrm{Co}_{3} \mathrm{Sb}_{4} \mathrm{O}_{6} \mathrm{~F}_{6}$ & $\mathrm{OF}$ & $1 \mathrm{M} \mathrm{KOH}$ & $\begin{array}{l}\text { Glassy } \\
\text { carbon }\end{array}$ & - & 443 & 84 & $64 \mathrm{~h}$ & [107] \\
\hline $\mathrm{NiCoFO}$ & $\mathrm{OF}$ & $1 \mathrm{M} \mathrm{KOH}$ & $\mathrm{Ni}$ foam & - & 350 & 23 & $10 \mathrm{~h}$ & [101] \\
\hline $\mathrm{NiFe}_{2} \mathrm{~F}_{4.4} \mathrm{O}_{1.8 \text { with } \mathrm{CoS} x}$ & $\mathrm{OF}$ & $1 \mathrm{M} \mathrm{KOH}$ & $\begin{array}{r}\text { Carbon } \\
\text { Paper }\end{array}$ & 100 & 270 & $40-60$ & $270 \mathrm{~h}$ & [100] \\
\hline CFO-RH400 & $\mathrm{OF}$ & $1 \mathrm{M} \mathrm{KOH}$ & $\begin{array}{l}\text { Glassy } \\
\text { carbon }\end{array}$ & - & 230 & 68 & $\begin{array}{l}10,000 \\
\text { cycles }\end{array}$ & [106] \\
\hline $\begin{array}{l}\mathrm{La}_{0.5} \mathrm{Ba}_{0.25} \mathrm{~S} \\
\quad \text { r0.25 } \mathrm{CoO}_{2.9-\delta} \mathrm{F}_{0.1} \\
\quad \text { (LBSCOF) }\end{array}$ & $\mathrm{OF}$ & $1 \mathrm{M} \mathrm{KOH}$ & $\begin{array}{l}\text { Glassy } \\
\text { Carbon }\end{array}$ & $\begin{array}{l}256 \\
\quad\left(100 \mathrm{~mA} \mathrm{~cm}^{-2}\right)\end{array}$ & $\begin{array}{l}518 \\
\quad\left(100 \mathrm{~mA} \mathrm{~cm}^{-2}\right)\end{array}$ & $44 \& 113$ & $700 \mathrm{~min}$ & [104] \\
\hline CoMoOF/GF & $\mathrm{OF}$ & $\begin{array}{l}0.5 \mathrm{M} \\
\mathrm{H}_{2} \mathrm{SO}_{4} \\
1 \mathrm{M} \mathrm{KOH}\end{array}$ & Graphite felt & $\begin{array}{l}94 \\
79\end{array}$ & - & $\begin{array}{l}60.2 \\
43.3\end{array}$ & $100 \mathrm{~h}$ & [108] \\
\hline FeVNbTiZrOF & $\mathrm{OH}-\mathrm{F}$ & $1 \mathrm{M} \mathrm{KOH}$ & $\begin{array}{l}\text { Carbon fiber } \\
\text { paper }\end{array}$ & - & $348 \pm 2$ & $110.3 \pm 0.1$ & $50 \mathrm{~h}$ & [113] \\
\hline $\mathrm{Co}(\mathrm{OH}) \mathrm{F}$ & $\mathrm{OH}-\mathrm{F}$ & $1 \mathrm{M} \mathrm{KOH}$ & $\begin{array}{l}\text { Glassy } \\
\text { carbon }\end{array}$ & - & 313 & 52 & $10 \mathrm{~h}$ & {$[60]$} \\
\hline
\end{tabular}


Table 1 (continued)

\begin{tabular}{|c|c|c|c|c|c|c|c|c|}
\hline Catalyst & $\begin{array}{l}\text { Mixed } \\
\text { anions }\end{array}$ & Electrolyte & Substrate & $\begin{array}{l}\text { Overpotential } \\
(\mathrm{mV}) \\
\text { HER } \\
\left(10 \mathrm{~mA} \mathrm{~cm}^{-2}\right)\end{array}$ & $\begin{array}{l}\text { Overpotential } \\
(\mathrm{mV}) \\
\text { OER } \\
\left(10 \mathrm{~mA} \mathrm{~cm}^{-2}\right)\end{array}$ & $\begin{array}{l}\text { Tafel slope } \\
\left(\mathrm{mVdec}^{-1}\right)\end{array}$ & Stability & Refs. \\
\hline $\mathrm{NiFe}-\mathrm{OH}-\mathrm{F}$ & $\mathrm{OH}-\mathrm{F}$ & $1 \mathrm{M} \mathrm{KOH}$ & Ni foam & 91 & - & - & $12 \mathrm{~h}$ & [109] \\
\hline $\mathrm{NiFe}-\mathrm{OH}-\mathrm{F}-\mathrm{SR}$ & $\mathrm{OH}-\mathrm{F}$ & $1 \mathrm{M} \mathrm{KOH}$ & Ni foam & - & 176 & 23 & $165 \mathrm{~h}$ & {$[110]$} \\
\hline$(\mathrm{NiFe}-\mathrm{PBA})-\mathrm{F}$ & $\mathrm{OH}-\mathrm{F}$ & $1 \mathrm{M} \mathrm{KOH}$ & Ni foam & - & 190 & 57 & $50 \mathrm{~h}$ & {$[112]$} \\
\hline $\begin{array}{l}\text { F-activated } \mathrm{Ni}(\mathrm{Fe}) \\
\mathrm{O}_{x} \mathrm{H}_{y}\end{array}$ & $\mathrm{OH}-\mathrm{F}$ & $1 \mathrm{M} \mathrm{KOH}$ & Ni foam & - & $218 \pm 5$ & $31 \pm 4$ & $50 \mathrm{~h}$ & [111] \\
\hline $\begin{array}{l}\mathrm{Fe}(\mathrm{Ni} / \mathrm{Co})\left(\mathrm{PO}_{4}\right) \\
\quad(\mathrm{OH})\end{array}$ & $\begin{array}{l}\left(\mathrm{PO}_{4}\right) \\
(\mathrm{OH})\end{array}$ & $1 \mathrm{M} \mathrm{KOH}$ & Ni foam & $145 \& 160$ & $220 \& 235$ & $\begin{array}{l}43 \& 54 \\
51 \& 57\end{array}$ & $24 \mathrm{~h}$ & {$[127]$} \\
\hline $\mathrm{CoFePO}$ & $\mathrm{PO}$ & $1 \mathrm{M} \mathrm{KOH}$ & Ni foam & 88 & 275 & $52 \& 38$ & $100 \mathrm{~h}$ & [116] \\
\hline $\mathrm{Co}_{3} \mathrm{FeP}_{x} \mathrm{O}$ & $\mathrm{PO}$ & $1 \mathrm{M} \mathrm{KOH}$ & MMOF & - & 291 & 85 & $18 \mathrm{~h}$ & {$[8]$} \\
\hline Activated Mn-Co & $\mathrm{PO}$ & $1 \mathrm{M} \mathrm{KOH}$ & $\begin{array}{l}\text { Glassy } \\
\text { carbon }\end{array}$ & - & 320 & 52 & $8 \mathrm{~h}$ & [118] \\
\hline $\mathrm{M}_{x} \mathrm{O} @ \mathrm{M}_{x} \mathrm{P} / \mathrm{PNCF}$ & $\mathrm{PO}$ & $1 \mathrm{M} \mathrm{KOH}$ & NiCo foam & $\begin{array}{l}256 \\
\quad\left(500 \mathrm{~mA} \mathrm{~cm}^{-2}\right) \\
343 \\
\left(1000 \mathrm{~mA} \mathrm{~cm}^{-2}\right)\end{array}$ & - & 40 & $100 \mathrm{~h}$ & {$[120]$} \\
\hline $\mathrm{Ni}-\mathrm{Zn}$ NSs & $\mathrm{PO}$ & $1 \mathrm{M} \mathrm{KOH}$ & $\begin{array}{l}\text { Glassy } \\
\text { carbon }\end{array}$ & - & 290 & 40 & $30 \mathrm{~h}$ & {$[122]$} \\
\hline $\begin{array}{l}\text { 3D-1D Co-ZnP / } \\
\text { CNTs }\end{array}$ & $\mathrm{PO}$ & $1 \mathrm{M} \mathrm{KOH}$ & $\begin{array}{l}\text { Glassy } \\
\text { carbon }\end{array}$ & - & 281 & 41 & $24 \mathrm{~h}$ & {$[123]$} \\
\hline $\mathrm{CoFeOP}$ & $\mathrm{PO}$ & $1 \mathrm{M} \mathrm{KOH}$ & $\begin{array}{l}\text { Glassy } \\
\text { carbon }\end{array}$ & 180 & 280 & $53 \& 62$ & $10 \mathrm{~h}$ & [119] \\
\hline $\mathrm{FeCoOP}$ & $\mathrm{PO}$ & $1 \mathrm{M} \mathrm{KOH}$ & $\begin{array}{l}\text { Carbon fiber } \\
\text { paper }\end{array}$ & - & 269 & 31 & $100 \mathrm{~h}$ & {$[215]$} \\
\hline $\mathrm{H}-\mathrm{NiFeOP}$ & $\mathrm{PO}$ & $1 \mathrm{M} \mathrm{KOH}$ & & - & 253 & 59 & $20 \mathrm{~h}$ & [121] \\
\hline NiMnOP & $\mathrm{PO}$ & $1 \mathrm{M} \mathrm{KOH}$ & $\begin{array}{l}\text { Ni foam or } \\
\text { carbon } \\
\text { cloth }\end{array}$ & 189 & 191 & 29 & $36 \mathrm{~h}$ & {$[115]$} \\
\hline $\mathrm{Sn}-\mathrm{Fe}-\mathrm{HP}$ & $\mathrm{OH}-\mathrm{P}$ & $1 \mathrm{M} \mathrm{KOH}$ & $\begin{array}{l}\text { Glassy } \\
\text { carbon }\end{array}$ & - & 359 & 81 & $13 \mathrm{~h}$ & [126] \\
\hline $\mathrm{Fe}_{2.95}\left(\mathrm{PO}_{4}\right)_{2}(\mathrm{OH})_{2}$ & $\mathrm{OH}-\mathrm{P}$ & $\begin{array}{l}1 \mathrm{M} \mathrm{KOH} \\
1 \mathrm{M} \mathrm{H}_{3} \mathrm{PO}_{4}\end{array}$ & $\begin{array}{l}\text { Stainless } \\
\text { steel metal } \\
\text { plates }\end{array}$ & $-\overline{165.7}$ & $\begin{array}{l}281 \\
-\end{array}$ & $\begin{array}{l}46.48 \\
85.54\end{array}$ & $\begin{array}{l}12 \mathrm{~h} \\
12 \mathrm{~h}\end{array}$ & [124] \\
\hline $\mathrm{CoNi-CuHP/NF}$ & $\mathrm{OH}-\mathrm{P}$ & $1 \mathrm{M} \mathrm{KOH}$ & Ni foam & - & $370\left(50 \mathrm{~mA} / \mathrm{cm}^{2}\right)$ & 88 & $45 \mathrm{~h}$ & {$[125]$} \\
\hline
\end{tabular}

(i) Polyanion-mixed and metal-free catalyst: Recently, polyanion-mixed catalysts have gradually become a research hotspot, and tri-anion-mixed such as SPO have been displayed [117]. Different anions have different electronegativity, and their effective combination can meet the diversified requirements of material properties. The synergy will significantly stimulate the intrinsic activity of the catalyst. Then, the development of anion-mixed with absolute metalfree nanocomposite (i.e., g- $\mathrm{C}_{3} \mathrm{~N}_{4}$ /graphene, $\mathrm{N}$-doped carbon, $\mathrm{C}_{3} \mathrm{~N}_{4}$ quantum dots on graphene) [242-244] is a further possible approach to improving electrical conductivity, reducing costs, and promoting durability of water-splitting activity. (ii) Progressive strategies: Single-atom catalysts (SACs) have demonstrated superior performance for electrocatalysts [245]. Drawing on SACs advantages, dispersing mixed anions and avoiding agglomeration as much as possible will be one of the promising ways to tune the water-splitting performance. Besides, for dimensional regulation, the Carbon quantum dots (CQDs) has possessed many unique advantages such as high electron-transfer abilities, abundant, nontoxic, and low cost [246]. Moreover, the surface of CQDs has many abundant functional groups $(-\mathrm{OH},-$ $\mathrm{COOH},-\mathrm{NH}_{2}$, etc.), which offer sufficient active sites for constructing electroactive catalysts. From these significant advantages, combining mixed anions with 
Table 2 Comparison of the OER and HER performance of typical mixed chalcogenides (oxysulfides, phosphosulfides)-based electrocatalysts

\begin{tabular}{|c|c|c|c|c|c|c|c|c|}
\hline Catalyst & Mixed anions & Electrolyte & Substrate & $\begin{array}{l}\text { Overpotential }(\mathrm{mV}) \\
\text { HER }\left(10 \mathrm{~mA} \mathrm{~cm}{ }^{-2}\right)\end{array}$ & $\begin{array}{l}\text { Overpotential }(\mathrm{mV}) \\
\text { OER }\left(10 \mathrm{~mA} \mathrm{~cm}^{-2}\right)\end{array}$ & $\begin{array}{l}\text { Tafel slope } \\
\left(\mathrm{mVdec}^{-1}\right)\end{array}$ & Durability & Refs. \\
\hline $\mathrm{CoO}_{x} \mathrm{~S}_{0.18}$ & OS & $0.1 \mathrm{M} \mathrm{KOH}$ & Glassy carbon & 375 & - & 200 & - & {$[50]$} \\
\hline $\mathrm{A}-\mathrm{CoS}_{4.6} \mathrm{O}_{0.6} \mathrm{PNCs}$ & OS & $\begin{array}{l}1 \mathrm{M} \mathrm{KOH} \\
0.1 \mathrm{M} \mathrm{PBS}\end{array}$ & Glassy carbon & - & $\begin{array}{l}290 \\
270 \text { (onset) }\end{array}$ & $\begin{array}{l}67 \\
164\end{array}$ & - & [48] \\
\hline $\mathrm{NiFeS}-2$ & OS & $0.1 \mathrm{M} \mathrm{KOH}$ & Glassy carbon & 281 & 286 & 56 & $3 \mathrm{~h}$ & [59] \\
\hline FNHNs/NF & OS & $1 \mathrm{M} \mathrm{KOH}$ & $\mathrm{Ni}$ foam & 140 & 340 & $82 \& 69$ & $10 \mathrm{~h}$ & [138] \\
\hline $\mathrm{NiCo}_{2} \mathrm{O}_{x} \mathrm{~S}_{4-x}$ & OS & $1 \mathrm{M} \mathrm{KOH}$ & FTO & - & 370 & 43 & $24 \mathrm{~h}$ & {$[52]$} \\
\hline $\begin{array}{l}\mathrm{NiCoS}_{0.14} \mathrm{O}_{3.25} \\
\mathrm{NSs} / \mathrm{NF}\end{array}$ & OS & $1 \mathrm{M} \mathrm{KOH}$ & Ni foam & 170 & 250 & 44 & $6 \mathrm{~h}$ & [136] \\
\hline $\mathrm{S}-\mathrm{CoO}_{x}$ & OS & $1 \mathrm{M} \mathrm{KOH}$ & Ni foam & 136 & 370 & $80 \& 109$ & $50 \mathrm{~h}$ & [128] \\
\hline $\begin{array}{l}\mathrm{Cu} @ \mathrm{Cu}_{2} \mathrm{~S} @ \\
\quad \mathrm{NiCoO}_{2-x} \mathrm{~S}_{x} \mathrm{NWs}\end{array}$ & OS & $1 \mathrm{M} \mathrm{KOH}$ & Copper foam & $203\left(20 \mathrm{mV} \mathrm{cm}^{-2}\right)$ & $295\left(50 \mathrm{~mA} \mathrm{~cm}^{-2}\right)$ & $63 \& 50$ & $30 \mathrm{~h} \& 24 \mathrm{~h}$ & [137] \\
\hline MoPIS & PS & $0.5 \mathrm{M} \mathrm{H}_{2} \mathrm{SO}_{4}$ & Ti foil & 64 & - & - & $\begin{array}{l}1000 \\
\text { cycles }\end{array}$ & [148] \\
\hline rGO-PdPS & PS & $0.5 \mathrm{M} \mathrm{H}_{2} \mathrm{SO}_{4}$ & Glassy carbon & 90 & - & 46 & $\begin{array}{l}1000 \\
\text { cycles }\end{array}$ & [149] \\
\hline $\begin{array}{l}\text { rGO-supported } \\
\text { few-layer FePS }\end{array}$ & PS & $0.5 \mathrm{M} \mathrm{H}_{2} \mathrm{SO}_{4}$ & Glassy carbon & 50 & - & 54 & - & [150] \\
\hline Co NPlsPS & PS & $0.5 \mathrm{M} \mathrm{H}_{2} \mathrm{SO}_{4}$ & Glassy carbon & 48 & - & 56 & $36 \mathrm{~h}$ & {$[68]$} \\
\hline $\begin{array}{l}\text { P-doped Ni-Fe-S } \\
\text { microspheres }\end{array}$ & PS & $1 \mathrm{M} \mathrm{KOH}$ & Glassy carbon & - & 264 & 48 & $50 \mathrm{~h}$ & [151] \\
\hline Co SIP/CNT & PS & $0.5 \mathrm{M} \mathrm{H}_{2} \mathrm{SO}_{4}$ & Carbon fiber & 48 & - & 55 & $100 \mathrm{~h}$ & [216] \\
\hline $\mathrm{Co}_{0.9} \mathrm{~S}_{0.58} \mathrm{P}_{0.42}$ & PS & $\begin{array}{l}0.5 \mathrm{M} \mathrm{H}_{2} \mathrm{SO}_{4} \\
1 \mathrm{M} \mathrm{KOH}\end{array}$ & Glassy carbon & 139 & 266 & $69 \& 48$ & $20 \mathrm{~h}$ & {$[64]$} \\
\hline $\mathrm{NiCoPS} / \mathrm{CC}$ & PS & $\begin{array}{l}1 \mathrm{M} \mathrm{KOH} \\
0.5 \mathrm{M} \mathrm{H}_{2} \mathrm{SO}_{4}\end{array}$ & Carbon cloth & 57 & 230 & $45 \& 62$ & $40 \mathrm{~h}$ & [141] \\
\hline $\mathrm{NiP}_{0.62} \mathrm{~S}_{0.38}$ & PS & $1 \mathrm{M} \mathrm{KOH}$ & Ni foam & 52 & 240 & $52.3 \&-$ & $200 \mathrm{~h}$ & {$[65]$} \\
\hline $\mathrm{Ni}_{0.95} \mathrm{Co}_{0.05} \mathrm{PS}_{3}$ & PS & $1 \mathrm{M} \mathrm{KOH}$ & Glassy carbon & 77 & - & 71 & - & [217] \\
\hline $\begin{array}{l}\text { FePIS/CNT } \\
\text { FeSIP/CNT }\end{array}$ & PS & $0.5 \mathrm{M} \mathrm{H}_{2} \mathrm{SO}_{4}$ & Carbon fiber & $\begin{array}{l}88 \\
130\end{array}$ & - & $\begin{array}{l}36 \\
45\end{array}$ & - & [218] \\
\hline NiFeSP-NF & PS & $1 \mathrm{M} \mathrm{KOH}$ & Ni foam & 94 & $240 @ 50 \mathrm{~mA} \mathrm{~cm}-2$ & $83 \& 76$ & $25 \mathrm{~h}$ & [219] \\
\hline $\mathrm{WS}_{2(1-x)} \mathrm{P}_{2 x}$ NRs & PS & $0.5 \mathrm{M} \mathrm{H}_{2} \mathrm{SO}_{4}$ & Carbon fiber & 98 & - & 71 & $25 \mathrm{~h}$ & [152] \\
\hline $\mathrm{Ni}_{0.9} \mathrm{Fe}_{0.1} \mathrm{PS}_{3}$ & PS & $1 \mathrm{M} \mathrm{KOH}$ & Glassy carbon & 72 & $329 @ 20 \mathrm{~mA} \mathrm{~cm}{ }^{-2}$ & $73 \& 69$ & $50 \mathrm{~h}$ & [66] \\
\hline CoPS/CP & PS & $0.5 \mathrm{M} \mathrm{H}_{2} \mathrm{SO}_{4}$ & Carbon paper & 26 & - & 43 & $100 \mathrm{~h}$ & [143] \\
\hline $\begin{array}{l}\text { NiCoPIS } \\
/ \mathrm{CC}\end{array}$ & PS & $\begin{array}{l}0.5 \mathrm{M} \mathrm{H}_{2} \mathrm{SO}_{4} \\
1 \mathrm{M} \mathrm{KOH}\end{array}$ & Carbon cloth & $\begin{array}{l}90 \\
76\end{array}$ & - & $\begin{array}{l}52 \\
65\end{array}$ & $\begin{array}{l}1000 \\
\text { cycles }\end{array}$ & [220] \\
\hline $\mathrm{NiFePS}_{3}$ & PS & $1 \mathrm{M} \mathrm{KOH}$ & Glassy carbon & - & 223 & 42 & $\begin{array}{l}2000 \\
\text { cycles }\end{array}$ & [221] \\
\hline $\mathrm{CoPS} / \mathrm{N}-\mathrm{C}$ & PS & $\begin{array}{l}0.5 \mathrm{M} \mathrm{H}_{2} \mathrm{SO}_{4} \\
1 \mathrm{M} \mathrm{KOH}\end{array}$ & Glassy carbon & $\begin{array}{l}80 \\
148\end{array}$ & - & $\begin{array}{l}68 \\
78\end{array}$ & $16 \mathrm{~h}$ & [144] \\
\hline $\begin{array}{l}\mathrm{NiPS}_{3} \text { NSs-G-1:1\& } \\
2 \text { mg NiPS3 }\end{array}$ & PS & $1 \mathrm{M} \mathrm{KOH}$ & Glassy carbon & - & 294 & 43 & $30 \mathrm{~h}$ & [153] \\
\hline CoP@PS/NCNT & PS & $0.5 \mathrm{M} \mathrm{H}_{2} \mathrm{SO}_{4}$ & NCNT & 80 & - & 53 & $4 \mathrm{~h}$ & [222] \\
\hline FeCoNiPS & PS & $1 \mathrm{M} \mathrm{KOH}$ & Carbon paper & 284 & 162 & $41 \& 43$ & $18 \mathrm{~h}$ & [154] \\
\hline
\end{tabular}

CQDs is an efficient method to fabricate advanced electrocatalysts for water-splitting. Furthermore, one-step synthesis strategies are urgently needed to improve production efficiency. (iii) Advanced characterizations: Catalytic reaction is a dynamic process, and advanced characterization techniques (i.e., in-situ XRD, Raman, TEM) are potent means to clarify the reaction pathway and internal mechanism. The clarification of these issues 
Table 3 Comparison of the OER and HER performance of typical mixed chalcogenides (sulfoselenides, selenotellurides, hydroxy (sulfates, sulfides), and phosphoselenides), (oxy)hydroxides, and borides/borates electrocatalysts

\begin{tabular}{|c|c|c|c|c|c|c|c|c|}
\hline Catalyst & Mixed anions & Electrolyte & Substrate & $\begin{array}{l}\text { Overpotential } \\
\text { (mV) } \\
\text { HER } \\
\left(10 \mathrm{~mA} \mathrm{~cm}^{-2}\right)\end{array}$ & $\begin{array}{l}\text { Overpotential } \\
\text { (mV) } \\
\text { OER } \\
\left(10 \mathrm{~mA} \mathrm{~cm}^{-2}\right)\end{array}$ & $\begin{array}{l}\text { Tafel slope (mV } \\
\left.\operatorname{dec}^{-1}\right)\end{array}$ & Durability & Refs. \\
\hline $\mathrm{WS}_{2(1-x)} \mathrm{Se}_{2 x}$ & $\mathrm{SSe}$ & $0.5 \mathrm{M} \mathrm{H}_{2} \mathrm{SO}_{4}$ & Glassy carbon & 80 & - & 85 & $67 \mathrm{~h}$ & [161] \\
\hline $\mathrm{WS}_{2(1-x)} \mathrm{Se}_{2 x} / \mathrm{NiSe}_{2}$ & $\mathrm{SSe}$ & $0.5 \mathrm{M} \mathrm{H}_{2} \mathrm{SO}_{4}$ & Ni foam & 88 & - & 46.7 & 1000 cycles & [165] \\
\hline $\operatorname{MoS}_{2\left(1^{-} x\right)} \mathrm{Se}_{2 x}$ & SSe & $0.5 \mathrm{M} \mathrm{H}_{2} \mathrm{SO}_{4}$ & Glassy carbon & $80-100$ & - & $45-55$ & 10,000 cycles & [157] \\
\hline $\mathrm{WS}_{2(1-x)} \mathrm{Se}_{2 x}(\mathrm{~S}$ NRs-Li) & $\mathrm{SSe}$ & $0.5 \mathrm{M} \mathrm{H}_{2} \mathrm{SO}_{4}$ & Carbon fibers & 173 & - & 68 & $6 \mathrm{~h}$ & [223] \\
\hline $\mathrm{Co}\left(\mathrm{S}_{0.73} \mathrm{Se}_{0.27}\right)_{2}$ & $\mathrm{SSe}$ & $0.5 \mathrm{M} \mathrm{H}_{2} \mathrm{SO}_{4}$ & $\begin{array}{l}\text { Carbon fiber } \\
\text { paper }\end{array}$ & 157 & - & 45 & $20 \mathrm{~h}$ & [224] \\
\hline $\operatorname{MoS}_{2(1-x)} \operatorname{Se}_{2 x}(\mathrm{X}-0.61)$ & $\mathrm{SSe}$ & $0.5 \mathrm{M} \mathrm{H}_{2} \mathrm{SO}_{4}$ & Glassy carbon & 279 & - & 106 & $22 \mathrm{~h}$ & [225] \\
\hline $\mathrm{W}\left(\mathrm{Se}_{0.4} \mathrm{~S}_{0.6}\right)_{2}-\mathrm{C}-10$ & $\mathrm{SSe}$ & $0.5 \mathrm{M} \mathrm{H}_{2} \mathrm{SO}_{4}$ & Carbon fiber mats & 174 & - & 106 & $12 \mathrm{~h}$ & [226] \\
\hline $\operatorname{Mo}\left(\mathrm{S}_{0.53} \mathrm{Se}_{0.47}\right)_{2}$ & $\mathrm{SSe}$ & $0.5 \mathrm{M} \mathrm{H}_{2} \mathrm{SO}_{4}$ & Carbon cloth & 183 & - & 56 & $\begin{array}{l}2000 \\
\text { cycles }\end{array}$ & [227] \\
\hline MoSSe@rGO & SSe & $0.5 \mathrm{M} \mathrm{H}_{2} \mathrm{SO}_{4}$ & Glassy carbon & $\begin{array}{l}135 @ 5 \\
\mathrm{~mA} \mathrm{~cm} \mathrm{~cm}^{-2}\end{array}$ & - & $51 @ 5 \mathrm{~mA} \mathrm{~cm}^{-2}$ & $\begin{array}{l}5000 \\
\text { cycles }\end{array}$ & {$[26]$} \\
\hline $\mathrm{Mo}_{0.3} \mathrm{~W}_{0.67} \mathrm{~S}_{1.33} \mathrm{Se}_{0.67}$ & $\mathrm{SSe}$ & $0.5 \mathrm{M} \mathrm{H}_{2} \mathrm{SO}_{4}$ & Glassy carbon & 93 & - & 55 & $\begin{array}{l}5000 \\
\text { cycles }\end{array}$ & [167] \\
\hline $\mathrm{CoS}_{2} \mathrm{Se}_{2(1-x)}$ & SSe & $0.5 \mathrm{M} \mathrm{H}_{2} \mathrm{SO}_{4}$ & Carbon fiber & 130 & - & 44 & $\begin{array}{l}1000 \\
\text { cycles }\end{array}$ & [164] \\
\hline $\mathrm{MoS}_{2} \mathrm{Se}_{2(1-x)}(\mathrm{X}-0.54)$ & SSe & $0.5 \mathrm{M} \mathrm{H}_{2} \mathrm{SO}_{4}$ & Glassy carbon & 219 & - & 55 & $\begin{array}{l}1000 \\
\text { cycles }\end{array}$ & {$[72]$} \\
\hline $\mathrm{MoS}_{2(1-x)} \mathrm{Se}_{2 x} / \mathrm{NiSe}_{2}$ & $\mathrm{SSe}$ & $0.5 \mathrm{M} \mathrm{H}_{2} \mathrm{SO}_{4}$ & $\mathrm{NiSe}_{2}$ foam & 69 & - & 42 & $16 \mathrm{~h}$ & [228] \\
\hline $\mathrm{WS}_{2(1-x)} \mathrm{Se}_{2 \lambda} / \mathrm{NiSe}_{2}$ & $\mathrm{SSe}$ & $0.5 \mathrm{M} \mathrm{H}_{2} \mathrm{SO}_{4}$ & $\mathrm{NiSe}_{2}$ foam & 88 & - & 47 & $8 \mathrm{~h}$ & [228] \\
\hline $\begin{array}{l}\mathrm{Co}\left(\mathrm{S}_{0.71} \mathrm{Se}_{0.29}\right)_{2} \\
\operatorname{Co}\left(\mathrm{S}_{0.22} \mathrm{Se}_{0.78}\right)_{2}\end{array}$ & $\mathrm{SSe}$ & $1 \mathrm{M} \mathrm{KOH}$ & Ni Foam & 122 & 283 & $86 \& 66$ & $20 \mathrm{~h}$ & [229] \\
\hline $\begin{array}{l}\mathrm{MoS}_{2(1-)} \mathrm{Se}_{2 x} \\
\mathrm{WS}_{2(1-x)} \mathrm{Se}_{2 x}\end{array}$ & $\mathrm{~S}, \mathrm{Se}$ & $0.5 \mathrm{M} \mathrm{H}_{2} \mathrm{SO}_{4}$ & FTO & $\begin{array}{l}141 \\
167\end{array}$ & - & $\begin{array}{l}67 \\
107\end{array}$ & $20 \mathrm{~h}$ & [166] \\
\hline $\mathrm{WSe}_{x} \mathrm{Se}_{1-x}-15 \mathrm{NPA}$ & $\mathrm{SSe}$ & $0.5 \mathrm{M} \mathrm{H}_{2} \mathrm{SO}_{4}$ & W foil & 110 & - & 59 & $6 \mathrm{~h}$ & [230] \\
\hline $\mathrm{Fe}_{4.5} \mathrm{Ni}_{4.5} \mathrm{~S}_{8-y} \mathrm{Se}_{y}$ & $\mathrm{SSe}$ & $0.5 \mathrm{M} \mathrm{H}_{2} \mathrm{SO}_{4}$ & Brass rod & 172 & - & 40 & - & [168] \\
\hline $\mathrm{P} / \mathrm{Se}-\mathrm{MoS}_{2} / \mathrm{CFP}$ & $\mathrm{SSeP}$ & $0.5 \mathrm{M} \mathrm{H}_{2} \mathrm{SO}_{4}$ & $\begin{array}{l}\text { Carbon fiber } \\
\text { paper }\end{array}$ & 93 & - & 50 & $10 \mathrm{~h}$ & [158] \\
\hline $\mathrm{MoSe}_{0.12} \mathrm{Te}_{1.79}$ & $\mathrm{SeTe}$ & $0.5 \mathrm{M} \mathrm{H}_{2} \mathrm{SO}_{4}$ & Graphite & 410 & - & 62 & - & [170] \\
\hline ZCS-30 & $\mathrm{OHSO}_{4}$ & $0.5 \mathrm{M} \mathrm{KOH}$ & Glassy carbon & - & 370 & 60 & $11 \mathrm{~h}$ & [171] \\
\hline $\mathrm{NiCo}_{2}(\mathrm{SOH})_{x}$ & OHS & $1.0 \mathrm{M} \mathrm{NaOH}$ & $\mathrm{Ni}$ foam & - & 290 & 47 & $30 \mathrm{~h}$ & [61] \\
\hline NiFeLDH OHS & OHS & $0.1 \mathrm{M} \mathrm{KOH}$ & Glassy carbon & - & 286 & 82 & $6 \mathrm{~h}$ & [172] \\
\hline $\mathrm{P}-\mathrm{NiSe}_{2} @ \mathrm{~N}-\mathrm{CNTs} / \mathrm{NC}$ & PSe & $1 \mathrm{M} \mathrm{KOH}$ & Glassy carbon & 95 & 306 & $82 \& 61$ & 2000 cycles & [73] \\
\hline $\mathrm{EG} / \mathrm{H}-\mathrm{Co}_{0.85}-\mathrm{SelP}$ & PSe & $1 \mathrm{M} \mathrm{KOH}$ & EG foil & 150 & - & 83 & $10 \mathrm{~h}$ & [176] \\
\hline $\mathrm{CoP}_{1.37} \mathrm{Se}_{0.63} \mathrm{NWs}$ & PSe & $\begin{array}{l}0.5 \mathrm{M} \mathrm{H}_{2} \mathrm{SO}_{4} 1 \mathrm{M} \\
\mathrm{KOH}\end{array}$ & Carbon fiber & $\begin{array}{l}70 \\
98\end{array}$ & - & 54 & $12 \mathrm{~h}$ & [175] \\
\hline CoOSeP@Co foil & PSe & $1 \mathrm{M} \mathrm{KOH}$ & Co foil & 155 & 347 & $76 \& 74$ & $30 \mathrm{~h}$ & [231] \\
\hline $\mathrm{FeCoCr} / \mathrm{GC}$ & $\mathrm{OOH}$ & $0.1 \mathrm{M} \mathrm{KOH}$ & Glassy carbon & - & 490 & 60 & $40,000 \mathrm{~s}$ & [199] \\
\hline $\mathrm{CoOOH}$ NS & $\mathrm{OOH}$ & $1 \mathrm{M} \mathrm{KOH}$ & Glassy carbon & - & 300 & 38 & $12 \mathrm{~h}$ & [232] \\
\hline $\mathrm{FeCoW}$ & $\mathrm{OOH}$ & $0.1 \mathrm{M} \mathrm{KOH}$ & Gold foam & - & 191 & - & $500 \mathrm{~h}$ & [7] \\
\hline $\mathrm{Fe}-\mathrm{OOH} / \mathrm{NF}-200$ & $\mathrm{OOH}$ & $1 \mathrm{M} \mathrm{KOH}$ & Ni foam & - & 290 & 48 & $11 \mathrm{~h}$ & {$[51]$} \\
\hline $\mathrm{Fe}-\mathrm{CoOOH} / \mathrm{G}$ & $\mathrm{OOH}$ & $1 \mathrm{M} \mathrm{KOH}$ & Glassy carbon & - & 330 & 37 & $5.5 \mathrm{~h}$ & [233] \\
\hline $\mathrm{W}_{0.5} \mathrm{Co}_{0.4} \mathrm{Fe}_{0.1} / \mathrm{NF}$ & $\mathrm{OOH}$ & $1 \mathrm{M} \mathrm{KOH}$ & $\mathrm{Ni}$ foam & - & $\begin{array}{l}310 @ 100 \\
\mathrm{~mA} \mathrm{~cm} \mathrm{~cm}^{-2}\end{array}$ & 32 & $510 \mathrm{~h}$ & [234] \\
\hline $\mathrm{NiFeOOH/EG}$ & $\mathrm{OOH}$ & $1 \mathrm{M} \mathrm{KOH}$ & $\begin{array}{r}\text { Exfoliated } \\
\text { graphite }\end{array}$ & - & 214 & 21 & $100 \mathrm{~h}$ & [235] \\
\hline $\mathrm{Ni}(\mathrm{OH}) / \mathrm{FeOOH}$ & $\mathrm{OOH}$ & $1 \mathrm{M} \mathrm{NaOH}$ & FTO & - & 300 & - & $50 \mathrm{~h}$ & [193] \\
\hline $\begin{array}{l}\text { Ir-Doped Ni-(Oxy) } \\
\text { hydroxide }\end{array}$ & $\mathrm{OOH}$ & $1 \mathrm{M} \mathrm{KOH}$ & Glassy carbon & - & 270 & 45.2 & $20 \mathrm{~h}$ & [196] \\
\hline $\mathrm{Fe}-\mathrm{CoNi}-\mathrm{OH}$ & $\mathrm{OOH}$ & $1 \mathrm{M} \mathrm{KOH}$ & $\mathrm{Ni}$ foam & - & 210 & 28.0 & $108 \mathrm{~h}$ & [198] \\
\hline CoCuFeMoOOH@Cu & $\mathrm{OOH}$ & $1 \mathrm{M} \mathrm{KOH}$ & $\mathrm{Cu}$ foil & - & 199 & 48.8 & $72 \mathrm{~h}$ & [201] \\
\hline $\mathrm{CoV}-\mathrm{UAH}$ & $\mathrm{OOH}$ & $1 \mathrm{M} \mathrm{KOH}$ & Au foam & - & 215 & 44 & $170 \mathrm{~h}$ & [202] \\
\hline $\mathrm{Ni}_{70} \mathrm{Fe}_{30}(\mathrm{H})$ & $\mathrm{OOH}$ & $0.1 \mathrm{M} \mathrm{KOH}$ & Glassy carbon & - & 292 & 30 & $2 \mathrm{~h}$ & [236] \\
\hline
\end{tabular}


Table 3 (continued)

\begin{tabular}{|c|c|c|c|c|c|c|c|c|}
\hline Catalyst & Mixed anions & Electrolyte & Substrate & $\begin{array}{l}\text { Overpotential } \\
(\mathrm{mV}) \\
\text { HER } \\
\left(10 \mathrm{~mA} \mathrm{~cm}^{-2}\right)\end{array}$ & $\begin{array}{l}\text { Overpotential } \\
(\mathrm{mV}) \\
\text { OER } \\
\left(10 \mathrm{~mA} \mathrm{~cm}^{-2}\right)\end{array}$ & $\begin{array}{l}\text { Tafel slope }(\mathrm{mV} \\
\left.\operatorname{dec}^{-1}\right)\end{array}$ & Durability & Refs. \\
\hline Elox $\mathrm{H}_{2} \mathrm{~S}$ NF & $\mathrm{OOH}$ & $1 \mathrm{M} \mathrm{KOH}$ & Ni foam & - & 256 & 41 & $10 \mathrm{~h}$ & [237] \\
\hline $\mathrm{Ni}-\mathrm{Fe}-\mathrm{SS}-\mathrm{NC}$ & $\mathrm{OOH}$ & $1 \mathrm{M} \mathrm{KOH}$ & Stainless steel & - & 232 & 51 & $340 \mathrm{~h}$ & [194] \\
\hline $\mathrm{FeNiO}_{x} \mathrm{H}_{y}$ & $\mathrm{OOH}$ & $1 \mathrm{M} \mathrm{KOH}$ & Ni foam & - & 206 & 39 & $50 \mathrm{~h}$ & [195] \\
\hline $\begin{array}{l}\mathrm{Fe}_{0.03} \mathrm{Co}_{0.67} \mathrm{OOHPNSAs} / \\
\quad \text { CFC }\end{array}$ & $\mathrm{OOH}$ & $1 \mathrm{M} \mathrm{KOH}$ & Carbon fiber cloth & - & 266 & 30 & $24 \mathrm{~h}$ & [197] \\
\hline $\mathrm{Ni}_{3} \mathrm{Ge}_{2} \mathrm{O}_{5}(\mathrm{OH})_{4}$ & $\mathrm{OOH}$ & $1 \mathrm{M} \mathrm{KOH}$ & Glassy carbon & - & 320 & 68 & $4.5 \mathrm{~h}$ & [238] \\
\hline $1 \mathrm{~T}-\mathrm{MoS}_{2} / \mathrm{Ni}^{2+} \mathrm{OOH}_{2-}$ & $\mathrm{OOH}$ & $1 \mathrm{M} \mathrm{KOH}$ & $\begin{array}{l}\text { Carbon fiber } \\
\text { paper }\end{array}$ & 73 & - & 75 & $30 \mathrm{~h}$ & [239] \\
\hline $\mathrm{Zn}_{0.2} \mathrm{Co}_{0.8} \mathrm{OOH}$ & $\mathrm{OOH}$ & $1 \mathrm{M} \mathrm{KOH}$ & Glassy carbon & - & 235 & 34.7 & $40 \mathrm{~h}$ & [49] \\
\hline $\begin{array}{l}\mathrm{Co}_{1.8} \mathrm{Ni}(\mathrm{OH})_{5.6} @ \\
\mathrm{Co}_{1.8} \mathrm{NiS}_{0.4}(\mathrm{OH})_{4.8}\end{array}$ & $\mathrm{OH}-\mathrm{OHS}$ & $0.1 \mathrm{M} \mathrm{KOH}$ & Glassy carbon & - & 274 & 45 & $2.5 \mathrm{~h}$ & [240] \\
\hline $\mathrm{Ni}_{x} \mathrm{Fe}_{1-x}-\mathrm{AHNAs}$ & OOH-alloy & $1 \mathrm{M} \mathrm{KOH}$ & Ni foam & - & 190 & 21 & $120 \mathrm{~h}$ & {$[241]$} \\
\hline $\mathrm{Ni}-\mathrm{Bi}-\mathrm{Pi} / \mathrm{CC}$ & $\mathrm{BP}$ & $0.1 \mathrm{M} \mathrm{KBi}$ & Carbon cloth & - & 440 & 139 & $23 \mathrm{~h}$ & [208] \\
\hline $\mathrm{Fe}-\mathrm{Pi}-\mathrm{Bi} / \mathrm{CC}$ & $\mathrm{BP}$ & $0.1 \mathrm{M} \mathrm{KBi}$ & Carbon cloth & & 434 & 89 & $20 \mathrm{~h}$ & [209] \\
\hline $\mathrm{Co}-\mathrm{B}-\mathrm{P} / \mathrm{NF}$ & $\mathrm{BP}$ & $1 \mathrm{M} \mathrm{KOH}$ & Ni foam & 42 & - & 42.1 & $20 \mathrm{~h}$ & {$[74]$} \\
\hline Co-P-B/CP & $\mathrm{BP}$ & $0.5 \mathrm{M} \mathrm{H}_{2} \mathrm{SO}_{4}$ & Carbon paper & - & - & $62-68$ & - & [207] \\
\hline NiVFe-B-P LDHs@NF & $\mathrm{BP}$ & $1.0 \mathrm{M} \mathrm{KOH}$ & Ni foam & 117 & - & 68 & $24 \mathrm{~h}$ & [210] \\
\hline
\end{tabular}

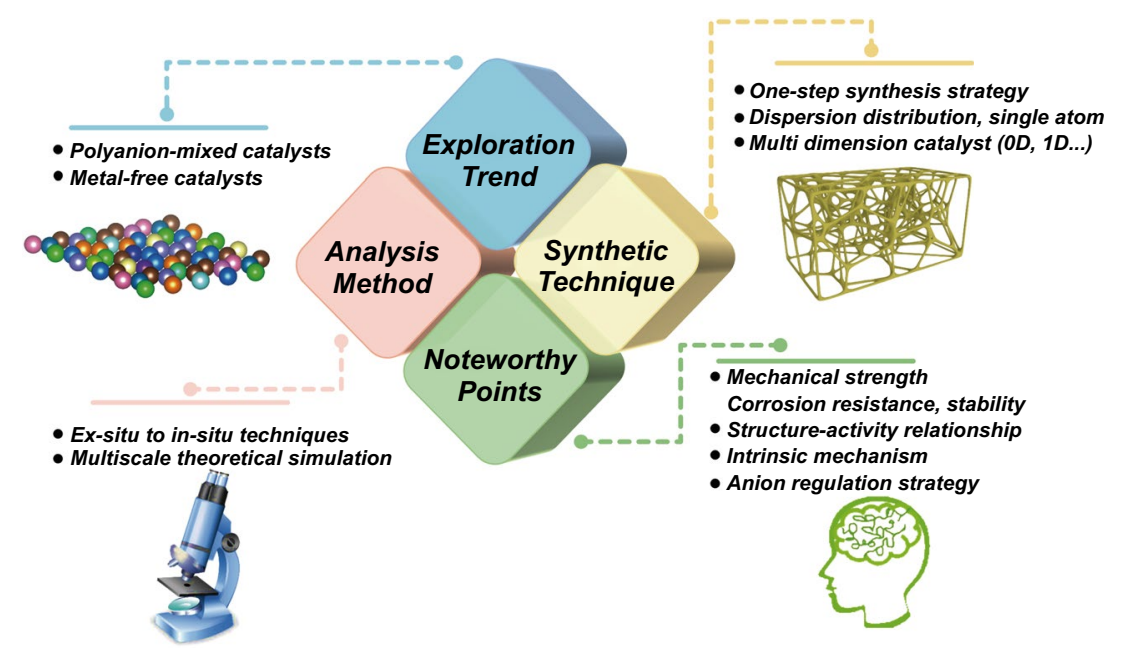

Fig. 16 Outlook and perspective research directions for anion-mixed catalysts served for water electrolysis

can in turn guide material design, thereby shortening the development cycle. Besides, computer simulations (DFT calculations, machine learning, molecular dynamics simulations (MD), etc.) can effectively assist in verifying conjectures about the mechanism and expanding the library of advanced materials, thereby greatly reducing the cost of trial and error and correcting the traditional cooking research mode.

(iv) Focus on core issues: Except for meeting laboratory conditions, catalysts that are close to actual production needs are more worthy of researchers' attention. Anion-mixed catalysts are mostly lowdimensional nanostructures, and it is necessary to construct a series of reasonable evaluation indexes such as service life, mechanical strength, and corrosion resistance. Besides, many catalysts have attractive appearance structures. The exploration of their formation mechanism and even the atomic level structure-activity relationship is of great importance. Moreover, the internal mechanism that anion- 
mixed-promoted catalytic activity urgently needs more intuitive physical models to explain, rather than perceptual understanding. Theoretical explorations need to be strengthened, such as LOM mechanism and the diversified influence of anion mixing on electron transfer. Finally, anion regulation strategy deserves more attention. Accurate regulation at the atomic scale will be more required to achieve the unique coordination environment and intrinsic catalytic improvement.

Acknowledgements This work was jointly supported by the National Natural Science Foundation of China (Grant No. 51802252), Natural Science Foundation of Shaanxi Province (No. 2020JM-032), China Postdoctoral Science Foundation (No. 2019M663698), and the fund of the State Key Laboratory of Solidification Processing in NPU (Grant No. SKLSP202116).

Funding Open access funding provided by Shanghai Jiao Tong University.

Open Access This article is licensed under a Creative Commons Attribution 4.0 International License, which permits use, sharing, adaptation, distribution and reproduction in any medium or format, as long as you give appropriate credit to the original author(s) and the source, provide a link to the Creative Commons licence, and indicate if changes were made. The images or other third party material in this article are included in the article's Creative Commons licence, unless indicated otherwise in a credit line to the material. If material is not included in the article's Creative Commons licence and your intended use is not permitted by statutory regulation or exceeds the permitted use, you will need to obtain permission directly from the copyright holder. To view a copy of this licence, visit http://creativecommons.org/licenses/by/4.0/.

\section{References}

1. F. Lyu, Q. Wang, S.M. Choi, Y. Yin, Noble-metal-free electrocatalysts for oxygen evolution. Small 15(1), 1804201 (2018). https://doi.org/10.1002/smll.201804201

2. P.W. Du, R. Eisenberg, Catalysts made of earth-abundant elements $(\mathrm{Co}, \mathrm{Ni}, \mathrm{Fe})$ for water splitting: recent progress and future challenges. Energy Environ. Sci. 5(3), 6012-6021 (2012). https://doi.org/10.1039/c2ee03250c

3. H.M. Chen, C.K. Chen, R.S. Liu, L. Zhang, J. Zhang et al., Nano-architecture and material designs for water splitting photoelectrodes. Chem. Soc. Rev. 41(17), 5654-5671 (2012). https://doi.org/10.1039/c2cs35019j

4. J. Ke, F. He, H. Wu, S. Lyu, J. Liu et al., Nanocarbonenhanced 2D photoelectrodes: a new paradigm in photoelectrochemical water splitting. Nano-Micro Lett. 13, 24 (2021). https://doi.org/10.1007/s40820-020-00545-8
5. Z.P. Ifkovits, J.M. Evans, M.C. Meier, K.M. Papadantonakis, N.S. Lewis, Decoupled electrochemical water-splitting systems: a review and prospective. Energy Environ. Sci. 14(9), 4740-4759 (2021). https://doi.org/10.1039/D1EE0 $1226 \mathrm{~F}$

6. C. Kuo, M. Neumann, K. Balamurugan, H.J. Park, S. Kang et al., Exfoliation and Raman spectroscopic fingerprint of few-layer $\mathrm{NiPS}_{3}$ van der Waals crystals. Sci. Rep. 6(1), 20904 (2016). https://doi.org/10.1038/srep20904

7. B. Zhang, X. Zheng, O. Voznyy, R. Comin, M. Bajdich et al., Homogeneously dispersed multimetal oxygen-evolving catalysts. Science 352(6283), 333-337 (2016). https://doi.org/10. 1126/science.aaf 1525

8. D.D. Babu, Y. Huang, G. Anandhababu, M.A. Ghausi, Y. Wang, Mixed-metal-organic framework self-template synthesis of porous hybrid oxyphosphides for efficient oxygen evolution reaction. ACS Appl. Mater. Interfaces 9(44), 3862138628 (2017). https://doi.org/10.1021/acsami.7b13359

9. W. Qian, S. Xu, X. Zhang, C. Li, W. Yang et al., Differences and similarities of photocatalysis and electrocatalysis in twodimensional nanomaterials: strategies, traps, applications and challenges. Nano-Micro Lett. 13, 156 (2021). https://doi.org/ 10.1007/s40820-021-00681-9

10. L. Ouyang, J. Jiang, K. Chen, M. Zhu, Z. Liu, Hydrogen production via hydrolysis and alcoholysis of light metal-based materials: a review. Nano-Micro Lett. 13, 134 (2021). https:// doi.org/10.1007/s40820-021-00657-9

11. L. Li, P. Wang, Q. Shao, X. Huang, Metallic nanostructures with low dimensionality for electrochemical water splitting. Chem. Soc. Rev. 49(10), 3072-3106 (2020). https://doi.org/ 10.1039/D0CS00013B

12. Y. Chen, K. Rui, J. Zhu, S.X. Dou, W. Sun, Recent progress on nickel-based oxide/(oxy)hydroxide electrocatalysts for the oxygen evolution reaction. Chem 25(3), 703-713 (2018). https://doi.org/10.1002/chem.201802068

13. R. Boppella, J. Tan, J. Yun, S.V. Manorama, J. Moon, Anionmediated transition metal electrocatalysts for efficient water electrolysis: recent advances and future perspectives. Coord. Chem. Rev. 427, 213552 (2021). https://doi.org/10.1016/j. ccr.2020.213552

14. Y. Yan, B.Y. Xia, B. Zhao, X. Wang, A review on noblemetal-free bifunctional heterogeneous catalysts for overall electrochemical water splitting. J. Mater. Chem. A 4(45), 17587-17603 (2016). https://doi.org/10.1039/c6ta08075h

15. N.K. Chaudhari, H. Jin, B. Kim, K. Lee, Nanostructured materials on 3D nickel foam as electrocatalysts for water splitting. Nanoscale 9(34), 12231-12247 (2017). https://doi. org/10.1039/c7nr04187j

16. N.T. Suen, S.F. Hung, Q. Quan, N. Zhang, Y.J. Xu et al., Electrocatalysis for the oxygen evolution reaction: recent development and future perspectives. Chem. Soc. Rev. 46(2), 337-365 (2017). https://doi.org/10.1039/c6cs00328a

17. V. Vij, S. Sultan, A.M. Harzandi, A. Meena, J.N. Tiwari et al., Nickel-based electrocatalysts for energy-related applications: oxygen reduction, oxygen evolution, and hydrogen evolution 
reactions. ACS Catal. 7(10), 7196-7225 (2017). https://doi. org/10.1021/acscatal.7b01800

18. R. Gusmao, Z. Sofer, M. Pumera, Metal phosphorous trichalcogenides (MPCh3): from synthesis to contemporary energy challenges. Angew. Chem. Int. Ed. 58(28), 9326-9337 (2019). https://doi.org/10.1002/anie.201810309

19. H. Wang, C. Tang, B. Li, Q. Zhang, A review of anion-regulated multi-anion transition metal compounds for oxygen evolution electrocatalysis. Inorg. Chem. Front. 5(3), 521-534 (2018). https://doi.org/10.1039/c7qi00780a

20. Y. Yan, T. He, B. Zhao, K. Qi, H. Liu et al., Metal/covalentorganic frameworks-based electrocatalysts for water splitting. J. Mater. Chem. A 6(33), 15905-15926 (2018). https://doi. org/10.1039/c8ta05985c

21. G. Zhao, K. Rui, S.X. Dou, W. Sun, Heterostructures for electrochemical hydrogen evolution reaction: a review. Adv. Funct. Mater. 28(43), 1803291 (2018). https://doi.org/10. 1002/adfm.201803291

22. P. Li, W. Chen, Recent advances in one-dimensional nanostructures for energy electrocatalysis. Chin. J. Catal. 40(1), 4-22 (2019). https://doi.org/10.1016/S1872-2067(18) 63177-8

23. H. Zhang, A.W. Maijenburg, X. Li, S.L. Schweizer, R.B. Wehrspohn, Bifunctional heterostructured transition metal phosphides for efficient electrochemical water splitting. Adv. Funct. Mater. 30(34), 2003261 (2020). https://doi.org/ 10.1002/adfm.202003261

24. H. Wang, H.W. Lee, Y. Deng, Z. Lu, P.C. Hsu et al., Bifunctional non-noble metal oxide nanoparticle electrocatalysts through lithium-induced conversion for overall water splitting. Nat. Commun. 6, 7261 (2015). https://doi.org/10.1038/ ncomms 8261

25. B. Jin, X. Zhou, L. Huang, M. Licklederer, M. Yang et al., Aligned $\mathrm{MoO}_{x} / \mathrm{MoS}_{2}$ core-shell nanotubular structures with a high density of reactive sites based on self-ordered anodic molybdenum oxide nanotubes. Angew. Chem. Int. Ed. Engl. 55(40), 12252-12256 (2016). https://doi.org/10.1002/anie. 201605551

26. B. Konkena, J. Masa, W. Xia, M. Muhler, W. Schuhmann, MoSSe@ reduced graphene oxide nanocomposite heterostructures as efficient and stable electrocatalysts for the hydrogen evolution reaction. Nano Energy 29, 46-53 (2016). https:// doi.org/10.1016/j.nanoen.2016.04.018

27. C. Tang, H.F. Wang, X. Chen, B.Q. Li, T.Z. Hou et al., Topological defects in metal-free nanocarbon for oxygen electrocatalysis. Adv. Mater. 28(32), 6845-6851 (2016). https://doi. org/10.1002/adma.201601406

28. W. Zhu, X. Yue, W. Zhang, S. Yu, Y. Zhang et al., Nickel sulfide microsphere film on $\mathrm{Ni}$ foam as an efficient bifunctional electrocatalyst for overall water splitting. Chem. Commun. 52(7), 1486-1489 (2016). https://doi.org/10.1039/c5cc0 $8064 \mathrm{a}$

29. K. Liang, L. Guo, K. Marcus, S. Zhang, Z. Yang et al., Overall water splitting with room-temperature synthesized $\mathrm{NiFe}$ oxyfluoride nanoporous films. ACS Catal. 7(12), 8406-8412 (2017). https://doi.org/10.1021/acscatal.7b02991
30. F. Yan, C. Zhu, C. Li, S. Zhang, X. Zhang et al., Highly stable three-dimensional nickel-iron oxyhydroxide catalysts for oxygen evolution reaction at high current densities. Electrochim. Acta 245, 770-779 (2017). https://doi.org/10.1016/j. electacta.2017.05.200

31. X. Fan, Y. Liu, S. Chen, J. Shi, J. Wang et al., Defect-enriched iron fluoride-oxide nanoporous thin films bifunctional catalyst for water splitting. Nat. Commun. 9, 1809 (2018). https:// doi.org/10.1038/s41467-018-04248-y

32. J. Huang, Y. Sun, Y. Zhang, G. Zou, C. Yan et al., A new member of electrocatalysts based on nickel metaphosphate nanocrystals for efficient water oxidation. Adv. Mater. 30(5), 1705045 (2018). https://doi.org/10.1002/adma.201705045

33. X. Ma, W. Zhang, Y. Deng, C. Zhong, W. Hu et al., Phase and composition controlled synthesis of cobalt sulfide hollow nanospheres for electrocatalytic water splitting. Nanoscale 10(10), 4816-4824 (2018). https://doi.org/10.1039/c7nr0 $9424 \mathrm{~h}$

34. M. Sial, H. Lin, X. Wang, Microporous 2D NiCoFe phosphate nanosheets supported on $\mathrm{Ni}$ foam for efficient overall water splitting in alkaline media. Nanoscale 10(27), 1297512980 (2018). https://doi.org/10.1039/c8nr03350a

35. P. Xu, J. Li, J. Luo, L. Wei, D. Zhang et al., $\left(\mathrm{Fe}_{0.2} \mathrm{Ni}_{0.8}\right)_{0.96} \mathrm{~S}$ tubular spheres supported on $\mathrm{Ni}$ foam as an efficient bifunctional electrocatalyst for overall water splitting. Sci. Rep. 8(1), 9425 (2018). https://doi.org/10.1038/s41598-018-27477-z

36. S. Gupta, M.K. Patel, A. Miotello, N. Patel, Metal boridebased catalysts for electrochemical water-splitting: a review. Adv. Funct. Mater. 30(1), 1906481 (2020). https://doi.org/10. 1002/adfm.201906481

37. G. Su, S. Chen, H. Dong, Y. Cheng, Q. Liu et al., Tuning the electronic structure of layered vanadium pentoxide by pre-intercalation of potassium ions for superior room/lowtemperature aqueous zinc-ion batteries. Nanoscale 13(4), 2399-2407 (2021). https://doi.org/10.1039/D0NR07358J

38. N. Wang, A. Xu, P. Ou, S.-F. Hung, A. Ozden et al., Boridederived oxygen-evolution catalysts. Nat. Commun. 12, 6089 (2021). https://doi.org/10.1038/s41467-021-26307-7

39. X.Y. Yu, X.W. Lou, Mixed metal sulfides for electrochemical energy storage and conversion. Adv. Energy Mater. 8(3), 1701592 (2018). https://doi.org/10.1002/aenm.201701592

40. X. Liu, J. Du, C. Li, X. Han, X. Hu et al., The anion effect on the oxygen reduction of $\mathrm{MnX}(\mathrm{X}=\mathrm{O}, \mathrm{S}$, and $\mathrm{Se})$ catalysts. J. Mater. Chem. A 3(7), 3425-3431 (2015). https://doi.org/10. 1039/c4ta05995f

41. S.W. Kim, N. Pereira, N.A. Chernova, F. Omenya, P. Gao et al., Structure stabilization by mixed anions in oxyfluoride cathodes for high-energy lithium Batteries. ACS Nano 9(10), 1007610084 (2015). https://doi.org/10.1021/acsnano.5b03643

42. Y. Liu, T. Liang, Y. Li, Y. Zhao, Z. Guo et al., Silicene oxide: a potential Battery500 cathode for sealed non-aqueous lithium-oxygen batteries. Mater. Today Energy 18, 100503 (2020). https://doi.org/10.1016/j.mtener.2020.100503

43. X. Yin, L. Yang, Q. Gao, Core-shell nanostructured electrocatalysts for water splitting. Nanoscale 12(30), 15944-15969 (2020). https://doi.org/10.1039/D0NR03719B 
44. J. Cui, C. Li, F. Zhang, Development of mixed-anion photocatalysts with wide visible-light absorption bands for solar water splitting. Chemsuschem 12(9), 1872-1888 (2019). https://doi.org/10.1002/cssc.201801829

45. N. Yao, P. Li, Z. Zhou, R. Meng, G. Cheng et al., Nitrogen engineering on 3D dandelion-flower-like $\mathrm{CoS}_{2}$ for highperformance overall water splitting. Small 15(31), 1901993 (2019). https://doi.org/10.1002/smll.201901993

46. H. Zhang, W. Zhou, J. Dong, X. Lu, X. Lou, Intramolecular electronic coupling in porous iron cobalt (oxy)phosphide nanoboxes enhances the electrocatalytic activity for oxygen evolution. Energy Environ. Sci. 12(11), 3348-3355 (2019). https://doi.org/10.1039/c9ee02787d

47. C. Pei, H. Chen, B. Dong, X. Yu, L. Feng, Electrochemical oxygen evolution reaction efficiently catalyzed by a novel porous iron-cobalt-fluoride nanocube easily derived from 3-dimensional Prussian blue analogue. J. Power Sources 424, 131-137 (2019). https://doi.org/10.1016/j.jpowsour.2019.03. 089

48. P. Cai, J. Huang, J. Chen, Z. Wen, Oxygen-containing amorphous cobalt sulfide porous nanocubes as high-activity electrocatalysts for the oxygen evolution reaction in an alkaline/ neutral medium. Angew. Chem. Int. Ed. 56(17), 4858-4861 (2017). https://doi.org/10.1002/anie.201701280

49. Z.-F. Huang, J. Song, Y. Du, S. Xi, S. Dou et al., Chemical and structural origin of lattice oxygen oxidation in Co-Zn oxyhydroxide oxygen evolution electrocatalysts. Nat. Energy 4(4), 329-338 (2019). https://doi.org/10.1038/ s41560-019-0355-9

50. A. Nelson, K.E. Fritz, S. Honrao, R.G. Hennig, R.D. Robinson et al., Increased activity in hydrogen evolution electrocatalysis for partial anionic substitution in cobalt oxysulfide nanoparticles. J. Mater. Chem. A 4(8), 2842-2848 (2016). https://doi.org/10.1039/c5ta08706f

51. P.T. Babar, B.S. Pawar, A.C. Lokhande, M.G. Gang, J.S. Jang et al., Annealing temperature dependent catalytic water oxidation activity of iron oxyhydroxide thin films. J. Energy Chem. 26(4), 757-761 (2017). https://doi.org/10.1016/j. jechem.2017.04.012

52. S. Ganguli, S. Das, S. Kumari, H.R. Inta, A.K. Tiwari et al., Effect of intrinsic properties of anions on the electrocatalytic activity of $\mathrm{NiCO}_{2} \mathrm{O}_{4}$ and $\mathrm{NiCo}_{2} \mathrm{O}_{x} \mathrm{~S}_{4-x}$ grown by chemical bath deposition. ACS Omega 3(8), 9066-9074 (2018). https://doi. org/10.1021/acsomega.8b00952

53. J. Bai, T. Meng, D. Guo, S. Wang, B. Mao et al., $\mathrm{Co}_{9} \mathrm{~S}_{8} @$ $\mathrm{MoS}_{2}$ core-shell heterostructures as trifunctional electrocatalysts for overall water splitting and $\mathrm{Zn}$-air batteries. ACS Appl. Mater. Interfaces 10(2), 1678-1689 (2018). https://doi. org/10.1021/acsami.7b14997

54. J. An, X. Wang, M. Ming, J. Li, N. Ye, Determination of sulfonamides in milk by capillary electrophoresis with PEG@ $\mathrm{MoS}_{2}$ as a dispersive solid-phase extraction sorbent. R. Soc. Open Sci. 5(5), 172104 (2018). https://doi.org/10.1098/rsos. 172104

55. B. Chang, L. Deng, S. Wang, D. Shi, Z. Ai et al., A vanadium-nickel oxynitride layer for enhanced electrocatalytic nitrogen fixation in neutral media. J. Mater. Chem. A 8(1), 91-96 (2020). https://doi.org/10.1039/C9TA11378A

56. H. Kageyama, K. Hayashi, K. Maeda, J.P. Attfield, Z. Hiroi et al., Expanding frontiers in materials chemistry and physics with multiple anions. Nat. Commun. 9, 772 (2018). https:// doi.org/10.1038/s41467-018-02838-4

57. S.R. Lingampalli, K. Manjunath, S. Shenoy, U.V. Waghmare, C.N. Rao, $\mathrm{Zn}_{2} \mathrm{NF}$ and related analogues of $\mathrm{ZnO}$. J. Am. Chem. Soc. 138(26), 8228-8234 (2016). https://doi.org/ 10.1021/jacs.6b04198

58. L. Chen, J. Chang, Y. Zhang, Z. Gao, D. Wu et al., Fluorine anion-enriched nickel hydroxyl oxide as an efficient oxygen evolution reaction electrocatalyst. Chem. Commun. 55(23), 3406-3409 (2019). https://doi.org/10.1039/c9cc00555b

59. B. Li, S. Zhang, C. Tang, X. Cui, Q. Zhang, Anionic regulated $\mathrm{NiFe}$ (oxy) sulfide electrocatalysts for water oxidation. Small 13(25), 1700610 (2017). https://doi.org/10.1002/smll. 201700610

60. S. Wan, J. Qi, W. Zhang, W. Wang, S. Zhang et al., Hierarchical $\mathrm{Co}(\mathrm{OH}) \mathrm{F}$ superstructure built by low-dimensional substructures for electrocatalytic water oxidation. Adv. Mater. 29(28), 1700286 (2017). https://doi.org/10.1002/adma.20170 0286

61. L. Peng, J. Wang, Y. Nie, K. Xiong, Y. Wang et al., Dualligand synergistic modulation: a satisfactory strategy for simultaneously improving the activity and stability of oxygen evolution electrocatalysts. ACS Catal. 7(12), 8184-8191 (2017). https://doi.org/10.1021/acscatal.7b01971

62. J.K. Nørskov, T. Bligaard, A. Logadottir, J. Kitchin, J.G. Chen et al., Trends in the exchange current for hydrogen evolution. J. Electrochem. Soc. 152(3), J23 (2005). https://doi.org/10. 1149/1.1856988

63. J.S. Yoo, X. Rong, Y. Liu, A.M. Kolpak, Role of lattice oxygen participation in understanding trends in the oxygen evolution reaction on perovskites. ACS Catal. 8(5), 4628-4636 (2018). https://doi.org/10.1021/acscatal.8b00612

64. Z. Dai, H. Geng, J. Wang, Y. Luo, B. Li et al., Hexagonalphase cobalt monophosphosulfide for highly efficient overall water splitting. ACS Nano 11(11), 11031-11040 (2017). https://doi.org/10.1021/acsnano.7b05050

65. J. Luo, H. Wang, G. Su, Y. Tang, H. Liu et al., Self-supported nickel phosphosulphide nanosheets for highly efficient and stable overall water splitting. J. Mater. Chem. A 5(28), 14865-14872 (2017). https://doi.org/10.1039/ C7TA02651J

66. B. Song, K. Li, Y. Yin, T. Wu, L. Dang et al., Tuning mixed nickel iron phosphosulfide nanosheet electrocatalysts for enhanced hydrogen and oxygen evolution. ACS Catal. 7(12), 8549-8557 (2017). https://doi.org/10.1021/acscatal.7b02575

67. J. Xie, J. Zhang, S. Li, F. Grote, X. Zhang et al., Controllable disorder engineering in oxygen-incorporated $\mathrm{MoS}_{2}$ ultrathin nanosheets for efficient hydrogen evolution. J. Am. Chem. Soc. 135(47), 17881-17888 (2013). https://doi.org/10.1021/ ja408329q

68. M. Caban-Acevedo, M.L. Stone, J.R. Schmidt, J.G. Thomas, Q. Ding et al., Efficient hydrogen evolution catalysis using 
ternary pyrite-type cobalt phosphosulphide. Nat. Mater. 14(12), 1245-1251 (2015). https://doi.org/10.1038/nmat4410

69. B. Hammer, J.K. Nørskov, Theoretical surface science and catalysis - calculations and concepts. Adv. Catal. 45, 71-129 (2000). https://doi.org/10.1016/S0360-0564(02)45013-4

70. M. Li, H. Liu, L. Feng, Fluoridation-induced high-performance catalysts for the oxygen evolution reaction: a mini review. Electrochem. Commun. 122, 106901 (2020). https:// doi.org/10.1016/j.elecom.2020.106901

71. R. Zhang, M. Zhang, H. Yang, G. Li, S. Xing et al., Creating fluorine-doped $\mathrm{MoS}_{2}$ edge electrodes with enhanced hydrogen evolution activity. Small Methods 5(11), 2100612 (2021). https://doi.org/10.1002/smtd.202100612

72. J. Zhang, M. Wu, Z. Shi, M. Jiang, W. Jian et al., Composition and interface engineering of alloyed $\mathrm{MoS}_{2 x} \mathrm{Se}_{2(1-x)}$ nanotubes for enhanced hydrogen evolution reaction activity. Small 12(32), 4379-4385 (2016). https://doi.org/10.1002/ smll.201601496

73. J. Yu, W.-J. Li, G. Kao, C.-Y. Xu, R. Chen et al., In-situ growth of CNTs encapsulating P-doped $\mathrm{NiSe}_{2}$ nanoparticles on carbon framework as efficient bifunctional electrocatalyst for overall water splitting. J. Energy Chem. 60, 111-120 (2021). https://doi.org/10.1016/j.jechem.2020.12.030

74. H. Sun, X. Xu, Z. Yan, X. Chen, L. Jiao et al., Superhydrophilic amorphous Co-B-P nanosheet electrocatalysts with Ptlike activity and durability for the hydrogen evolution reaction. J. Mater. Chem. A 6(44), 22062-22069 (2018). https:// doi.org/10.1039/C8TA02999G

75. N. Zhang, Y. Chai, Lattice oxygen redox chemistry in solidstate electrocatalysts for water oxidation. Energy Environ. Sci. 14(9), 4647-4671 (2021). https://doi.org/10.1039/ D1EE01277K

76. M.E. Kreider, M.B. Stevens, Y. Liu, A.M. Patel, M.J. Statt et al., Nitride or oxynitride? Elucidating the compositionactivity relationships in molybdenum nitride electrocatalysts for the oxygen reduction reaction. Chem. Mater. 32(7), 29462960 (2020). https://doi.org/10.1021/acs.chemmater.9b05212

77. L. Yuan, S. Liu, S. Xu, X. Yang, J. Bian et al., Modulation of Volmer step for efficient alkaline water splitting implemented by titanium oxide promoting surface reconstruction of cobalt carbonate hydroxide. Nano Energy 82, 105732 (2021). https://doi.org/10.1016/j.nanoen.2020.105732

78. G. Zeng, T.A. Pham, S. Vanka, G. Liu, C. Song et al., Development of a photoelectrochemically self-improving $\mathrm{Si} / \mathrm{GaN}$ photocathode for efficient and durable $\mathrm{H}_{2}$ production. Nat. Mater. 20(8), 1130-1135 (2021). https://doi.org/10.1038/ s41563-021-00965-w

79. M. Ahmed, G. Xinxin, A review of metal oxynitrides for photocatalysis. Inorg. Chem. Front. 3(5), 578-590 (2016). https://doi.org/10.1039/c5qi00202h

80. A.K. Tareen, G.S. Priyanga, S. Behara, T. Thomas, M. Yang, Mixed ternary transition metal nitrides: a comprehensive review of synthesis, electronic structure, and properties of engineering relevance. Prog. Solid State Chem. 53, 1-26 (2019). https://doi.org/10.1016/j.progsolidstchem.2018.11.001
81. M. Chisaka, A. Ishihara, K.-I. Ota, H. Muramoto, Synthesis of carbon-supported titanium oxynitride nanoparticles as cathode catalyst for polymer electrolyte fuel cells. Electrochim. Acta 113, 735-740 (2013). https://doi.org/10.1016/j. electacta.2013.06.048

82. A. Miura, Low-temperature synthesis and rational design of nitrides and oxynitrides for novel functional material development. J. Ceram. Soc. Jpn. 125(7), 552-558 (2017). https:// doi.org/10.2109/jcersj2.17055

83. B. Cao, G.M. Veith, R.E. Diaz, J. Liu, E.A. Stach et al., Cobalt molybdenum oxynitrides: synthesis, structural characterization, and catalytic activity for the oxygen reduction reaction. Angew. Chem. Int. Ed. 52(41), 10753-10757 (2013). https://doi.org/10.1002/anie.201303197

84. W. Liu, Y. Hou, Z. Lin, S. Yang, C. Yu et al., Porous cobalt oxynitride nanosheets for efficient electrocatalytic water oxidation. Chemsuschem 11(9), 1479-1485 (2018). https://doi. org/10.1002/cssc. 201800380

85. N.R. Mucha, J. Som, J. Choi, S. Shaji, R.K. Gupta et al., High-performance titanium oxynitride thin films for electrocatalytic water oxidation. ACS Appl. Energy Mater. 3(9), 8366-8374 (2020). https://doi.org/10.1021/acsaem.0c00988

86. J. Di, H. Zhu, J. Xia, J. Bao, P. Zhang et al., High-performance electrolytic oxygen evolution with a seamless armor core-shell FeCoNi oxynitride. Nanoscale 11(15), 7239-7246 (2019). https://doi.org/10.1039/c8nr10191d

87. A. Miura, C. Rosero-Navarro, Y. Masubuchi, M. Higuchi, S. Kikkawa et al., Nitrogen-rich manganese oxynitrides with enhanced catalytic activity in the oxygen reduction reaction. Angew. Chem. Int. Ed. 55(28), 7963-7967 (2016). https:// doi.org/10.1002/anie.201601568

88. H. Tan, Z. Liu, D. Chao, P. Hao, D. Jia et al., Partial nitridation-induced electrochemistry enhancement of ternary oxide nanosheets for fiber energy storage device. Adv. Energy Mater. 8(21), 1800685 (2018). https://doi.org/10.1002/aenm. 201800685

89. S. Wang, L. Li, Y. Shao, L. Zhang, Y. Li et al., Transitionmetal oxynitride: a facile strategy for improving electrochemical capacitor storage. Adv. Mater. 31(10), 1806088 (2019). https://doi.org/10.1002/adma.201806088

90. S. Dutta, A. Indra, Y. Feng, H. Han, T. Song, Promoting electrocatalytic overall water splitting with nanohybrid of transition metal nitride-oxynitride. Appl. Catal. B 241, 521-527 (2019). https://doi.org/10.1016/j.apcatb.2018.09.061

91. J. Xiong, J. Di, C. Yan, M. Xu, J. Yu et al., Size-dependent activity of iron-nickel oxynitride towards electrocatalytic oxygen evolution. ChemNanoMat 5(7), 883-887 (2019). https://doi.org/10.1002/cnma.201900127

92. Z. Kou, T. Wang, H. Wu, L. Zheng, S. Mu et al., Twinned tungsten carbonitride nanocrystals boost hydrogen evolution activity and stability. Small 15(19), 1900248 (2019). https:// doi.org/10.1002/smll.201900248

93. H. Fu, Q. Zhang, J. Luo, L. Shen, X. Chen et al., Boosting HER activities of 3D flower-Like tungsten carbonitride via anions regulation. ACS Sustain. Chem. Eng. 37(8), 
14109-14116 (2020). https://doi.org/10.1021/acssuschem eng.0c04773

94. Z. Zeng, X. Chen, K. Weng, Y. Wu, P. Zhang et al., Computational screening study of double transition metal carbonitrides M'2M"CNO2-MXene as catalysts for hydrogen evolution reaction. npj Comput. Mater. 7(1), 80 (2021). https://doi. org/10.1038/s41524-021-00550-4

95. Y. Zhao, K. Kamiya, K. Hashimoto, S. Nakanishi, In situ $\mathrm{CO}_{2}$-emission assisted synthesis of molybdenum carbonitride nanomaterial as hydrogen evolution electrocatalyst. J. Am. Chem. Soc. 137(1), 110-113 (2015). https://doi.org/10.1021/ ja5114529

96. H. Wei, J. Wang, Q. Lin, Y. Zou, X.a. Chen et al., Incorporating ultra-small $\mathrm{N}$-doped $\mathrm{Mo}_{2} \mathrm{C}$ nanoparticles onto $3 \mathrm{D}$ $\mathrm{N}$-doped flower-like carbon nanospheres for robust electrocatalytic hydrogen evolution. Nano Energy 86, 106047 (2021). https://doi.org/10.1016/j.nanoen.2021.106047

97. B. Chang, L. Li, D. Shi, H. Jiang, Z. Ai et al., Metal-free boron carbonitride with tunable boron Lewis acid sites for enhanced nitrogen electroreduction to ammonia. Appl. Catal. B 283, 119622 (2021). https://doi.org/10.1016/j.apcatb.2020. 119622

98. D. Shi, B. Chang, Z. Ai, H. Jiang, F. Chen et al., Boron carbonitride with tunable $\mathrm{B} / \mathrm{N}$ Lewis acid/base sites for enhanced electrocatalytic overall water splitting. Nanoscale 13(5), 2849-2854 (2021). https://doi.org/10.1039/D0NR0 $6857 \mathrm{H}$

99. J. Wang, Y. Shin, J.R. Paudel, J.D. Grassi, R.K. Sah et al., Strain-induced anion-site occupancy in perovskite oxyfluoride films. Chem. Mater. 33(5), 1811-1820 (2021). https://doi.org/10.1021/acs.chemmater.0c04793

100. K. Lemoine, J. Lhoste, A. Hemon-Ribaud, N. Heidary, V. Maisonneuve et al., Investigation of mixed-metal (oxy) fluorides as a new class of water oxidation electrocatalysts. Chem. Sci. 10(40), 9209-9218 (2019). https://doi.org/10. 1039/c9sc04027g

101. H. Han, J. Woo, Y.-R. Hong, Y.-C. Chung, S. Mhin, Polarized electronic configuration in transition metal-fluoride oxide hollow nanoprism for highly efficient and robust water splitting. ACS Appl. Mater. Interfaces 2(6), 3999-4007 (2019). https://doi.org/10.1021/acsaem.9b00449

102. X.L. Cao, C.L. Hu, F. Kong, J.G. Mao, Cs $\left(\mathrm{TaO}_{2}\right)_{3}\left(\mathrm{SeO}_{3}\right)_{2}$ and $\mathrm{Cs}(\mathrm{TiOF})_{3}\left(\mathrm{SeO}_{3}\right)_{2}$ : structural and second harmonic generation changes induced by the different $\mathrm{d}(0)$-TM coordination octahedra. Inorg. Chem. 54(8), 3875-3882 (2015). https://doi.org/10.1021/acs.inorgchem.5b00052

103. Q. Feng, Y. Zhu, J. Hong, M. Zhang, W. Duan et al., Growth of large-area $2 \mathrm{D} \mathrm{MoS}_{2(1-x)} \mathrm{Se}_{2 x}$ semiconductor alloys. Adv. Mater. 26(17), 2648-2653 (2014). https://doi.org/10.1002/ adma.201306095

104. B. Hua, M. Li, W. Pang, W. Tang, S. Zhao et al., Activating $p$-blocking centers in perovskite for efficient water splitting. Chem 4(12), 2902-2916 (2018). https://doi.org/10.1016/j. chempr.2018.09.012

105. K.v. Lemoine, Z. Gohari-Bajestani, R. Moury, A. Terry, A. Guiet et al., Amorphous iron-manganese oxyfluorides, promising catalysts for oxygen evolution reaction under acidic media. ACS Appl. Energy Mater. 4(2), 1173-1181 (2021). https://doi.org/10.1021/acsaem.0c02417

106. K. Huang, Z. Zhao, H. Du, P. Du, H. Wang et al., Rapid thermal annealing toward high-quality $2 \mathrm{D}$ cobalt fluoride oxide as an advanced oxygen evolution electrocatalyst. ACS Sustainable Chem. Eng. 8(18), 6905-6913 (2020). https:// doi.org/10.1021/acssuschemeng.0c00830

107. H. Svengren, N. Torapava, I. Athanassiadis, S.I. Ali, M. Johnsson, A transition metal oxofluoride offering advantages in electrocatalysis and potential use in applications. Faraday Discuss. 188, 481-498 (2016). https://doi.org/10. 1039/c5fd00169b

108. L. Lei, D. Huang, Y. Chen, S. Chen, R. Deng, Design of an amorphous and defect-rich CoMoOF layer as a $\mathrm{pH}$ universal catalyst for the hydrogen evolution reaction. J. Mater. Chem. A. 9(13), 8730-8739 (2021). https://doi.org/ 10.1039/D1TA00505G

109. B. Zhang, S. Hu, Turning Ni-based hydroxide into an efficient hydrogen evolution electrocatalyst by fluoride incorporation. Electrochem. Commun. 86, 108-112 (2018). https://doi.org/10.1016/j.elecom.2017.12.001

110. B. Zhang, K. Jiang, H. Wang, S. Hu, Fluoride-induced dynamic surface self-reconstruction produces unexpectedly efficient oxygen-evolution catalyst. Nano Lett. 19(1), 530-537 (2019). https://doi.org/10.1021/acs.nanolett.8b044 66

111. Q. Xu, H. Jiang, X. Duan, Z. Jiang, Y. Hu et al., Fluorinationenabled reconstruction of $\mathrm{NiFe}$ electrocatalysts for efficient water oxidation. Nano Lett. 21(1), 492-499 (2020). https:// doi.org/10.1021/acs.nanolett.0c03950

112. F. Ma, Q. Wu, M. Liu, L. Zheng, F. Tong et al., Surface fluorination engineering of NiFe Prussian blue analogue derivatives for highly efficient oxygen evolution reaction. ACS Appl. Mater. Interfaces 13(4), 5142-5152 (2021). https:// doi.org/10.1021/acsami.0c20886

113. Y.A. Zhu, W.J. Dai, X. Zhong, T. Lu, Y. Pan, In-situ reconstruction of non-noble multi-metal core-shell oxyfluorides for water oxidation. J. Colloid Interface Sci. 602, 55-63 (2021). https://doi.org/10.1016/j.jcis.2021.05.170

114. Y.P. Zhu, J. Yin, E. Abou-Hamad, X. Liu, W. Chen et al., Highly stable phosphonate-based MOFs with engineered bandgaps for efficient photocatalytic hydrogen production. Adv. Mater. 32(16), 1906368 (2020). https://doi.org/10.1002/ adma.201906368

115. J. Balamurugan, T.T. Nguyen, V. Aravindan, N.H. Kim, J.H. Lee, Highly reversible water splitting cell building from hierarchical 3D nickel manganese oxyphosphide nanosheets. Nano Energy 69, 104432 (2020). https://doi.org/10.1016/j. nanoen.2019.104432

116. J. Duan, S. Chen, A. Vasileff, S.Z. Qiao, Anion and cation modulation in metal compounds for bifunctional overall water splitting. ACS Nano 10(9), 8738-8745 (2016). https:// doi.org/10.1021/acsnano.6b04252

117. R.A. Marquez-Montes, K. Kawashima, Y.J. Son, J.A. Weeks, H.H. Sun et al., Mass transport-enhanced electrodeposition 
of Ni-S-P-O films on nickel foam for electrochemical water splitting. J. Mater. Chem. A 9(12), 7736-7749 (2021). https:// doi.org/10.1039/D0TA12097A

118. B.Y. Guan, L. Yu, X.W. Lou, General synthesis of multishell mixed-metal oxyphosphide particles with enhanced electrocatalytic activity in the oxygen evolution reaction. Angew. Chem. Int. Ed. 56(9), 2386-2389 (2017). https://doi.org/10. 1002/anie.201611804

119. P. Zhang, X.F. Lu, J. Nai, S.Q. Zang, X.W.D. Lou, Construction of hierarchical Co-Fe oxyphosphide microtubes for electrocatalytic overall water splitting. Adv. Sci. 6(17), 1900576 (2019). https://doi.org/10.1002/advs.201900576

120. Q. Zhang, W. Chen, G.L. Chen, J. Huang, B. Ouyang et al., Trimetallic octahedral Ni-Co-W phosphoxide sprouted from plasma-defect-engineered Ni-Co support for ultrahigh-performance electrocatalytic hydrogen evolution. ACS Sustain. Chem. Eng. 9(22), 7454-7465 (2021). https://doi.org/10. 1021/acssuschemeng.1c00730

121. Y. Jia, W. Cai, X. Li, X.Y. Yu, Z. Hong, Fe ions modulated formation of hollow $\mathrm{NiFe}$ oxyphosphide spheres with enhanced oxygen evolution performance. Chem. Commun. 55(95), 14371-14374 (2019). https://doi.org/10.1039/c9cc0 $7747 \mathrm{~b}$

122. H. Xu, P. Song, C. Liu, Y. Zhang, Y. Du, Facile construction of ultrafine nickel-zinc oxyphosphide nanosheets as highperformance electrocatalysts for oxygen evolution reaction. J. Colloid Interface Sci. 530, 58-66 (2018). https://doi.org/ 10.1016/j.jcis.2018.06.061

123. H. Xu, K. Zhang, C. Liu, L. Tian, Y. Du, 3D-1D heterostructure of CoZn oxyphosphide nanosheets anchored on carbon nanotubes as electrocatalysts for the oxygen evolution reaction. ChemElectroChem 5(18), 2558-2563 (2018). https:// doi.org/10.1002/celc.201800656

124. S.A. Khalate, S.A. Kadam, Y.-R. Ma, S.S. Pujari, S.J. Marje et al., Hydrothermally synthesized iron phosphate hydroxide thin film electrocatalyst for electrochemical water splitting. Electrochim. Acta 319, 118-128 (2019). https://doi.org/10. 1016/j.electacta.2019.06.162

125. Y. Zhang, T. Qu, F. Bi, P. Hao, M. Li et al., Trimetallic (Co/ $\mathrm{Ni} / \mathrm{Cu}$ ) hydroxyphosphate nanosheet array as efficient and durable electrocatalyst for oxygen evolution reaction. ACS Sustain. Chem. Eng. 12(6), 16859-16866 (2018). https://doi. org/10.1021/acssuschemeng.8b04180

126. V. Mani, S. Anantharaj, S. Mishra, N. Kalaiselvi, S. Kundu, Iron hydroxyphosphate and Sn-incorporated iron hydroxyphosphate: efficient and stable electrocatalysts for oxygen evolution reaction. Catal.: Sci. Technol. 7(21), 5092-5104 (2017). https://doi.org/10.1039/c7cy00515f

127. P. Babar, A. Lokhande, E. Jo, B. Pawar, M. Gang et al., Facile electrosynthesis of $\mathrm{Fe}(\mathrm{Ni} / \mathrm{Co})$ hydroxyphosphate as a bifunctional electrocatalyst for efficient water splitting. J. Ind. Eng. Chem. 70, 116-123 (2019). https://doi.org/10. 1016/j.jiec.2018.09.041

128. X. Yu, Z. Yu, X. Zhang, P. Li, B. Sun et al., Highly disordered cobalt oxide nanostructure induced by sulfur incorporation for efficient overall water splitting. Nano Energy
71, 104652 (2020). https://doi.org/10.1016/j.nanoen.2020. 104652

129. C.X. Zhao, J.N. Liu, J. Wang, D. Ren, B.Q. Li et al., Recent advances of noble-metal-free bifunctional oxygen reduction and evolution electrocatalysts. Chem. Soc. Rev. 50(13), 7745-7778 (2021). https://doi.org/10.1039/d1cs00135c

130. X. Bao, D.Y. Petrovykh, P. Alpuim, D.G. Stroppa, N. Guldris et al., Amorphous oxygen-rich molybdenum oxysulfide decorated $p$-type silicon microwire Arrays for efficient photoelectrochemical water reduction. Nano Energy 16, 130-142 (2015). https://doi.org/10.1016/j.nanoen.2015.06.014

131. D. Thanh Tran, T. Kshetri, N. Dinh Chuong, J. Gautam, H. Van Hien et al., Emerging core-shell nanostructured catalysts of transition metal encapsulated by two-dimensional carbon materials for electrochemical applications. Nano Today 22, 100-131 (2018). https://doi.org/10.1016/j.nantod.2018.08.006

132. L. Liu, Nano-aggregates of cobalt nickel oxysulfide as a high-performance electrode material for supercapacitors. Nanoscale 5(23), 11615-11619 (2013). https://doi.org/10. 1039/c3nr03533f

133. J. Fu, F.M. Hassan, C. Zhong, J. Lu, H. Liu et al., Defect engineering of chalcogen-tailored oxygen electrocatalysts for rechargeable quasi-solid-state zinc-air batteries. Adv. Mater. 29(35), 1702526 (2017). https://doi.org/10.1002/adma.20170 2526

134. H. Kim, J. Kim, S.-K. Kim, S.H. Ahn, A transition metal oxysulfide cathode for the proton exchange membrane water electrolyzer. Appl. Catal. B 232, 93-100 (2018). https://doi. org/10.1016/j.apcatb.2018.03.023

135. Y. Zhang, X. Wang, D. Hu, C. Xue, W. Wang et al., Monodisperse ultrasmall manganese-doped multimetallic oxysulfide nanoparticles as highly efficient oxygen reduction electrocatalyst. ACS Appl. Mater. Interfaces 10(16), 13413-13424 (2018). https://doi.org/10.1021/acsami.7b19498

136. C. Li, X. Zhao, Y. Liu, W. Wei, Y. Lin, 3D Ni-Co sulfoxide nanosheet arrays electrodeposited on $\mathrm{Ni}$ foam: a bifunctional electrocatalyst towards efficient and stable water splitting. Electrochim. Acta 292, 347-356 (2018). https://doi.org/10. 1016/j.electacta.2018.06.159

137. D.T. Tran, H.T. Le, N.H. Kim, J.H. Lee, Highly efficient overall water splitting over a porous interconnected network by nickel cobalt oxysulfide interfacial assembled $\mathrm{Cu} @ \mathrm{Cu}_{2} \mathrm{~S}$ nanowires. J. Mater. Chem. A 8(29), 14746-14756 (2020). https://doi.org/10.1039/D0TA04638H

138. J. Liu, Y. Yang, B. Ni, H. Li, X. Wang, Fullerene-like nickel oxysulfide hollow nanospheres as bifunctional electrocatalysts for water splitting. Small 13(6), 1602637 (2017). https:// doi.org/10.1002/smll.201602637

139. D.J. Goossens, D. James, J. Dong, R.E. Whitfield, L. Noren et al., Local order in layered $\mathrm{NiPS}_{3}$ and $\mathrm{Ni}_{0.7} \mathrm{Mg}_{0.3} \mathrm{PS}_{3}$. J. Phys.: Condens. Matter. 23(6), 065401 (2011). https://doi. org/10.1088/0953-8984/23/6/065401

140. N. Ismail, M. Madian, A.A. El-Meligi, Synthesis of $\mathrm{NiPS}_{3}$ and CoPS and its hydrogen storage capacity. J. Alloys Compd. 588, 573-577 (2014). https://doi.org/10.1016/j.jallc om.2013.11.073 
141. J. Li, Z. Xia, X. Zhou, Y. Qin, Y. Ma et al., Quaternary pyritestructured nickel/cobalt phosphosulfide nanowires on carbon cloth as efficient and robust electrodes for water electrolysis. Nano Res. 10(3), 814-825 (2017). https://doi.org/10.1007/ s12274-016-1335-Z

142. P. He, X. Yu, X. Lou, Carbon-incorporated nickel-cobalt mixed metal phosphide nanoboxes with enhanced electrocatalytic activity for oxygen evolution. Angew. Chem. Int. Ed. 56(14), 3897-3900 (2017). https://doi.org/10.1002/anie. 201612635

143. J. Chang, Y. Ouyang, J. Ge, J. Wang, C. Liu et al., Cobalt phosphosulfide in the tetragonal phase: a highly active and durable catalyst for the hydrogen evolution reaction. J. Mater. Chem. A 6(26), 12353-12360 (2018). https://doi.org/10. 1039/c8ta03951h

144. Y. Li, S. Niu, D. Rakov, Y. Wang, M. Caban-Acevedo et al., Metal organic framework-derived CoPS/N-doped carbon for efficient electrocatalytic hydrogen evolution. Nanoscale 10(15), 7291-7297 (2018). https://doi.org/10.1039/c8nr0 $1811 \mathrm{a}$

145. J. Li, C. Zhang, H. Ma, T. Wang, Z. Guo et al., Modulating interfacial charge distribution of single atoms confined in molybdenum phosphosulfide heterostructures for high efficiency hydrogen evolution. Chem. Eng. J. 414, 128834 (2021). https://doi.org/10.1016/j.cej.2021.128834

146. K. Maiti, K. Kim, K.-J. Noh, J.W. Han, Synergistic coupling ensuing cobalt phosphosulfide encapsulated by heteroatomdoped two-dimensional graphene shell as an excellent catalyst for oxygen electroreduction. Chem. Eng. J. 423, 130233 (2021). https://doi.org/10.1016/j.cej.2021.130233

147. Y. Tong, P.Z. Chen, L. Chen, X.J. Cui, Dual vacancies confined in nickel phosphosulfide nanosheets enabling robust overall water splitting. Chemsuschem 14(12), 2576-2584 (2021). https://doi.org/10.1002/cssc.202100720

148. J. Kibsgaard, T.F. Jaramillo, Molybdenum phosphosulfide: an active, acid-stable, earth-abundant catalyst for the hydrogen evolution reaction. Angew. Chem. Int. Ed. 53(52), 1443314437 (2014). https://doi.org/10.1002/anie.201408222

149. S. Sarkar, S. Sampath, Equiatomic ternary chalcogenide: PdPS and its reduced graphene oxide composite for efficient electrocatalytic hydrogen evolution. Chem. Commun. 50(55), 7359-7362 (2014). https://doi.org/10.1039/c4cc02364a

150. D. Mukherjee, P.M. Austeria, S. Sampath, Two-dimensional, few-layer phosphochalcogenide, $\mathrm{FePS}_{3}$ : a new catalyst for electrochemical hydrogen evolution over wide $\mathrm{pH}$ range. ACS Energy Lett. 1(2), 367-372 (2016). https://doi.org/10.1021/ acsenergylett.6b00184

151. D. Lim, C. Lim, M. Hwang, M. Kim, S.E. Shim et al., Facile synthesis of flower-like P-doped nickel-iron disulfide microspheres as advanced electrocatalysts for the oxygen evolution reaction. J. Power Sources 490, 229552 (2021). https://doi. org/10.1016/j.jpowsour.2021.229552

152. T.A. Shifa, F. Wang, K. Liu, Z. Cheng, K. Xu et al., Efficient catalysis of hydrogen evolution reaction from $\mathrm{WS}_{2(1-x)} \mathrm{P}_{2 x}$ nanoribbons. Small 13(16), 1603706 (2017). https://doi.org/ 10.1002/smll.201603706
153. S. Xue, L. Chen, Z. Liu, H.-M. Cheng, W. Ren, $\mathrm{NiPS}_{3}$ nanosheet-graphene composites as highly efficient electrocatalysts for oxygen evolution reaction. ACS Nano 12(6), 5297-5305 (2018). https://doi.org/10.1021/acsnano.7b09146

154. L. Yin, X. Ding, W. Wei, Y. Wang, Z. Zhu et al., Improving catalysis for electrochemical water splitting using phosphosulphide surface. Inorg. Chem. Front. 7(12), 2388-2395 (2020). https://doi.org/10.1039/D0QI00295J

155. J. Mann, Q. Ma, P.M. Odenthal, M. Isarraraz, D. Le et al., 2-Dimensional transition metal dichalcogenides with tunable direct band gaps: $\mathrm{MoS}_{2(1-x)} \mathrm{Se}_{2 x}$ monolayers. Adv. Mater. 26(9), 1399-1404 (2014). https://doi.org/10.1002/adma. 201304389

156. O.E. Meiron, L. Houben, M. Bar-Sadan, Understanding the formation mechanism and the $3 \mathrm{D}$ structure of $\mathrm{Mo}\left(\mathrm{S}_{x} \mathrm{Se}_{1-x}\right)_{2}$ nanoflowers. RSC Adv. 5(107), 88108-88114 (2015). https:// doi.org/10.1039/c5ra16853h

157. Q. Gong, L. Cheng, C. Liu, M. Zhang, Q. Feng et al., Ultrathin $\mathrm{MoS}_{2(1-x)} \mathrm{Se}_{2 x}$ alloy nanoflakes for electrocatalytic hydrogen evolution reaction. ACS Catal. 5(4), 2213-2219 (2015). https://doi.org/10.1021/cs501970w

158. R. Bose, V.R. Jothi, B. Koh, C. Jung, S.C. Yi, Molybdenum sulphoselenophosphide spheroids as an effective catalyst for hydrogen evolution reaction. Small 14(8), 1703862 (2018). https://doi.org/10.1002/smll.201703862

159. J. Huang, Y. Jiang, T. An, M. Cao, Increasing the active sites and intrinsic activity of transition metal chalcogenide electrocatalysts for enhanced water splitting. J. Mater. Chem. A. 8(48), 25465-25498 (2020). https://doi.org/10.1039/D0TA0 $8802 \mathrm{~A}$

160. K. Xu, F. Wang, Z. Wang, X. Zhan, Q. Wang et al., Component-controllable $\mathrm{WS}_{2(1-x)} \mathrm{Se}_{2 x}$ nanotubes for efficient hydrogen evolution reaction. ACS Nano 8(8), 8468-8476 (2014). https://doi.org/10.1021/nn503027k

161. Q. Fu, L. Yang, W. Wang, A. Han, J. Huang et al., Synthesis and enhanced electrochemical catalytic performance of monolayer $\mathrm{WS}_{2(1-x)} \mathrm{Se}_{2 x}$ with a tunable band gap. Adv. Mater. 27(32), 4732-4738 (2015). https://doi.org/10.1002/adma. 201500368

162. R. Bar-Ziv, O.E. Meiron, M. Bar-Sadan, Enhancing the catalytic activity of the alkaline hydrogen evolution reaction by tuning the $\mathrm{S} / \mathrm{Se}$ ratio in the $\mathrm{Mo}\left(\mathrm{S}_{x} \mathrm{Se}_{1-x}\right)_{2}$ catalyst. Nanoscale 10(34), 16211-16216 (2018). https://doi.org/10. 1039/c8nr05738a

163. J. Sun, X. Hu, Z. Huang, T. Huang, X. Wang et al., Atomically thin defect-rich $\mathrm{Ni}-\mathrm{Se}-\mathrm{S}$ hybrid nanosheets as hydrogen evolution reaction electrocatalysts. Nano Res. 13(8), 2056-2062 (2020). https://doi.org/10.1007/ s12274-020-2807-8

164. K. Liu, F. Wang, K. Xu, T.A. Shifa, Z. Cheng et al., $\mathrm{CoS}_{2 x} \mathrm{Se}_{2(1-x)}$ nanowire array: an efficient ternary electrocatalyst for the hydrogen evolution reaction. Nanoscale 8(8), 4699-4704 (2016). https://doi.org/10.1039/c5nr07735d

165. H. Zhou, F. Yu, J. Sun, H. Zhu, I.K. Mishra et al., Highly efficient hydrogen evolution from edge-oriented $\mathrm{WS}_{2(1-x)} \mathrm{Se}_{2 x}$ particles on three-dimensional porous $\mathrm{NiSe}_{2}$ foam. Nano Lett. 
16(12), 7604-7609 (2016). https://doi.org/10.1021/acs.nanol ett.6b03467

166. S. Hussain, K. Akbar, D. Vikraman, K. Karuppasamy, H.-S. Kim et al., Synthesis of $\mathrm{MoS}_{2(1-x)} \mathrm{Se}_{2 x}$ and $\mathrm{WS}_{2(1-x)} \mathrm{Se}_{2 x}$ alloys for enhanced hydrogen evolution reaction performance. Inorg. Chem. Front. 4(12), 2068-2074 (2017). https://doi. org/10.1039/c7qi00457e

167. Q. Gong, S. Sheng, H. Ye, N. Han, L. Cheng et al., $\mathrm{Mo}_{x} \mathrm{~W}_{1-x}\left(\mathrm{~S}_{y} \mathrm{Se}_{1-y}\right)_{2}$ alloy nanoflakes for high-performance electrocatalytic hydrogen evolution. Part. Part. Syst. Charact. 33(8), 576-582 (2016). https://doi.org/10.1002/ppsc.20150 0255

168. M. Smialkowski, D. Siegmund, K. Pellumbi, L. Hensgen, H. Antoni et al., Seleno-analogues of pentlandites $\left(\mathrm{Fe}_{4.5} \mathrm{Ni}_{4.5} \mathrm{~S}_{8-Y} \mathrm{Se}_{Y}, \mathrm{Y}=1-6\right)$ : tuning bulk Fe/Ni sulphoselenides for hydrogen evolution. Chem. Commun. 55(60), 87928795 (2019). https://doi.org/10.1039/c9cc01842e

169. H.-P. Komsa, A.V. Krasheninnikov, Two-dimensional transition metal dichalcogenide alloys: stability and electronic properties. J. Phys. Chem. Lett. 3(23), 3652-3656 (2012). https://doi.org/10.1021/jz301673x

170. T. Kosmala, H. Coy Diaz, H.-P. Komsa, Y. Ma, A.V. Krasheninnikov et al., Metallic twin boundaries boost the hydrogen evolution reaction on the basal plane of molybdenum selenotellurides. Adv. Energy Mater. 8(20), 1800031 (2018). https:// doi.org/10.1002/aenm.201800031

171. S. Dutta, C. Ray, Y. Negishi, T. Pal, Facile synthesis of unique hexagonal nanoplates of $\mathrm{Zn} / \mathrm{Co}$ hydroxy sulfate for efficient electrocatalytic oxygen evolution reaction. ACS Appl. Mater. Interfaces 9(9), 8134-8141 (2017). https://doi.org/10.1021/ acsami.7b00030

172. C.-X. Zhao, B.-Q. Li, M. Zhao, J.-N. Liu, L.-D. Zhao et al., Precise anionic regulation of $\mathrm{NiFe}$ hydroxysulfide assisted by electrochemical reactions for efficient electrocatalysis. Energy Environ. Sci. 13(6), 1711-1716 (2020). https://doi. org/10.1039/C9EE03573G

173. L. Huang, H. Wu, Y. Zhang, One-step synthesis of CoPSe$\mathrm{CoSe}_{2} / \mathrm{CNTs}$ as efficient electrocatalyst for oxygen evolution reaction. Electrochim. Acta 331, 135362 (2020). https://doi. org/10.1016/j.electacta.2019.135362

174. Y. Liu, Q. Feng, W. Liu, Q. Li, Y. Wang et al., Boosting interfacial charge transfer for alkaline hydrogen evolution via rational interior Se modification. Nano Energy 81, 105641 (2021). https://doi.org/10.1016/j.nanoen.2020.105641

175. K. Liu, F. Wang, T.A. Shifa, Z. Wang, K. Xu et al., An efficient ternary $\mathrm{CoP}_{2 x} \mathrm{Se}_{2(1-x)}$ nanowire array for overall water splitting. Nanoscale 9(11), 3995-4001 (2017). https://doi.org/ 10.1039/c7nr00460e

176. Y. Hou, M. Qiu, T. Zhang, X. Zhuang, C.S. Kim et al., Ternary porous cobalt phosphoselenide nanosheets: an efficient electrocatalyst for electrocatalytic and photoelectrochemical water splitting. Adv. Mater. 29(35), 1701589 (2017). https:// doi.org/10.1002/adma.201701589

177. R. Subbaraman, D. Tripkovic, K.C. Chang, D. Strmcnik, A.P. Paulikas et al., Trends in activity for the water electrolyser reactions on $3 \mathrm{~d} \mathrm{M}(\mathrm{Ni} \mathrm{Co}, \mathrm{Fe}, \mathrm{Mn}$ ) hydr(oxy)oxide catalysts.
Nat. Mater. 11(6), 550-557 (2012). https://doi.org/10.1038/ nmat3313

178. M. Fang, D. Han, W.B. Xu, Y. Shen, Y. Lu et al., Surfaceguided formation of amorphous mixed-metal oxyhydroxides on ultrathin $\mathrm{MnO}_{2}$ nanosheet arrays for efficient electrocatalytic oxygen evolution. Adv. Energy Mater. 10(27), 2001059 (2020). https://doi.org/10.1002/aenm.202001059

179. W. Hua, H. Sun, L. Ren, Y. Li, J. Wang, 2-Methylimidazoleinduced reconstruction of cobalt (oxy) hydroxide electrocatalysts toward efficient water oxidation. Chem. Eng. J. 420, 129717 (2021). https://doi.org/10.1016/j.cej.2021.129717

180. C. Kim, S.H. Kim, S. Lee, I. Kwon, S. Kim et al., Boosting overall water splitting by incorporating sulfur into NiFe (oxy) hydroxide. J. Energy Chem. 64, 364-371 (2022). https://doi. org/10.1016/j.jechem.2021.04.067

181. Z. Kuang, S. Liu, X. Li, M. Wang, X. Ren et al., Topotactically constructed nickel-iron (oxy) hydroxide with abundant in-situ produced high-valent iron species for efficient water oxidation. J. Energy Chem. 57, 212-218 (2021). https://doi. org/10.1016/j.jechem.2020.09.014

182. L. Lei, D. Huang, C. Zhou, S. Chen, X. Yan et al., Demystifying the active roles of NiFe-based oxides/(oxy) hydroxides for electrochemical water splitting under alkaline conditions. Coord. Chem. Rev. 408, 213177 (2020). https://doi.org/10. 1016/j.ccr.2019.213177

183. C. Li, J. Zhao, L. Xie, J. Wu, Q. Ren et al., Surface-adsorbed carboxylate ligands on layered double hydroxides/metalorganic frameworks promote the electrocatalytic oxygen evolution reaction. Angew. Chem. Int. Ed. 60(33), 18129-18137 (2021). https://doi.org/10.1002/ange.202104148

184. J. Dong, Y. Wang, Q. Jiang, Z.-A. Nan, F.R. Fan et al., Charged droplet-driven fast formation of nickel-iron (oxy) hydroxides with rich oxygen defects for boosting overall water splitting. J. Mater. Chem. A. 9(35), 20058-20067 (2021). https://doi.org/10.1039/D1TA05332A

185. L. Trotochaud, S.L. Young, J.K. Ranney, S.W. Boettcher, Nickel-iron oxyhydroxide oxygen-evolution electrocatalysts: the role of intentional and incidental iron incorporation. J. Am. Chem. Soc. 136(18), 6744-6753 (2014). https://doi.org/ 10.1021/ja502379c

186. M.S. Burke, L.J. Enman, A.S. Batchellor, S. Zou, S.W. Boettcher, Oxygen evolution reaction electrocatalysis on transition metal oxides and (oxy)hydroxides: activity trends and design principles. Chem. Mater. 27(22), 7549-7558 (2015). https://doi.org/10.1021/acs.chemmater.5b03148

187. D. Friebel, M.W. Louie, M. Bajdich, K.E. Sanwald, Y. Cai et al., Identification of highly active $\mathrm{Fe}$ sites in $(\mathrm{Ni}, \mathrm{Fe}) \mathrm{OOH}$ for electrocatalytic water splitting. J. Am. Chem. Soc. 137(3), 1305-1313 (2015). https://doi.org/10.1021/ja511559d

188. S.R. Mellsop, A. Gardiner, B. Johannessen, A.T. Marshall, Structure and transformation of oxy-hydroxide films on $\mathrm{Ni}$ anodes below and above the oxygen evolution potential in alkaline electrolytes. Electrochim. Acta 168, 356-364 (2015). https://doi.org/10.1016/j.electacta.2015.04.020

189. F. Dionigi, P. Strasser, NiFe-based (oxy)hydroxide catalysts for oxygen evolution reaction in non-acidic electrolytes. Adv. 
Energy Mater. 6(23), 1600621 (2016). https://doi.org/10. 1002/aenm.201600621

190. L.J. Enman, M.S. Burke, A.S. Batchellor, S.W. Boettcher, Effects of intentionally incorporated metal cations on the oxygen evolution electrocatalytic activity of nickel (oxy) hydroxide in alkaline media. ACS Catal. 6(4), 2416-2423 (2016). https://doi.org/10.1021/acscatal.5b02924

191. M. Gorlin, J. Ferreira de Araujo, H. Schmies, D. Bernsmeier, $\mathrm{S}$. Dresp et al., Tracking catalyst redox states and reaction dynamics in $\mathrm{Ni}-\mathrm{Fe}$ oxyhydroxide oxygen evolution reaction electrocatalysts: The role of catalyst support and electrolyte pH. J. Am. Chem. Soc. 139(5), 2070-2082 (2017). https:// doi.org/10.1021/jacs.6b12250

192. M.B. Stevens, C.D.M. Trang, L.J. Enman, J. Deng, S.W. Boettcher, Reactive $\mathrm{Fe}$-sites in $\mathrm{Ni} / \mathrm{Fe}$ (oxy)hydroxide are responsible for exceptional oxygen electrocatalysis activity. J. Am. Chem. Soc. 139(33), 11361-11364 (2017). https://doi. org/10.1021/jacs.7b07117

193. K. Zhu, W. Luo, G. Zhu, J. Wang, Y. Zhu et al., Interfaceengineered $\mathrm{Ni}(\mathrm{OH})_{2}$ /beta-like $\mathrm{FeOOH}$ electrocatalysts for highly efficient and stable oxygen evolution reaction. Chem. Asian. J. 12(20), 2720-2726 (2017). https://doi.org/10.1002/ asia.201700964

194. J. Shen, M. Wang, L. Zhao, J. Jiang, H. Liu et al., Self-supported stainless steel nanocone array coated with a layer of $\mathrm{Ni}-\mathrm{Fe}$ oxides/(oxy) hydroxides as a highly active and robust electrode for water oxidation. ACS Appl. Mater. Interfaces 10(10), 8786-8796 (2018). https://doi.org/10.1021/acsami. $8 \mathrm{~b} 00498$

195. X. Wu, Y. Zhao, T. Xing, P. Zhang, F. Li et al., Hierarchically structured $\mathrm{FeNiO}_{x} \mathrm{H}_{y}$ electrocatalyst formed by in situ transformation of metal phosphate for efficient oxygen evolution reaction. Chemsuschem 11(11), 1761-1767 (2018). https:// doi.org/10.1002/cssc.201800407

196. J. Liu, J. Xiao, Z. Wang, H. Yuan, Z. Lu et al., Structural and electronic engineering of Ir-doped Ni-(oxy) hydroxide nanosheets for enhanced oxygen evolution activity. ACS Catal. 11(9), 5386-5395 (2021). https://doi.org/10.1021/ acscatal.1c00110

197. S.H. Ye, Z.X. Shi, J.X. Feng, Y.X. Tong, G.R. Li, Activating $\mathrm{CoOOH}$ porous nanosheet arrays by partial Iron substitution for efficient oxygen evolution reaction. Angew. Chem. Int. Ed. Engl. 57(10), 2672-2676 (2018). https:// doi.org/10.1002/anie.201712549

198. C. Huang, Y. Zhong, J. Chen, J. Li, W. Zhang et al., Fe induced nanostructure reorganization and electronic structure modulation over CoNi (oxy) hydroxide nanorod arrays for boosting oxygen evolution reaction. Chem. Eng. J. 403, 126304 (2021). https://doi.org/10.1016/j.cej.2020.126304

199. X. Bo, Y. Li, X. Chen, C. Zhao, Operando Raman spectroscopy reveals $\mathrm{Cr}$-induced-phase reconstruction of $\mathrm{NiFe}$ and $\mathrm{CoFe}$ oxyhydroxides for enhanced electrocatalytic water oxidation. Chem. Mater. 32(10), 4303-4311 (2020). https:// doi.org/10.1021/acs.chemmater.0c01067

200. J.T. Mefford, A.R. Akbashev, M. Kang, C.L. Bentley, W.E. Gent et al., Correlative operando microscopy of oxygen evolution electrocatalysts. Nature 593(7857), 67-73 (2021). https://doi.org/10.1038/s41586-021-03454-x

201. L. Zhang, W. Cai, N. Bao, Top-level design strategy to construct an advanced high-entropy $\mathrm{Co}-\mathrm{Cu}-\mathrm{Fe}-\mathrm{Mo}$ (oxy) hydroxide electrocatalyst for the oxygen evolution reaction. Adv. Mater. 33(22), 2100745 (2021). https://doi.org/ 10.1002/adma.202100745

202. J. Liu, Y. Ji, J. Nai, X. Niu, Y. Luo et al., Ultrathin amorphous cobalt-vanadium hydr(oxy)oxide catalysts for the oxygen evolution reaction. Energy Environ. Sci. 11(7), 1736-1741 (2018). https://doi.org/10.1039/c8ee00611c

203. Z.-F. Huang, S. Xi, J. Song, S. Dou, X. Li et al., Tuning of lattice oxygen reactivity and scaling relation to construct better oxygen evolution electrocatalyst. Nat. Commun. 12, 3992 (2021). https://doi.org/10.1038/s41467-021-24182-w

204. S. Gupta, N. Patel, R. Fernandes, R. Kadrekar, A. Dashora et al., Co-Ni-B nanocatalyst for efficient hydrogen evolution reaction in wide $\mathrm{pH}$ range. Appl. Catal. B 192, 126-133 (2016). https://doi.org/10.1016/j.apcatb.2016.03.032

205. X. Ai, X. Zou, H. Chen, Y. Su, X. Feng et al., Transitionmetal-boron intermetallics with strong interatomic $d-s p$ orbital hybridization for high-performance electrocatalysis. Angew. Chem. Int. Ed. 59(10), 3961-3965 (2020). https:// doi.org/10.1002/anie.201915663

206. F. Ma, S. Wang, X. Liang, C. Wang, F. Tong et al., $\mathrm{Ni}_{3} \mathrm{~B}$ as a highly efficient and selective catalyst for the electrosynthesis of hydrogen peroxide. Appl. Catal. B 279, 119371 (2020). https://doi.org/10.1016/j.apcatb.2020.119371

207. J. Kim, H. Kim, S.-K. Kim, S.H. Ahn, Electrodeposited amorphous Co-P-B ternary catalyst for hydrogen evolution reaction. J. Mater. Chem. A 6(15), 6282-6288 (2018). https://doi.org/10.1039/C7TA11033B

208. M. Ma, D. Liu, S. Hao, R. Kong, G. Du et al., A nickelborate-phosphate nanoarray for efficient and durable water oxidation under benign conditions. Inorg. Chem. Front. 4(5), 840-844 (2017). https://doi.org/10.1039/C6QI00594B

209. W. Wang, D. Liu, S. Hao, F. Qu, Y. Ma et al., High-efficiency and durable water oxidation under mild $\mathrm{pH}$ conditions: an iron phosphate-borate nanosheet array as a non-noble-metal catalyst electrode. Inorg. Chem. 56(6), 3131-3135 (2017). https://doi.org/10.1021/acs.inorgchem. $6 \mathrm{~b} 03171$

210. X. Ma, S. Zhang, Y. He, T. He, H. Li et al., Boron and phosphorus co-doped NiVFe LDHs@NF as a highly efficient self-supporting electrocatalyst for the hydrogen evolution reaction. J. Electroanal. Chem. 886, 115107 (2021). https:// doi.org/10.1016/j.jelechem.2021.115107

211. Q. Li, W. Cui, J. Tian, Z. Xing, Q. Liu et al., N-doped carbon-coated tungsten oxynitride nanowire arrays for highly efficient electrochemical hydrogen evolution. Chemsuschem 8(15), 2487-2491 (2015). https://doi.org/10.1002/ cssc. 201500398

212. Y. Li, K.A. Kuttiyiel, L. Wu, Y. Zhu, E. Fujita et al., Enhancing electrocatalytic performance of bifunctional cobalt-manganese-oxynitride nanocatalysts on graphene. 
Chemsuschem 10(1), 68-73 (2017). https://doi.org/10. 1002/cssc. 201601188

213. K.K. Yong Zhao, K. Hashimoto, S. Nakanishi, Hydrogen evolution by tungsten carbonitride nanoelectrocatalysts synthesized by the formation of a tungsten acid/polymer hybridIn situ. Angew. Commun. 125(51), 13883-13886 (2013). https://doi.org/10.1002/anie.201307527

214. J. Wang, D. Liu, L. Zhang, Y. Qian, C. Chen et al., Rational design of 2D super holey metal carboniride leaf-like nanostructure for efficient oxygen electrocatalysis. Carbon 164, 287-295 (2020). https://doi.org/10.1016/j.carbon.2020.04. 014

215. H. Zhang, P. An, W. Zhou, B.Y. Guan, P. Zhang et al., Dynamic traction of lattice-confined platinum atoms into mesoporous carbon matrix for hydrogen evolution reaction. Sci. Adv. 4(1), eaao6657 (2018). https://doi.org/10.1126/sciadv.aao6657

216. W. Liu, E. Hu, H. Jiang, Y. Xiang, Z. Weng et al., A highly active and stable hydrogen evolution catalyst based on pyritestructured cobalt phosphosulfide. Nat. Commun. 7, 10771 (2016). https://doi.org/10.1038/ncomms 10771

217. K. Li, D. Rakov, W. Zhang, P. Xu, Improving the intrinsic electrocatalytic hydrogen evolution activity of few-layer $\mathrm{NiPS}_{3}$ by cobalt doping. Chem. Commun. 53(58), 8199-8202 (2017). https://doi.org/10.1039/C7CC03173D

218. Z. Wu, X. Li, W. Liu, Y. Zhong, Q. Gan et al., Materials chemistry of iron phosphosulfide nanoparticles: synthesis, solid state chemistry, surface structure, and electrocatalysis for the hydrogen evolution reaction. ACS Catal. 7(6), 40264032 (2017). https://doi.org/10.1021/acscatal.7b00466

219. Y. Xin, X. Kan, L.Y. Gan, Z. Zhang, Heterogeneous bimetallic phosphide/sulfide nanocomposite for efficient solar-energydriven overall water splitting. ACS Nano 11(10), 1030310312 (2017). https://doi.org/10.1021/acsnano.7b05020

220. Y. Liu, Y. Du, W.-K. Gao, B. Dong, Y. Han et al., Surface phosphorsulfurization of $\mathrm{NiCo}_{2} \mathrm{O}_{4}$ nanoneedles supported on carbon cloth with enhanced electrocatalytic activity for hydrogen evolution. Electrochim. Acta 290, 339-346 (2018). https://doi.org/10.1016/j.electacta.2018.09.053

221. Z. Liu, Y. Wang, R. Chen, C. Chen, H. Yang et al., Quaternary bimetallic phosphosulphide nanosheets derived from prussian blue analogues: origin of the ultra-high activity for oxygen evolution. J. Power Sources 403, 90-96 (2018). https://doi.org/10.1016/j.jpowsour.2018.09.078

222. D.J. Li, J. Kang, H.J. Lee, D.S. Choi, S.H. Koo et al., High activity hydrogen evolution catalysis by uniquely designed amorphous/metal interface of core-shell phosphosulfide/Ndoped CNTs. Adv. Energy Mater. 8(13), 1702806 (2018). https://doi.org/10.1002/aenm.201702806

223. F. Wang, J. Li, F. Wang, T.A. Shifa, Z. Cheng et al., Enhanced electrochemical $\mathrm{H}_{2}$ evolution by few-layered metallic $\mathrm{WS}_{2(1-x)} \mathrm{Se}_{2 x}$ nanoribbons. Adv. Funct. Mater. 25(38), 60776083 (2015). https://doi.org/10.1002/adfm.201502680

224. K. Wang, C. Zhou, D. Xi, Z. Shi, C. He et al., Componentcontrollable synthesis of $\mathrm{Co}\left(\mathrm{S}_{x} \mathrm{Se}_{1-x}\right)_{2}$ nanowires supported by carbon fiber paper as high-performance electrode for hydrogen evolution reaction. Nano Energy 18, 1-11 (2015). https://doi.org/10.1016/j.nanoen.2015.10.001

225. L. Yang, Q. Fu, W. Wang, J. Huang, J. Huang et al., Largearea synthesis of monolayered $\mathrm{MoS}_{2(1-x)} \mathrm{Se}_{2 x}$ with a tunable band gap and its enhanced electrochemical catalytic activity. Nanoscale 7(23), 10490-10497 (2015). https://doi.org/10. $1039 / \mathrm{c} 5 \mathrm{nr} 02652 \mathrm{k}$

226. M. Zou, J. Chen, L. Xiao, H. Zhu, T. Yang et al., WSe $\mathrm{W}_{2}$ and $\mathrm{W}\left(\mathrm{Se}_{x} \mathrm{~S}_{1-x}\right)_{2}$ nanoflakes grown on carbon nanofibers for the electrocatalytic hydrogen evolution reaction. J. Mater. Chem. A 3(35), 18090-18097 (2015). https://doi.org/10.1039/c5ta0 $4426 \mathrm{j}$

227. X. Chen, Z. Wang, Y. Qiu, J. Zhang, G. Liu et al., Controlled growth of vertical 3D $\mathrm{MoS}_{2(1-x)} \mathrm{Se}_{2 x}$ nanosheets for an efficient and stable hydrogen evolution reaction. J. Mater. Chem. A 4(46), 18060-18066 (2016). https://doi.org/10.1039/c6ta0 $7904 \mathrm{k}$

228. H. Zhou, F. Yu, Y. Huang, J. Sun, Z. Zhu et al., Efficient hydrogen evolution by ternary molybdenum sulfoselenide particles on self-standing porous nickel diselenide foam. Nat. Commun. 7, 12765 (2016). https://doi.org/10.1038/ncomm s12765

229. L. Fang, W. Li, Y. Guan, Y. Feng, H. Zhang et al., Tuning unique peapod-like $\mathrm{Co}\left(\mathrm{S}_{x} \mathrm{Se}_{1-x}\right)_{2}$ nanoparticles for efficient overall water splitting. Adv. Funct. Mater. 27(24), 1701008 (2017). https://doi.org/10.1002/adfm.201701008

230. K. Liang, Y. Yan, L. Guo, K. Marcus, Z. Li et al., Strained $\mathrm{W}\left(\mathrm{Se}_{x} \mathrm{~S}_{1-x}\right)_{2}$ nanoporous films for highly efficient hydrogen evolution. ACS Energy Lett. 2(6), 1315-1320 (2017). https:// doi.org/10.1021/acsenergylett.7b00326

231. Y.-F. Jiang, C.-Z. Yuan, X. Zhou, Y.-N. Liu, Z.-W. Zhao et al., Selenium phosphorus co-doped cobalt oxide nanosheets anchored on Co foil: a self-supported and stable bifunctional electrode for efficient electrochemical water splitting. Electrochim. Acta 292, 247-255 (2018). https://doi.org/10.1016/j. electacta.2018.09.162

232. J. Huang, J. Chen, T. Yao, J. He, S. Jiang et al., CoOOH nanosheets with high mass activity for water oxidation. Angew. Chem. Int. Ed. 54(30), 8722-8727 (2015). https:// doi.org/10.1002/anie.201502836

233. X. Han, C. Yu, S. Zhou, C. Zhao, H. Huang et al., Ultrasensitive iron-triggered nanosized $\mathrm{Fe}-\mathrm{CoOOH}$ integrated with graphene for highly efficient oxygen evolution. Adv. Energy Mater. 7(14), 1602148 (2017). https://doi.org/10.1002/aenm. 201602148

234. Y. Pi, Q. Shao, P. Wang, F. Lv, S. Guo et al., Trimetallic oxyhydroxide coralloids for efficient oxygen evolution electrocatalysis. Angew. Chem. Int. Ed. 56(16), 4502-4506 (2017). https://doi.org/10.1002/anie.201701533

235. Y.-J. Ye, N. Zhang, X.-X. Liu, Amorphous NiFe(oxy)hydroxide nanosheet integrated partially exfoliated graphite foil for high efficiency oxygen evolution reaction. J. Mater. Chem. A 5(46), 24208-24216 (2017). https://doi.org/10.1039/c7ta0 $6906 \mathrm{e}$

236. E. Lee, A.H. Park, H.U. Park, Y.U. Kwon, Facile sonochemical synthesis of amorphous NiFe-(oxy)hydroxide 
nanoparticles as superior electrocatalysts for oxygen evolution reaction. Ultrason. Sonochem. 40(Pt A), 552-557 (2018). https://doi.org/10.1016/j.ultsonch.2017.07.048

237. M. Lee, H.-S. Oh, M.K. Cho, J.-P. Ahn, Y.J. Hwang et al., Activation of a Ni electrocatalyst through spontaneous transformation of nickel sulfide to nickel hydroxide in an oxygen evolution reaction. Appl. Catal. B 233, 130-135 (2018). https://doi.org/10.1016/j.apcatb.2018.03.083

238. N. Zhang, B. Yang, Y. He, Y. He, X. Liu et al., Serpentine $\mathrm{Ni}_{3} \mathrm{Ge}_{2} \mathrm{O}_{5}(\mathrm{OH})_{4}$ nanosheets with tailored layers and size for efficient oxygen evolution reactions. Small 14(48), 1803015 (2018). https://doi.org/10.1002/smll.201803015

239. X. Zhang, Y. Liang, Nickel hydr(oxy)oxide nanoparticles on metallic $\mathrm{MoS}_{2}$ nanosheets: a synergistic electrocatalyst for hydrogen evolution reaction. Adv. Sci. 5(2), 1700644 (2018). https://doi.org/10.1002/advs.201700644

240. B. Wang, C. Tang, H.F. Wang, X. Chen, R. Cao et al., A nanosized CoNi hydroxide@ hydroxysulfide core-shell heterostructure for enhanced oxygen evolution. Adv. Mater. 31(4), 1805658 (2018). https://doi.org/10.1002/adma.201805658

241. C. Liang, P. Zou, A. Nairan, Y. Zhang, J. Liu et al., Exceptional performance of hierarchical Ni-Fe oxyhydroxide@ $\mathrm{NiFe}$ alloy nanowire array electrocatalysts for large current density water splitting. Energy Environ. Sci. 13(1), 86-95 (2020). https://doi.org/10.1039/c9ee02388g
242. H. Jiang, J. Gu, X. Zheng, M. Liu, X. Qiu et al., Defect-rich and ultrathin $\mathrm{N}$ doped carbon nanosheets as advanced trifunctional metal-free electrocatalysts for the ORR, OER and HER. Energy Environ. Sci. 12(1), 322-333 (2019). https:// doi.org/10.1039/C8EE03276A

243. X. Wang, Y. Liang, W. An, J. Hu, Y. Zhu et al., Removal of chromium (VI) by a self-regenerating and metal free $\mathrm{g}-\mathrm{C}_{3} \mathrm{~N}_{4} /$ graphene hydrogel system via the synergy of adsorption and photo-catalysis under visible light. Appl. Catal. B 219, 53-62 (2017). https://doi.org/10.1016/j.apcatb.2017.07.008

244. Y. Guo, J. Tang, Z. Wang, Y.-M. Kang, Y. Bando et al., Elaborately assembled core-shell structured metal sulfides as a bifunctional catalyst for highly efficient electrochemical overall water splitting. Nano Energy 47, 494-502 (2018). https://doi.org/10.1016/j.nanoen.2018.03.012

245. J. Zhang, H. Yang, B. Liu, Coordination engineering of single-atom catalysts for the oxygen reduction reaction: a review. Adv. Energy Mater. 11(3), 2002473 (2021). https://doi.org/ 10.1002/aenm.202002473

246. X. Wang, Y. Feng, P. Dong, J. Huang, A mini review on carbon quantum dots: preparation, properties, and electrocatalytic application. Front. Chem. 7, 671 (2019). https://doi. org/10.3389/fchem.2019.00671 